\title{
Control Design and Performance Analysis for Autonomous Formation Flight Experiments
}

\author{
Caleb M. Rice
}

Follow this and additional works at: https://researchrepository.wvu.edu/etd

Part of the Aeronautical Vehicles Commons, and the Propulsion and Power Commons

\section{Recommended Citation}

Rice, Caleb M., "Control Design and Performance Analysis for Autonomous Formation Flight Experiments" (2014). Graduate Theses, Dissertations, and Problem Reports. 6495.

https://researchrepository.wvu.edu/etd/6495

This Thesis is protected by copyright and/or related rights. It has been brought to you by the The Research Repository @ WVU with permission from the rights-holder(s). You are free to use this Thesis in any way that is permitted by the copyright and related rights legislation that applies to your use. For other uses you must obtain permission from the rights-holder(s) directly, unless additional rights are indicated by a Creative Commons license in the record and/ or on the work itself. This Thesis has been accepted for inclusion in WVU Graduate Theses, Dissertations, and Problem Reports collection by an authorized administrator of The Research Repository @ WVU. For more information, please contact researchrepository@mail.wvu.edu. 


\title{
Control Design and Performance Analysis for Autonomous Formation Flight Experiments
}

\section{Caleb Michael Rice}

\author{
Thesis submitted to \\ the Benjamin M. Statler College of Engineering and Mineral Resources \\ at West Virginia University
}

\begin{abstract}
in partial fulfillment of the requirements for the degree of
Master of Science in

Aerospace engineering
\end{abstract}

\author{
Committee members \\ $\mathrm{Yu} \mathrm{Gu}$, Ph.D. \\ Marcello Napolitano, Ph.D. \\ Mario Perhinschi, Ph.D. \\ Department of Mechanical and Aerospace Engineering \\ Morgantown, West Virginia \\ 2014
}

Keywords: flight control, nonlinear control design, quadrotor, fixed wing, Phastball Copyright 2014, Caleb Michael Rice 


\title{
Abstract \\ Control Design and Performance Analysis for Autonomous Formation Flight Experiments
}

\author{
Caleb Michael Rice
}

\begin{abstract}
Autonomous Formation Flight is a key approach for reducing greenhouse gas emissions and managing traffic in future high density airspace. Unmanned Aerial Vehicles (UAV's) have made it possible for the physical demonstration and validation of autonomous formation flight concepts inexpensively and eliminates the flight risk to human pilots. This thesis discusses the design, implementation, and flight testing of three different formation flight control methods, Proportional Integral and Derivative (PID); Fuzzy Logic (FL); and NonLinear Dynamic Inversion (NLDI), and their respective performance behavior. Experimental results show achievable autonomous formation flight and performance quality with a pair of low-cost unmanned research fixed wing aircraft and also with a solo vertical takeoff and landing (VTOL) quadrotor.
\end{abstract}


"The LORD is my strength and my defense;

He has become my salvation.

He is my God, and I will praise him, my father's God, and I will exalt Him."

-Exodus 15:2 


\section{Acknowledgements}

Prof. Yu Gu, thank you for always being encouraging and patient with me. It amazes me what I've learned just by observing your gentleness and intelligence. Thank you for your guidance and provision. You honor me by leading my defense committee.

Prof. Marcelo Napolitano, thank you for providing financial support and your instruction. It was you who invited me to the Master's program. I have benefitted a great deal from what you have done for the university and for your students. You honor me by being a part of my defense committee.

Prof. Mario Perhinschi, thank you for your instruction. I have benefitted from what you have done for the university and for your students as well. You honor me by being a part of my defense committee.

I thank my team, Haiyang Chao; Srikanth ‘Srik’ Gururajan ; Tanmay Mandel; Trenton Larrabee; Kyle Lassak; James Riel; Trevor Caplinger; Ozias McKenzie; Lucas Behrens; Yaohui Ding; Jared Strader; Alex Gray; and Alex Hypes. You all have shown me a great deal of respect and friendship. There's always an encouraging word being said. When experiments don't work out, there's a certain comradery that pulled us onward. Blessings to you all as you progress toward your professional goals.

Dr. Majid Jaridi, Candy Cordwell, Nancy Cassis, and Amy Driznoff, you have been supporting me my entire college career. You are my super heroes and jump into action whenever I need your aid. I've never met a group possessing more joy. Thank you so much for the adventures, laughs, memories, and aid.

To the MAE Department, especially Prof. Victor Mucino, Deborah Willis, Kande Brand, Pat Goldie, and Pam Gilet, and my former class instructors, thank you for guiding me through my academic career and assisting me in becoming a successful young professional.

Mom and Dad, thank you for providing the best for me. Your prayers, instruction, and love matters to me more than anything else. Your homemade care packages were delicious and I kept all the cheesy cards and jokes that came with them. I hope I have honored you with my continuing success. 


\section{Table of Contents}

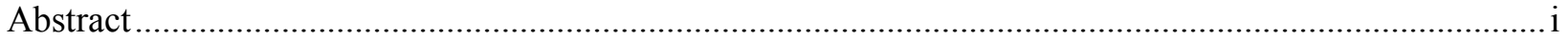

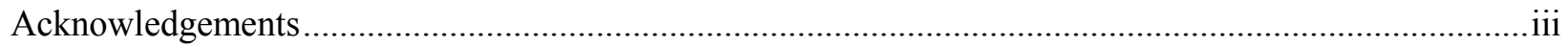

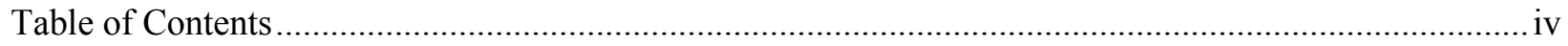

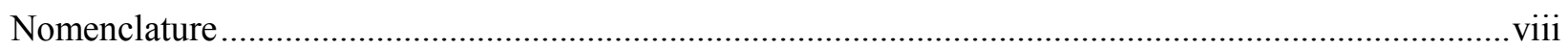

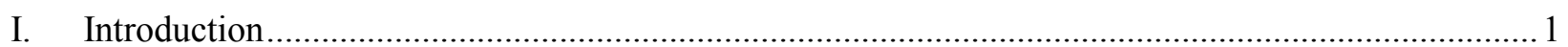

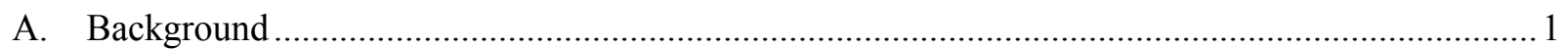

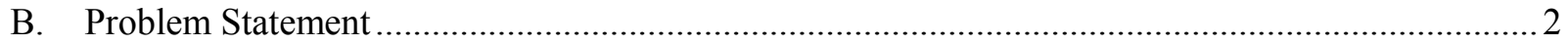

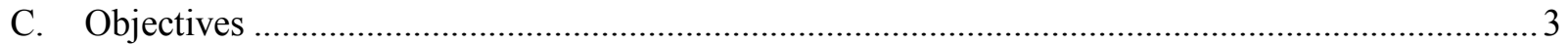

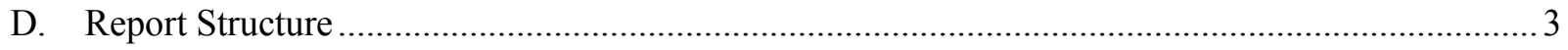

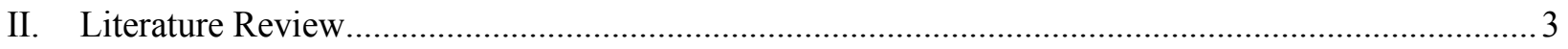

A. Overview of Autonomous Control Integration ...................................................................... 3

B. Overview of Autonomous Formation Flight Control Benefits and Progression............................. 4

C. Overview of Dynamic Inversion: Feedback Linearization ....................................................... 7

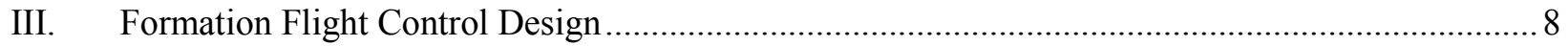

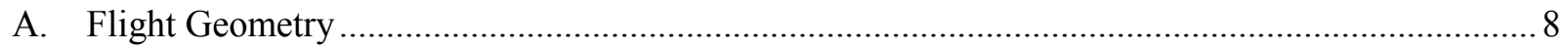

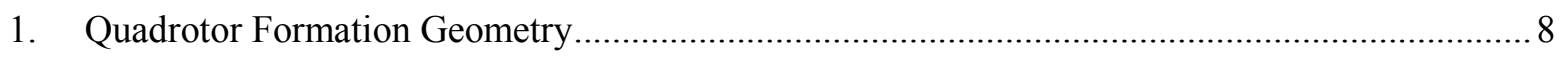

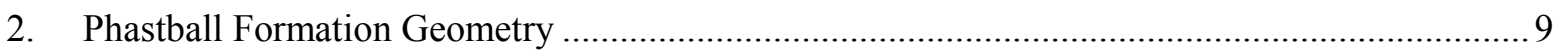

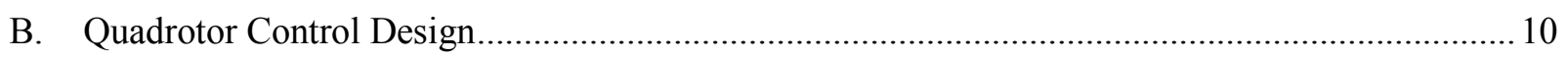

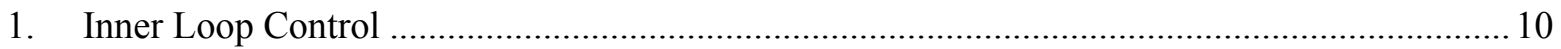

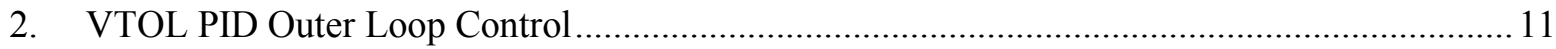

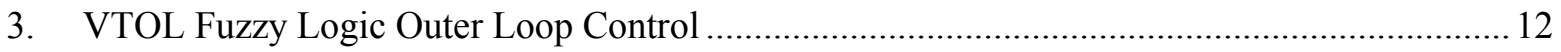

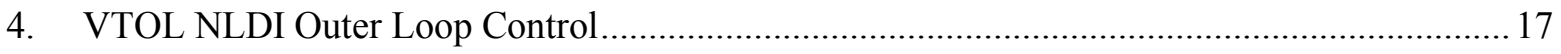

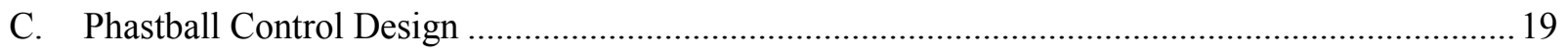

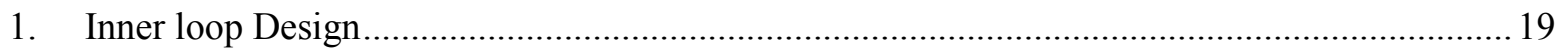

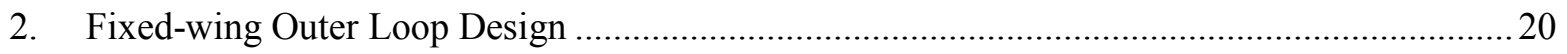

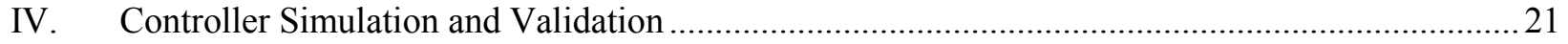




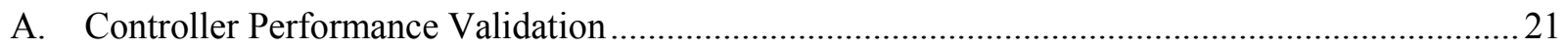

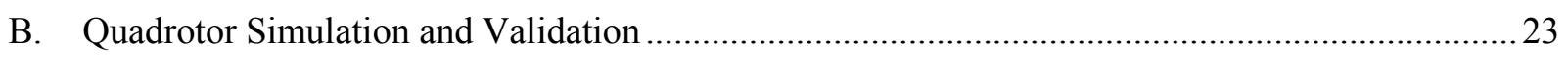

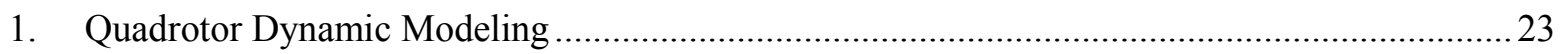

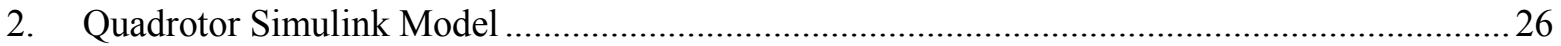

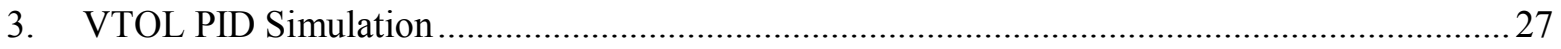

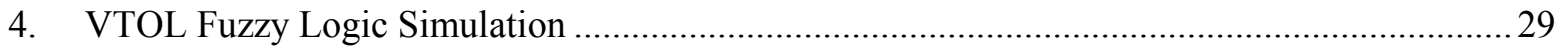

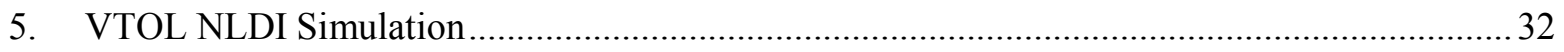

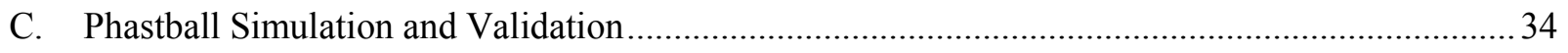

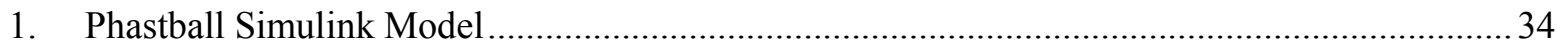

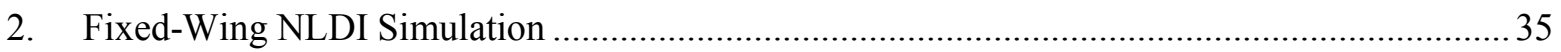

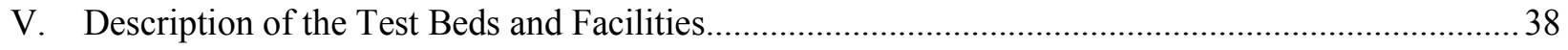

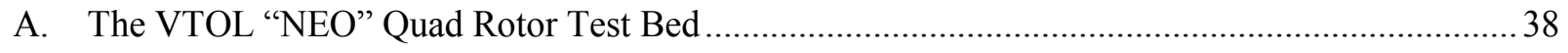

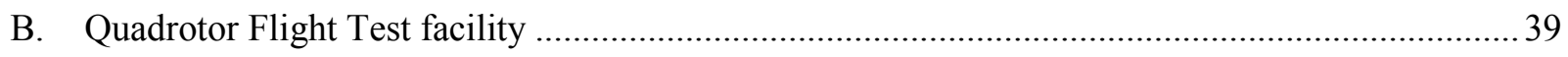

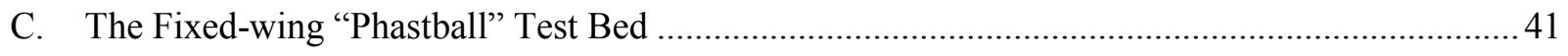

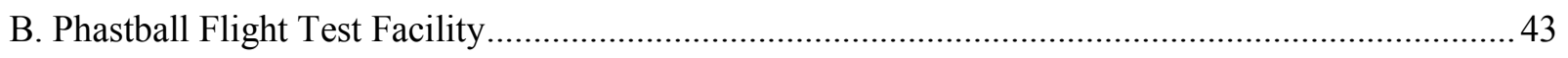

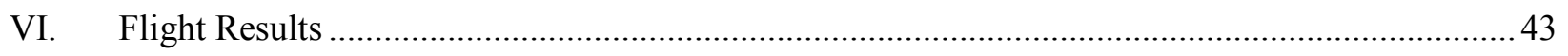

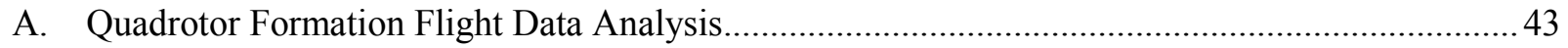

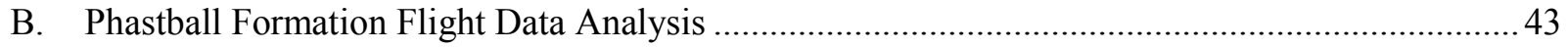

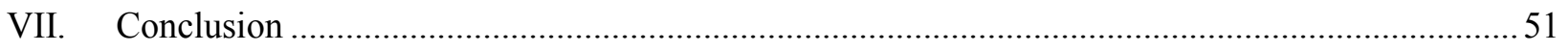

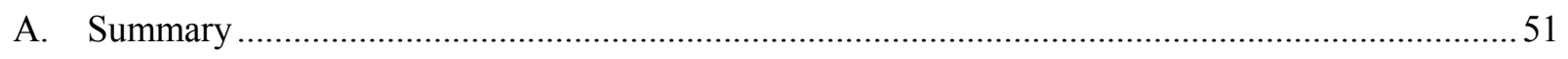

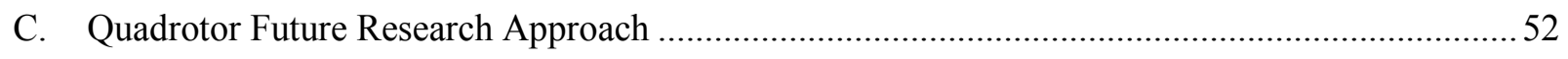

D. Phastball Future Research Approach …...........................................................................5

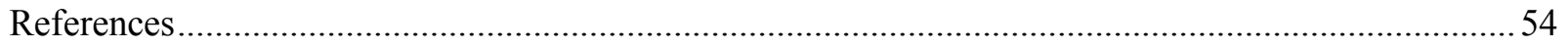




\section{List of Figures}

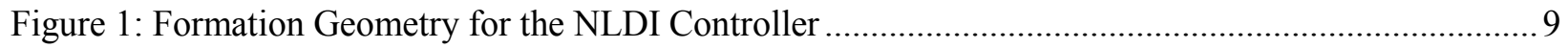

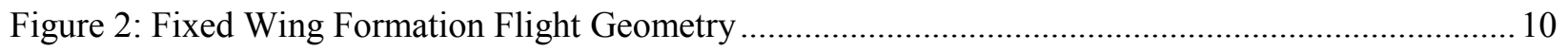

Figure 3: The Input Membership Functions of the Fuzzification Process .............................................. 14

Figure 4: Membership Function with Seven Linguistic Values.............................................................. 16

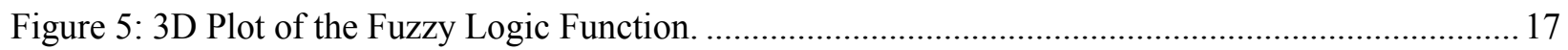

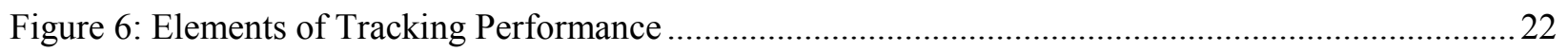

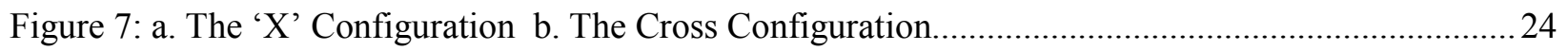

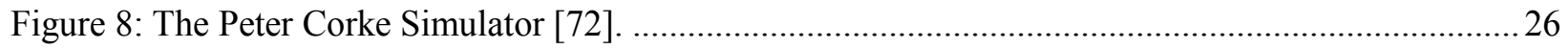

Figure 9: Graphics of the Simulator Showing the Quadrotor in a 3D Space ..........................................2 27

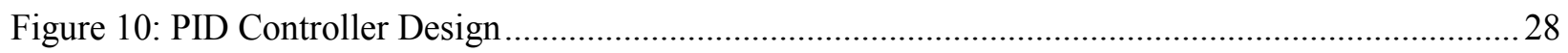

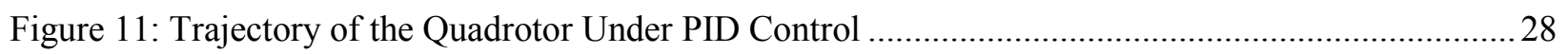

Figure 12: Position Error Using PID Controller .................................................................................2 29

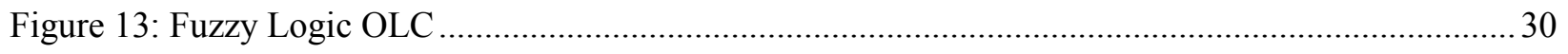

Figure 14: Trajectory of the Quadrotor Under Fuzzy Logic Control.................................................... 31

Figure 15: Position Error of the Fuzzy Logic Controller ...................................................................... 31

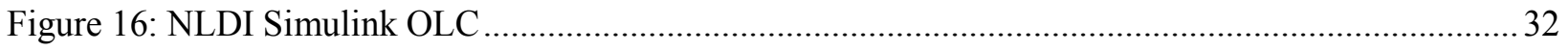

Figure 17: The Trajectory of the Quadrotor under VTOL NLDI Control ................................................ 33

Figure 18: Position Error of the VTOL NLDI Controller....................................................................... 33

Figure 19: Phastball Simulator Block Diagram Showing Two Follower Models .................................... 34

Figure 20: Isometric View of Flight Trajectories of the Virtual Leader and Two Followers ..................... 35

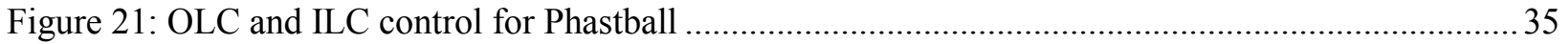

Figure 22: Phastball Leader and Follower Aircraft Trajectories ........................................................... 36

Figure 23: Error Distances in the Local Plane with Respect to the Leader Aircraft ................................. 37

Figure 24: The NEO Quadrotor test bed displaying components of the Gen VI avionics......................... 39

Figure 25: The Interactive Robotics Lab's flight test facility with motion tracking capability ................. 40

Figure 26: Schematic of Signal Communication ................................................................................... 41

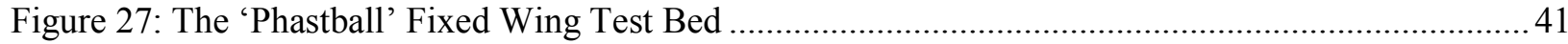

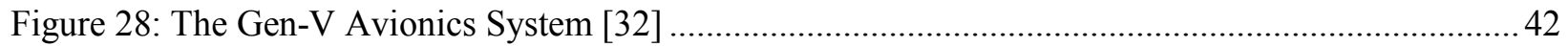

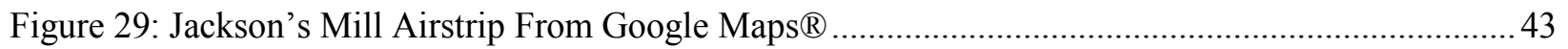

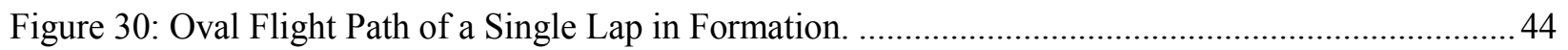

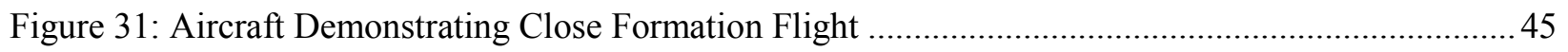

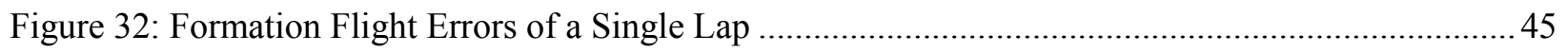

Figure 33: The Transient Response of the Forward Distance Error ......................................................... 46 


\section{List of Tables}

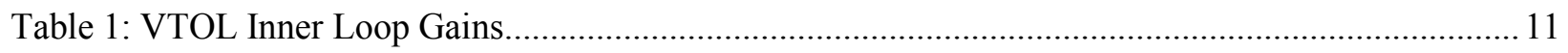

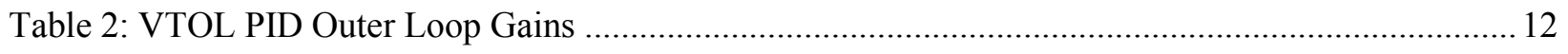

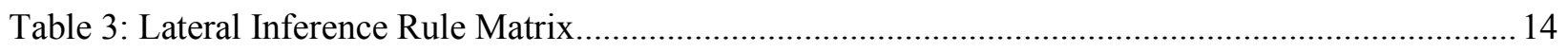

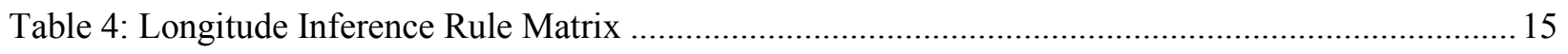

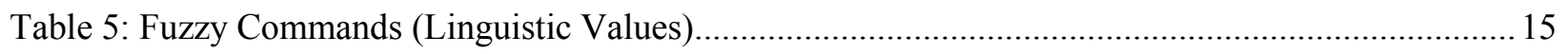

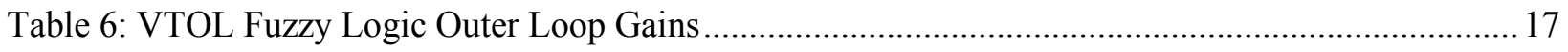

Table 7: VTOL Nonlinear Dynamic Inversion Outer Loop Gains ........................................................ 19

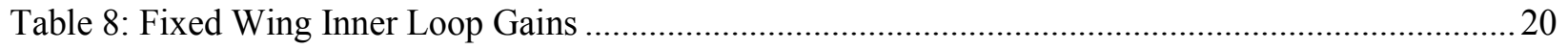

Table 9: Fixed Wing NonLinear Dynamic Inversion Outer Loop Gains................................................21

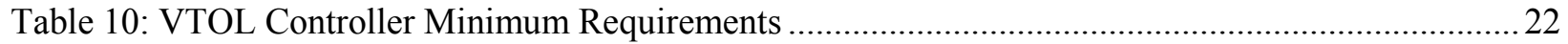

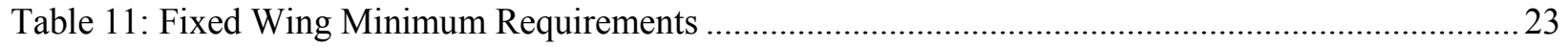

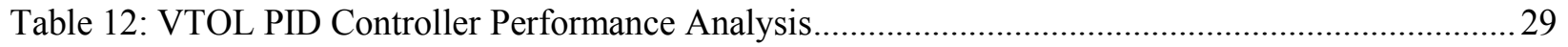

Table 13: VTOL Fuzzy Logic Controller Performance Analysis ............................................................. 32

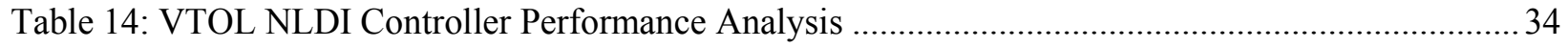

Table 15: Fixed Wing NLDI Controller Performance of Vertical Error.................................................. 37

Table 16: Fixed Wing NLDI Controller Performance of Lateral Error ................................................... 38

Table 17: Fixed Wing NLDI Controller Performance of Forward Error .................................................. 38

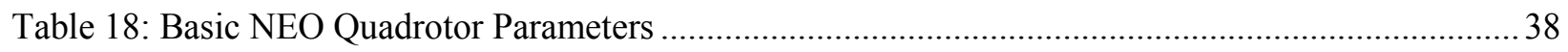

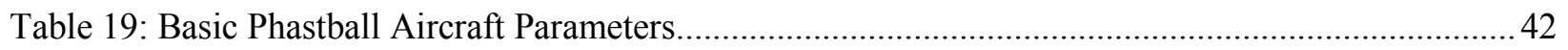

Table 20: Transient Behavior from the Initiation of Formation Flight .................................................. 47

Table 21: Performance of the Phastball 2-Aircraft Formation Flight During the Straight Legs.................48

Table 22: Performance of the Phastball 2-Aircraft Formation Flight During Turns .................................49

Table 23: Proximity Between Leader and Follower During Formation Flight.........................................50

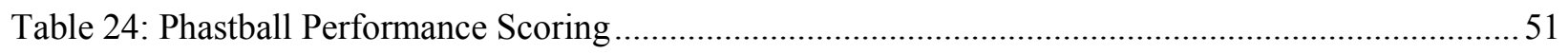




\section{Nomenclature}

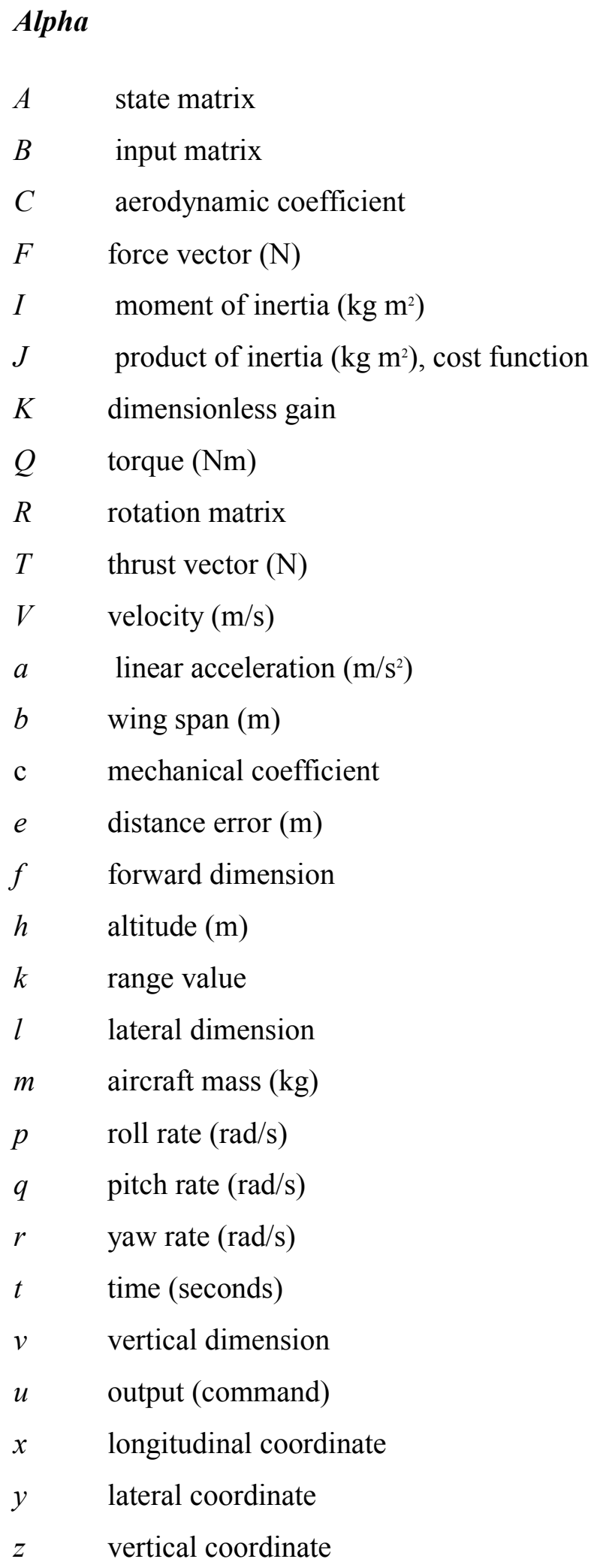




$$
\begin{array}{ll}
\text { Greek } & \text { Letters } \\
\Gamma & \text { torque vector }(\mathrm{Nm}) \\
\Theta & \text { vector of parameter estimates } \\
\Omega & \text { rotational velocity }(\mathrm{rad} / \mathrm{s}) \\
\alpha & \text { angle of attack }(\mathrm{rad}) \\
\beta & \text { angle of sideslip }(\mathrm{rad}) \\
\delta & \text { control surface deflection }(\mathrm{rad}) \\
\theta & \text { pitch angle }(\mathrm{rad}) \\
\phi & \text { roll angle }(\mathrm{rad}) \\
\rho & \text { air density }\left(\mathrm{kg} / \mathrm{m}^{3}\right) \\
\tau & \text { motor drive torque }(\mathrm{Nm}) \\
\psi & \text { yaw angle }(\mathrm{rad}) \\
\omega & \text { motor speed }(\mathrm{rad} / \mathrm{s})
\end{array}
$$

\section{Subscripts}

$D \quad$ derivative

I integral

L leader

$P \quad$ proportional

V velocity

$c \quad$ clearance

cmd command

$d \quad$ desired

$s \quad$ derivative (slope)

$x x \quad$ about the $\mathrm{x}$-axis (body)

$x z \quad$ about the $\mathrm{x}$ and $\mathrm{z}$ axes (body)

yy about the y-axis (body)

$z z \quad$ about the $\mathrm{z}$-axis (body)

\section{Acronyms}

EKF Extended Kalman Filter

FCSL Flight Control Systems Laboratory 
FDC Flight Dynamics and Control Toolbox

FL Fuzzy Logic

FPV First Person View

GPS Global Positioning System

ILC Inner Loop Control $\backslash$

IRL Interactive Robotics Laboratory

IMU Inertial Measurement Unit

NED North East Down

NLDI Non-Linear Dynamic Inversion

NWU North West Up

OLC Outer Loop Control

PID Proportional Integral Derivative

RPAS Remotely Piloted Aerial System

UAS Unmanned Aerial System

UAV Unmanned Aerial Vehicle

WVU West Virginia University

VTOL Vertical Take Off and Landing 


\section{Introduction}

\section{A. Background}

The earliest human accounts of autonomous flight control come from ancient bards, poems, and Old Testament Bible stories where doves and pigeons were used to deliver information over long distances. William Bernhard made mention of the direness of managing pigeons in France during the FrancoPrussian War (1871):

"The national pastime of Belgium, the great pigeon races for the southern provinces of France, has been abruptly put a stop to by the war. The French authorities have very naturally interdicted the entry of Belgian pigeons into France. When it is borne in mind that there are 10,000 trained pigeons, any one of which could convey intelligence from Paris to the frontier towns of Belgium in which they are located in the space of five or six hours, we cannot be surprised at the French authorities interfering with this pastime. The strategic information conveyed by a single pigeon might lose a battle or an empire.” [1]

In this, we see a cultural hobby interest in flight but also a necessary means by which to communicate. Today, these interests are still relevant in advertising, transportation, air shows, space travel, etc. Clearly, autonomous flight has a natural role and an insisting potential to change the world just as it has done again and again.

Of course, manned flight started in the early 1900's. Autonomous feedback control of aircraft came about shortly thereafter. Autopilots were reported to be under development as early as 1915 . The famous Sperry "Mechanical Mike" Gyropilot, engineered by Elmer Sperry, made it possible for Wiley Post to fly around the world in a record breaking eight days on June 31st, 1933 [2][3]. This technology enabled new capabilities for autonomous unmanned fixed wing aircraft, like the Curtis-Sperry flying bomb in 1918 [4]. Interest in Remote-Piloted Vehicles (RPV) came about during the Second World War, where the allies were looking for technology to counter the Axis V-2 rockets. This historic event spurred on advancements in remote flying in the years proceeding. There was a naval helicopter called QH-50 used for anti-submarine warfare. The N-69 Snark and X-10 Navaho were used to test new Inertial Navigation System (INS) technology of the day. Then in the Cold War, the MQM-57 and Model 147J Lightening Bug were used for spy missions over China and the Soviet Union to avoid putting U-2 pilots in danger [4]. 
Currently, the majority of UAV's with flight envelopes beyond the line of sight and above 500ft in operation are still militarily owned and operated. These aircraft are usually referred to as drones. Military troops rely on surveillance for up to the minute reports of enemy activity. A hand-launched USAF Puma can be mobilized and observing the ground within moments whereas spy satellites takes several minutes or more to focus in depending on the satellite orbit. Vertical Take Off and Landing (VTOL) Miniature Unmanned Aerial Vehicles (MUAVs) are not restricted to avoiding close quarters. UAV's can deliver munitions and surveillance or quickly search and destroy enemy targets. These systems are small, cost effective, and low risk for pilots, for they fly in hostile environments where a pilot's life would otherwise be threatened.

Civilian companies are hungry to use UAV's for their benefits too. In 2013, the United States shipped nearly 20 million pounds of freight and mail [8]. One of the largest shipment users is Amazon, who shipped 608 million packages in 2013 [9]. Amazon is developing an octocopter that can ship 80\% of their merchandise to the consumers' homes [10]. Other companies in freight [11], food delivery [12], and medicine [13][14] are developing similar UAV's to deliver goods to the home. Emergency services are also seeking to implement UAV's to extend their response capabilities [15].

The big factors holding these companies back are safety regulations enforced by the FAA and other international airspace authorities. Governments are opening the skies to private autonomous commercial flight, but the process is slow. On February $15^{\text {th }}$ the FAA released new legislation allowing for small unmanned aerial systems to be operated within the line of sight, below 500ft, and with a particular aeronautical knowledge certification [16]. International legislation is looking to categorize civilian UAVs as Remotely Piloted Aerial Systems or RPAS [5][6][7]. With the exception of Spain, European countries have individually legalized small RPAS deliveries with plans to create nationwide legislation. There are no easy solutions for the management of UAV's or for the increase in airspace traffic they will cause. A helpful technique that may lead to better management and organization is autonomous formation flight.

\section{B. Problem Statement}

The technology of today allows for autonomous control schemes to perform the same navigation routines of a pilot with equal or better agility and accuracy over traditional human piloted methods. As the demand for commercial drone use increases, so will the demand for autonomous flight technology. The goal of this research is to design and characterize the behavior of several different types of autonomous control schemes for the purpose of tracking. These schemes will be tested on two different UAV test beds, a fixed wing aircraft and a VTOL quad rotor. Also, flight test environments are designated for these test beds so that real-time data can be collected as safely as possible. 


\section{Objectives}

Designs of a PID, fuzzy logic, and Non Linear Dynamic Inversion controllers for a quad rotor test bed and a Non Linear Dynamic Inversion controller for the Phastball fixed wing test bed will be developed, simulated, and flight tested. The performance quality of each controller will be compared based on position tracking error behavior.

\section{Report Structure}

The second chapter is a literature review. The third is a concise description of the formation flight controllers' development and validation. The fourth chapter illustrates the test beds and flight facilities. The fifth chapter presents the results from flight testing, and the last chapter will summarize and conclude with and future research direction.

\section{Literature Review}

\section{A. Overview of Autonomous Control Integration}

Autonomous control is the enabling technology for future manned/unmanned flight and flight interaction in the national airspace. Miniaturization of computer and communication systems have enabled fly-by-wire and redundant systems. These have in turn enabled very precise and reliable autonomous control of aircraft flight. GPS is used for position and velocity measurements. Inertial Measurement Units (IMU's) are used to measure local acceleration change and orientation. A computer uses IMU measurements to create Internal Navigation Systems (INSs). Pressure and temperature instruments provide key air speed and altitude information. Also, these sensors and systems are not affected by fatigue as are pilots and drivers. All these factors together make a strong case that autonomous control is achievable and cost effective.

Although navigation systems are tested over countless hours of flight time, there are still reliability issues. In the case of Air France Flight 447, the pitot tubes iced up. The plane lost altitude and airspeed awareness. Instrument readings were inconsistent and pilots failed to apply correct procedure under the given conditions. Ultimately the aircraft fatally crashed into the Atlantic [17]. There is also the concern of traffic mitigation and obstacle avoidance. In 2014 an unmanned aircraft narrowly missed a DHC-8 which was on approach to Perth Airport [18]. In order for the technology to thrive, these issues need to be addressed.

Various studies have already demonstrated the possibilities of autonomous vehicle integration into other environments. DARPA held a competition where contenders build autonomous controlled vehicles 
that are capable of driving in traffic. The purpose of this is to demonstrate the interaction of autonomous vehicles with manned traffic in an urban environment. These vehicles often use a conglomerate of lidar, radar, and visual sensors to identify road markings and obstacles and maneuver around them safely [19]. Vehicles also demonstrated their adherence to urban traffic regulations [20]. Other organizations have demonstrated similar systems for boats [21][22], and subs [23][24]. Aircraft traffic law is more complex than motor vehicle or nautical traffic laws, but optimistically these demonstrations may contribute to eventual autonomous aircraft interaction control implementation in public airspace.

One of the most well-known flight tests dealing with a manually controlled aircraft and an autonomously controlled aircraft was demonstrated by DARPA and NASA in 2006. Real-time kinematic processing, inertial systems, and video tracking were all used in the design of the Autonomous Aerial Refueling Demonstration (AARD) system which leads an F-18 in behind a B707 fitted with a refueling basket drogue [25].

\section{B. Overview of Autonomous Formation Flight Control Benefits and Progression}

Integration of UAV's into the national airspace needs methods of control that will ensure aircraft safety and efficiency. There must be control laws that unmanned aircraft follow to reliably abide by the traffic rules of the sky. A case study done by Honeywell described how the autonomous formation flight controller used for military convoys of C-130's and C-17's could also be used to control commercial aircraft to increase the capacity of civilian air space. These aircraft in formation fly one nautical mile apart as opposed to commercial regulation separation of 3 to 20 nautical miles. A formation of aircraft is treated as a single aircraft with regard to position and reporting to Air Traffic Control (ATC). The formation leader interacts with ATC on behalf of the entire group; the trailing aircraft provide awareness to the lead aircraft [26].

There are additional benefits for Close Formation Flight (CFF), specifically. Experimental biology research found that certain birds flying in formation earned a $11.4 \%-14.0 \%$ energy savings when flying in ' $V$ ' shape formation [28][29]. Similar benefits for manned aircraft have also been investigated. NASA researchers at Dryden Flight Research Center demonstrated fuel savings of up to 14\% during CFF of two F-18 research aircraft [30] and 10\% during CFF of two C-17 aircraft [31]. The concept proposed for the C-17 program is called SAVE, Surfing Aircraft Vortices for Energy. This program, pitched by Air Mobility Command, has been funded by DARPA, NASA, Boeing, and the Air force Research LAB. All together, the project cost $\$ 10$ million up to 2013 , which is also the predicted annual return that this concept will save the Air Force [32]. 
The trailing aircraft have to be precisely controlled at specific locations behind the leader, and autonomous formation flight control is how formation is maintained. Autonomous formation flight control has been explored using a number of different strategies which are categorized as: 'Multiple-Input Multiple-Output', 'Leader-Follower', 'Cyclic', and 'Behavioral' [33]. Techniques for stability analysis of autonomous formation have also been developed for measuring how position errors propagate form one vehicle to another in a cascaded system [32][34]. The Leader-Follower approach is widely accepted for aircraft formation flight because the concept can be simplified into a series of tracking problems. Tracking can be solved using standard control techniques. There have been many studies conducted on theoretical and simulation based concepts using optimal control, compensation-type control, feedback linearization, adaptive control, robust control, and behavioral approaches. The following describes how some of these concepts work, what their benefits are, and what their short comings are.

A team at the Air Force Research Lab at Wright Patterson AFB designed a multi-input/output LQR and integral control for position tracking of a refueling jet. They studied the dynamics of the vortices caused by tanker aircraft with respect to the receiver aircraft. The three dimensional states for position tracking error are calculated with the integral control to ensure a zero steady-state error. Three control allocation scenarios were verified through simulation. What the controller is not able to track is non-zero yaw and a bank angle which means it couldn't be used while the tanker makes a bank turn [35]. Later research improves this design to include integral control of the yaw and bank angle states as well as timevarying inertial transfer of the jet fuel from the tanker to the receiver aircraft [36].

At the Queen's University Belfast, a mix UAV-manned mission integration method called "extension-decomposition-aggregation" (EDA) was studied. The EDA scheme transforms complex formations of aircraft into groups of sub-problems called individual augmented sub-systems, IAS. Lateral and longitudinal compensator type controllers navigate the aircraft based on the IAS [24]. This method is refined in 2014 by implementing the EDA strategy with support of a virtual overall system called coupled multiple inverted pendulums (CMIP) system. The result from simulation is a very stable 3D formation that works around obstacles, flight maneuvers, and geometry changes [25]. This research is still in a computer simulation phase. It works under the assumption that the states of the vehicles are all known despite the decentralized infrastructure. This assumption is difficult to work with physically due to actual sensor and communication related issues.

At A\&T State University, a robust controller was designed to track the heading speed, heading angle, and altitude of an aircraft. Lyapunov stability theory was used to demonstrate effectiveness while dealing with system uncertainties and external disturbances [37]. At Beihang University, stochastic robustness 
analysis and design method was used to create a formation flight control system for a single UAS. The dynamics of the aircraft are decoupled into latitude and longitude dynamics. For each dynamic, a thorough nonlinear mathematical model is produced and the robust cost function is chosen by using the method of Monte Carlo Evaluation and Genetic Algorithm. In simulation, one aircraft maintained a clearance distance of 50 meters behind the leader [38].

Some argue that the leader-follower approach is not robust with respect to the leader's failure. As well, the different flavors of leader-follower do not account for obstacle avoidance. These approaches are singularly focused on group synchronization or two-aircraft formation, but at the Naval Aeronautical and Astronautical University in China, Decentralized Model Predictive Control (DMPC) has been designed and tested through simulation for autonomous formation flight that overcomes these issues [39]. MPC is also known as Receding Horizon Control. This method is well known for use in slow processes like chemical processing. The flight control law continually updates the planned trajectory of the aircraft to maintain formation. A cost penalty prioritizes neighboring vehicle and obstacle information guaranteeing that the aircraft avoids a collision. DMPC is constrained to the designed model which is its major drawback. Detailed non-linear dynamic modeling and complete aerodynamic understanding is necessary for this method to succeed [40].

These methods as well as other compensation [41][42][43][44], feedback linearization [45][46], adaptive control [47], and behavioral [27] approaches have all been utilized for leader-follower formation flight applications. As discussed so far, these methods have only been theorized and simulated to correspond to a limited scope of formation flight. There are few studies that have actually implement real flight testing and fewer still that have quantified the benefits.

Experimental demonstrations of autonomous formation flight with fixed-wing aircraft are very limited due to the complexity in multiple aircraft operations. Formation Flight experiments have been conducted in collaboration by NASA, DARPA, and the USAF as mentioned previously with two-aircraft formations with F-18's in 2001 and again with C-17's in 2006 and 2013. Control systems utilized INS and GPS data from the leader aircraft calculate the commands that directed the trailing aircraft's heading [26][30][31][32][48][49].

Universities have had limited success of showing autonomous cooperative and formation flight control. The department of Aeronautics and Astronautics at MIT demonstrated waypoint following of two RPAS's with a vertical 50m offset [50]. The GRASP lab at the University of Pennsylvania demonstrated decentralized formation flight of two RPAS aircraft [51]. The Flight Control Systems Lab at West Virginia University was successful in demonstrating and measuring formation flight performance for 
three-aircraft formation of YF-22 RPASs. Autonomous CFF was maintained to within a mean distance of $27 \mathrm{~m}$ of the nominal formation geometry [52]. This lab later demonstrated CFF with another fixed wing test bed called the Phastball, and maintained a mean distance of $8.6 \mathrm{~m}-14.9 \mathrm{~m}$ of the nominal formation geometry [53].

In search of review material, there is little to no other evidence of measured benefit for autonomous CFF for UAV's. There is a gap where CFF has only been studied on a couple of full sized aircraft in cruise conditions and refueling. There is no established method by which formation flight controller performance is characterized which makes this current research so important.

\section{Overview of Dynamic Inversion: Feedback Linearization}

For this research, the highlighted NLDI control laws were inspired by dynamic inversion applications used for super-maneuverable aircraft in the 1980's and 90's [54][55][56][57]. The control laws were designed the same way for implementation with the YF-22 [52] and Phastball [53] RC aircraft flight test studies and also presented in this research for the NEO quadrotor.

Feedback linearization is a generic description for cancelling nonlinearity from all or part of a system's differential equations to allow linear approaches for controller design. Aircraft dynamics are non-linear which makes them hard to model. Input-output linearization describes the decomposition of those dynamics equations, which are a multi input multi output (MIMO) system of equations, into linearized decoupled control laws [58]. Once simplified to linear functions, the equations can be inverted. This linearization and inversion process is known as nonlinear dynamic inversion. This method by itself is limited due to multiple assumptions being made about the aircraft's dynamics, therefore the controller would only perform as desired in a limited flight envelope. However, adaptive [59][60][61][62], fuzzy logic [63], and neural network (NN) [64][65][66] approaches have been able to greatly expand the flight envelope of dynamic inversion control.

In the 1980's, a team from Lockheed Martin used dynamic inversion for the inner loop control laws of a tailless aircraft concept [54]. A tailless aircraft is a highly nonlinear coupled system. For instance, yawing of the aircraft induces pitching. This controller, making up the inner feedback control loop, settles out the aircraft by using dynamic inversion of the aircraft's modeling given the flight envelope conditions. The aircrafts control variables, roll rate $(p)$; pitch rate $(q)$; yaw rate $(r)$; and angle of attack $(\alpha)$, dominantly effect the aircrafts so-called fast dynamics of rotation about the $x(L), y(M)$, and $z(N)$ axes. The yaw terms are simplified so that the fast dynamics control can all be decoupled. Final outcome allows the vehicle to maintain steady flight conditions. The drawback is high order dynamics are ignored and therefore limits are set on the frequency range in order to experience the desired control [66]. This concept for tailless aircraft control was pursued further through NASA's Reconfigurable Control for 
Tailless Fighters (RESTORE) research program which contributed to the experimental Boeing/NASA X36 flight control approach [60].

Boeing used the RESTORE approach to design an adaptive controller for a MK-82 missile. The robust baseline control starts with gain scheduling established by state feedback LQR control. It is then projected into a matrix where the eigenstructure of the state feedback is used to form a static projection matrix. At this point the control is linearized and then adaptive control is applied as to provide desired behavior outside of the baseline conditions. This adaptive control is formed from the "Positive $\mu$ modification" which adapts the base line to ensure control saturation does not occur during tracking. This approach also deals with input saturation conditions with a tradeoff so that the integrity of the reference model is not distorted by adaptation. This method is designed to streamline control validation to the flight testing phase without costly wind tunnel testing. The limitations once again revolve around the assumptions for having a "good" reference baseline that will allow for super-maneuverable control over a large flight envelope [59].

In some respects, inversion gave way to backstepping, where Lyapunov synthesis recursively provides the stability for a dynamic system given initially known stable conditions. In other words global boundedness comes from backstepping from a reference condition without inversion. Since adaptive control is derived from Lyapunov stability theory, this authenticated the earlier adaptive approach with dynamic inversion [67]. In 2005, Rolf Rysdyk and affiliates explored the combination of dynamic inversion with an online adaptive $\mathrm{NN}$ for tiltrotor aircraft. Lyapunov stability analysis ensures updated NN laws will guarantee boundedness, which means that the control will not become unstable. The controller was tested aboard the Generic Tilt-Rotor Simulator (GTRS) at NASA Ames. The controller showed superior performance among aggressive and highly nonlinear applications. The end result is a practical, robust controller design. Flight stability was assured due to boundedness even with unmodeled dynamics. This proof was sufficient for some flightworthiness criteria which meant less flight hours and reduction in testing costs. The system can even deliver under fault conditions. A big drawback is the requirement of full state feedback, but output feedback formulation can rectify this [68].

\section{Formation Flight Control Design}

\section{A. Flight Geometry}

\section{Quadrotor Formation Geometry}

The geometry originated from previous YF-22 and Phastball research [52][53]. NEO quadrotors fly in a lead-follower configuration behind a leader as shown in Figure 1. The leader, highlighted in red, can be 
virtual data or a real object relaying state data to the controller. The follower, highlighted in green, obeys the autonomous formation flight control law based on these geometrical parameters.

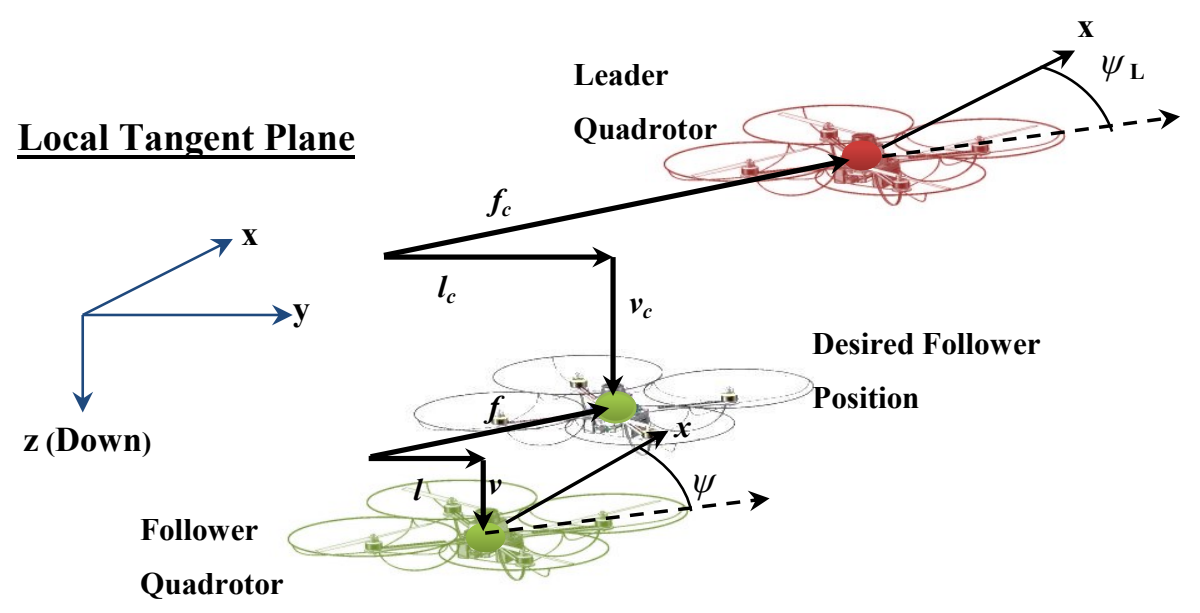

Figure 1: Formation Geometry for the NLDI Controller

The shape of the formation is in reference to a local inertial frame. The desired distance between the aircraft is defined as forward clearance, $f_{c}$, in the longitudinal direction, lateral clearance, $l_{c}$, in the lateral direction, and vertical clearance, $v_{c}$, in the vertical direction with respect to the leader aircraft. Error is measured from the desired follower position to the actual follower position in the forward and lateral directions. The geometry rotates with respect to the leader's yaw angle, $\psi_{L}$, with respect to the inertial $x$ axis. Performance is measured by the ability to maintain the lowest clearance error possible.

\section{Phastball Formation Geometry}

In the same way two Phastballs, Red, the leader; and Green, the autonomous follower, fly in a leadfollower "I" shaped configuration. Red Phastball is remotely controlled by a ground pilot and Green Phastball is piloted by the formation flight controller scheme uploaded to the Gen V flight computer. The controller scheme is designed to maintain predetermined formation geometry parameters. The formation geometry is defined by a lateral, vertical, and forward clearance in the leader aircraft body frame with respect to the position of the leader GPS antenna as shown in Figure 2. 


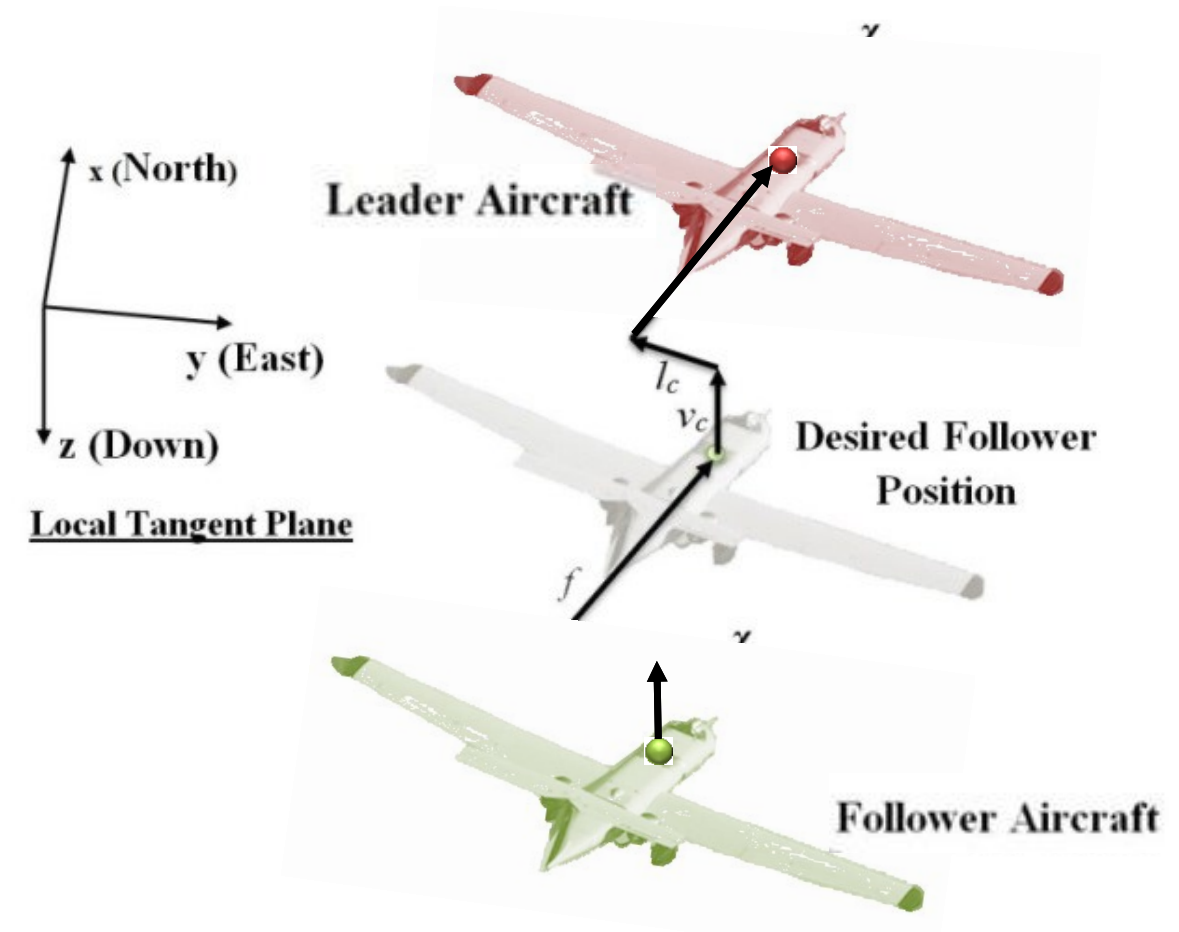

Figure 2: Fixed Wing Formation Flight Geometry

Within Figure 2, the vertical, $v$; lateral, $l$; and forward, $f$, distance errors count off from the predetermined formation clearance, marked by the subscript ' $c$ ', to the follower's position. How well these errors are dealt with is the measure of performance that is being analyzed in this research. The formation flight controller contains an inner and an outer loop structure. The outer-loop controller minimizes the lateral, forward, and vertical distance errors. It tracks the desired follower position (defined by the formation geometry) behind the leader and provides the desired pitch attitude, throttle position, and roll angle references to the inner-loop controller. The inner-loop control laws then perform the disturbance attenuation and attitude tracking functions.

\section{B. Quadrotor Control Design}

\section{Inner Loop Control}

The control design is broken into a two loop structure for the follower aircraft in a similar way that the F-22 and Phastball designs were done. The outer loop deals with minimizing position error, and the inner loop performs disturbance attenuation and attitude tracking. The inner loop translates commands to blade speed and mitigates state perturbation not produced by the outer loop. Roll and pitch commands are first expressed as linear trackers: 


$$
\begin{gathered}
\tau_{\text {pitch }}=K_{c m d}\left(\theta_{x, d}-\theta\right)+K_{q} q \\
\tau_{\text {roll }}=K_{c m d}\left(\phi_{y, d}-\phi\right)+K_{p} p
\end{gathered}
$$

The desired yaw angle and altitude are also expressed using relevant aircraft states:

$$
\begin{gathered}
\tau_{\text {yaw }}=K_{\psi} \Delta \psi+K_{r}\left(r_{L}-r\right) \\
\tau_{z}=K_{z}\left[\left(z_{L}-z\right)+K_{V_{z}}\left(V_{z, L}-V_{z}\right)\right]+\sqrt{\frac{\text { mass*gravity }}{4 * \text { Thrust }}}
\end{gathered}
$$

The control action, $\omega$, of each motor is based on the combination of equations 1 through 4 . Each motor is labeled as a subscript number $1-4$.

$$
\begin{aligned}
& \omega_{1} \\
& \omega_{2} \\
& \omega_{3} \\
& \omega_{4}
\end{aligned}=\left[\begin{array}{rrrr}
1 & -1 & 1 & 1 \\
-1 & -1 & -1 & 1 \\
-1 & 1 & 1 & 1 \\
1 & 1 & -1 & 1
\end{array}\right]\left\{\begin{array}{c}
\tau_{\text {pitch }} \\
\tau_{\text {roll }} \\
\tau_{\text {yaw }} \\
\tau_{z}
\end{array}\right\}
$$

Through simulation and iterative adjustment, the inner loop gains were refined until desirable performance was achieved. The refined gains are shown in Table 1.

Table 1: VTOL Inner Loop Gains

\begin{tabular}{|c|c|c|}
\hline \multicolumn{3}{|c|}{ VTOL ILC Gains } \\
\hline ROLL & $K_{c m d, \phi}=60$ & $K_{p}=20$ \\
\hline PITCH & $K_{c m d, \theta}=60$ & $K_{q}=20$ \\
\hline YAW & $K_{\psi}=-100$ & $K_{r}=-100$ \\
\hline TRUST & $K_{z}=40$ & $K_{V z}=1$ \\
\hline
\end{tabular}

\section{VTOL PID Outer Loop Control}

PID tracking is common practice in control engineering. The error is processed by proportional, derivative, and integral functions that are combined to produce controller output. The function is modeled as shown in equation 6 .

$$
u(t)=K_{P} e(t)+K_{I} \int e(\tau) d \tau+K_{D} \frac{d}{d t} e(t)
$$

where $K_{P}, K_{I}$, and $K_{D}$ are the proportional, integral, and derivative gains respectively. $e(t)$ is the measured state error and $u(t)$ is the command output. The proportional gain determines the ratio of the output response to the error signal. The integral control sums up the error over time. This type of control reduces the steady state error for the system. Steady state error is the eventual error that occurs once the system settles to a zero-change state. The derivative control causes the output to decrease as the rate of the input 
error increases. This type of control reduces the overshoot and causes a more gradual reaction of the system to the input error.

Since PID control is so widely used, it makes a great baseline for comparison with respect to the other control schemes. For the quadrotor, the input error is the $\mathrm{x}$ and $\mathrm{y}$ position error of the follower aircraft. The output is the desired roll and pitch angles that will cause the quadrotor to draw closer to the desired position.

The position errors, $e_{x}$ and $e_{y}$, are differenced in the inertial frame and then rotated into the body frame as shown in equation 7 :

$$
\begin{aligned}
& l \\
& f
\end{aligned}=\left[\begin{array}{cc}
-\sin \left(\psi_{L}-\psi\right) & \cos \left(\psi_{L}-\psi\right) \\
\cos \left(\psi_{L}-\psi\right) & \sin \left(\psi_{L}-\psi\right)
\end{array}\right]\left\{\begin{array}{l}
x_{L}-x \\
y_{L}-y
\end{array}\right\}-\left[\begin{array}{l}
l_{c} \\
f_{c}
\end{array}\right]
$$

where $x$ and $y$ represent the Cartesian position in the horizontal plane, the subscript ' $L$ ' indicates leader terms, and $\psi$ is the followers yaw angle. $f_{c}$ and $l_{c}$ are the forward and lateral clearances respectively. The error is input into the PID functions:

$$
\begin{aligned}
& \theta_{x, d}=K_{P, \theta} * f+K_{I, \theta} \int f d \tau+K_{D, \theta} \frac{d}{d t} f \\
& \phi_{y, d}=K_{P, \phi} * l+K_{I, \phi} \int l d \tau+K_{D, \phi} \frac{d}{d t} l
\end{aligned}
$$

The outer loop gains were refined until desirable performance was achieved. The refined gains are shown in Table 2.

Table 2: VTOL PID Outer Loop Gains

\begin{tabular}{|c|l|l|}
\hline \multirow{4}{*}{$\begin{array}{c}\text { VTOL } \\
\text { PID }\end{array}$} & Longitudinal & Lateral \\
\cline { 2 - 3 } OLC & $K_{P, \theta}=-0.01$ & $K_{P, \phi}=0.01$ \\
\cline { 2 - 3 } Gains & $K_{I, \theta}=-8.73 \mathrm{e}-5$ & $K_{I, \phi}=8.73 \mathrm{e}-5$ \\
\cline { 2 - 3 } & $K_{D, \theta}=-0.028$ & $K_{D, \phi}=0.028$ \\
\hline
\end{tabular}

\section{VTOL Fuzzy Logic Outer Loop Control}

Fuzzy logic is used in aerospace for qualitative analyses like detection of pilot fatigue at various levels of mental exhaustion [69] and tracking as mentioned in Chapter II section C. For this design, the Fuzzy Logic controller control output is a function of the position error, from equation 2, and the velocity of the follower quad rotor. 
Fuzzy logic operates in three phases: Fuzzification, Inference Check, and Defuzzification. The position and velocity errors are "fuzzified," which means these crisp inputs are related to a linguistic variable using a membership function. Equation 7 is used again for position error and equation 14 is defined for velocity error:

$$
\left[\begin{array}{l}
V_{l} \\
V_{f}
\end{array}\right]=\left[\begin{array}{cc}
-\sin \left(\psi_{L}-\psi\right) & \cos \left(\psi_{L}-\psi\right) \\
\cos \left(\psi_{L}-\psi\right) & \sin \left(\psi_{L}-\psi\right)
\end{array}\right]\left\{\begin{array}{l}
V_{x, L}-V_{x} \\
V_{y, L}-V_{y}
\end{array}\right\}
$$

$\psi$ is the yaw angle, the subscript ' ${ }_{L}$ ' represents the leader term. Equations 7 and 10 are decoupled. The lateral position and velocity error is used to calculate the desired roll command, and the longitudinal position and velocity errors are used to calculate the desired pitch command.

A membership function has an associating linguistic value. There are five membership functions in the Fuzzification process which are Large Negative $(L N)$, Negative $(N)$, Zero $(Z)$, Positive $(P)$, and Large Positive $(L P)$. Equations 10-13 displays the Fuzzification process for the lateral position error, lateral velocity error, forward position error, and forward velocity error respectively. Figure 3 shows the plotted membership functions. The input is scaled using a gain, $K l$ or $K_{f}$; $K_{v l}$ or $K_{v f}$, and then applied to each membership function.

$$
\begin{aligned}
& l_{F u z z y}=\left[L N\left(K_{l} l\right) N\left(K_{l} l\right) Z\left(K_{l} l\right) P\left(K_{l} l\right) L P\left(K_{l} l\right)\right] \\
& v_{l, F u z z y}=\left[L N\left(K_{v l} v_{l}\right) N\left(K_{v l} v_{l}\right) Z\left(K_{v l} v_{l}\right) P\left(K_{v l} v_{l}\right) L P\left(K_{v l} v_{l}\right)\right] \\
& f_{\text {Fuzzy }}=\left[L N\left(K_{f} f\right) N\left(K_{f} f\right) Z\left(K_{f} f\right) P\left(K_{f} f\right) L P\left(K_{f} f\right)\right] \\
& v_{f, F u z z y}=\left[L N\left(K_{v f} v_{f}\right) N\left(K_{v f} v_{f}\right) Z\left(K_{v f} v_{f}\right) P\left(K_{v f} v_{f}\right) L P\left(K_{v f} v_{f}\right)\right]
\end{aligned}
$$




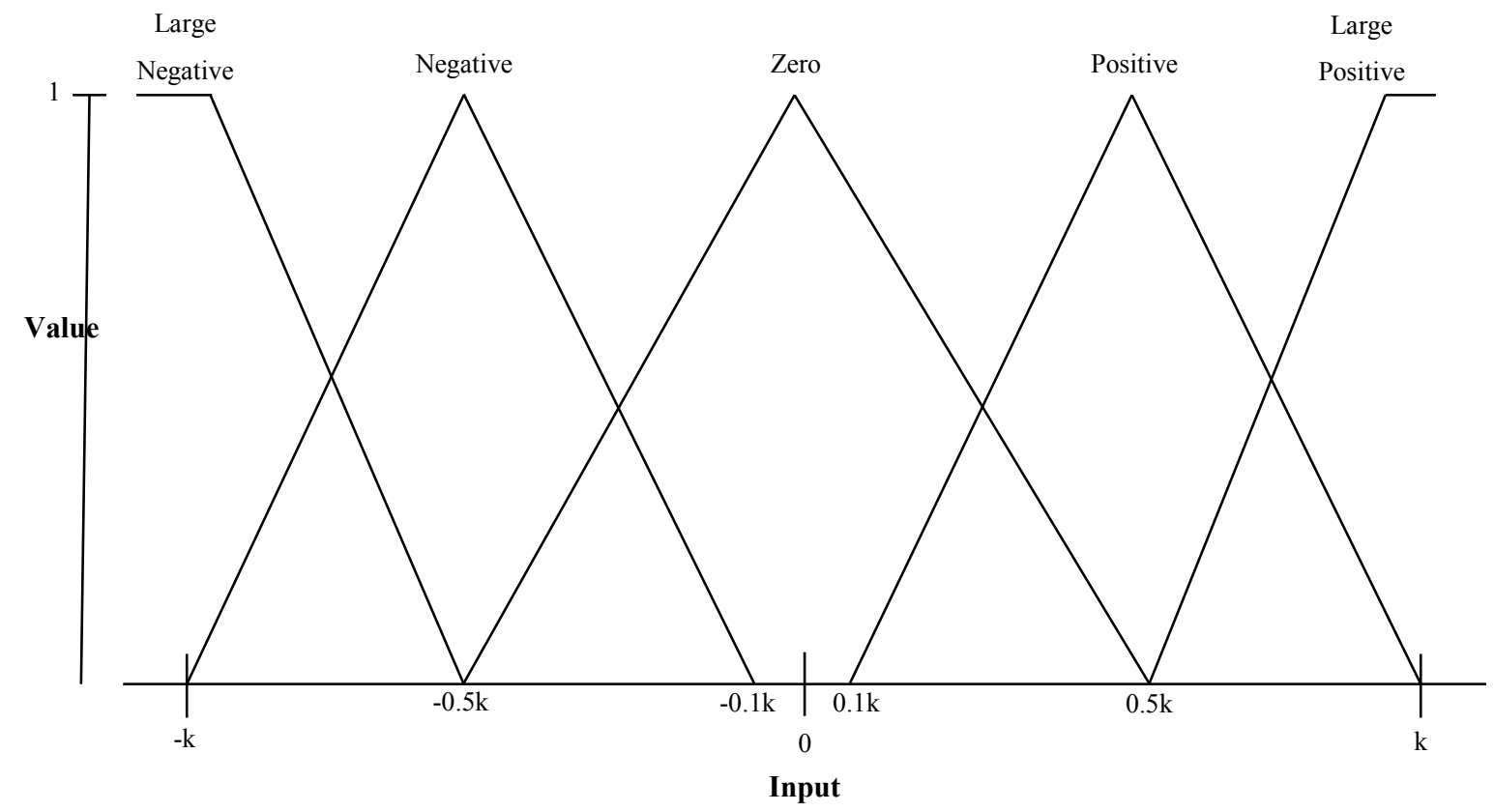

Figure 3: The Input Membership Functions of the Fuzzification Process

Each position error linguistic value is multiplied by the terms of the correlating velocity linguistic values in two inference rule matrices, one for the lateral terms and one for the longitude terms. Table 3 and Table 4 illustrate the projections as described for the lateral and forward terms respectively. The superscripted number refers to the cell of the fuzzy input.

Table 3: Lateral Inference Rule Matrix

\begin{tabular}{|c|c|c|c|c|c|c|}
\hline \multirow{2}{*}{} & \multicolumn{5}{|c|}{$V_{l, F u z z y}$} \\
\cline { 2 - 7 } & $\mathrm{LP}$ & $l_{F}^{1} * V_{l, F}^{1}$ & $l_{F}^{1} * V_{l, F}^{2}$ & $l_{F}^{1} * V_{l, F}^{3}$ & $l_{F}^{1} * V_{l, F}^{4}$ & $l_{F}^{1} * V_{l, F}^{5}$ \\
\cline { 2 - 7 }$l_{F u z z y}$ & $\mathrm{P}$ & $l_{F}^{2} * V_{l, F}^{1}$ & $l_{F}^{2} * V_{l, F}^{2}$ & $l_{F}^{2} * V_{l, F}^{3}$ & $l_{F}^{2} * V_{l, F}^{4}$ & $l_{F}^{2} * V_{l, F}^{5}$ \\
\cline { 2 - 7 } & $\mathrm{Z}$ & $l_{F}^{3} * V_{l, F}^{1}$ & $l_{F}^{3} * V_{l, F}^{2}$ & $l_{F}^{3} * V_{l, F}^{3}$ & $l_{F}^{3} * V_{l, F}^{4}$ & $l_{F}^{3} * V_{l, F}^{5}$ \\
\cline { 2 - 7 } & $\mathrm{N}$ & $l_{F}^{4} * V_{l, F}^{1}$ & $l_{F}^{4} * V_{l, F}^{2}$ & $l_{F}^{4} * V_{l, F}^{3}$ & $l_{F}^{4} * V_{l, F}^{4}$ & $l_{F}^{4} * V_{l, F}^{5}$ \\
\cline { 2 - 7 } & $\mathrm{LN}$ & $l_{F}^{5} * V_{l, F}^{1}$ & $l_{F}^{5} * V_{l, F}^{2}$ & $l_{F}^{5} * V_{l, F}^{3}$ & $l_{F}^{5} * V_{l, F}^{4}$ & $l_{F}^{5} * V_{l, F}^{5}$ \\
\hline
\end{tabular}




\begin{tabular}{|c|c|c|c|c|c|c|}
\hline & \multicolumn{5}{|c|}{$V_{f, F u z z y}$} \\
\hline & & LP & $\mathrm{P}$ & Z & $\mathrm{N}$ & LN \\
\hline \multirow{5}{*}{$f_{\text {Fuzzy }}$} & LP & $f_{F}^{1} * V_{f, F}^{1}$ & $f_{F}^{1} * V_{f, F}^{2}$ & $f_{F}^{1} * V_{F, F}^{3}$ & $f_{F}^{1} * V_{f, F}^{4}$ & $f_{F}^{1} * V_{f, F}^{5}$ \\
\hline & $\mathrm{P}$ & $f_{F}^{2} * V_{f, F}^{1}$ & $f_{F}^{2} * V_{f, F}^{2}$ & $f_{F}^{2} * V_{f, F}^{3}$ & $f_{F}^{2} * V_{f, F}^{4}$ & $f_{F}^{2} * V_{f, F}^{5}$ \\
\hline & $\mathrm{Z}$ & $f_{F}^{3} * V_{f, F}^{1}$ & $f_{F}^{3} * V_{f, F}^{2}$ & $f_{F}^{3} * V_{f, F}^{3}$ & $f_{F}^{3} * V_{f, F}^{4}$ & $f_{F}^{3} * V_{f, F}^{5}$ \\
\hline & $\mathrm{N}$ & $f_{F}^{4} * V_{f, F}^{1}$ & $f_{F}^{4} * V_{f, F}^{2}$ & $f_{F}^{4} * V_{f, F}^{3}$ & $f_{F}^{4} * V_{f, F}^{4}$ & $f_{F}^{4} * V_{f, F}^{5}$ \\
\hline & $\mathrm{LN}$ & $f_{F}^{5} * V_{f, F}^{1}$ & $f_{F}^{5} * V_{f, F}^{2}$ & $f_{F}^{5} * V_{f, F}^{3}$ & $f_{F}^{5} * V_{f, F}^{4}$ & $f_{F}^{5} * V_{f, F}^{5}$ \\
\hline
\end{tabular}

Each cell of the inference rule matrix also has a correlating fuzzy command as shown in Table 5. These fuzzy commands are Large Negative $(L N)$, Negative $(N)$, Small Negative $(S N)$, Zero $(Z)$, Small Positive (SP), Positive $(P)$, and Large Positive $(L P)$.

Table 5: Fuzzy Commands (Linguistic Values)

\begin{tabular}{|c|c|c|c|c|c|c|}
\hline \multirow{2}{*}{} & \multicolumn{5}{|c|}{ Velocity } \\
\cline { 2 - 7 } & LP & P & Z & N & LN \\
\hline \multirow{3}{*}{$\begin{array}{c}\text { Distance } \\
\text { Error }\end{array}$} & LP & SP & P & P & LP & LP \\
\cline { 2 - 7 } & P & Z & Z & SP & L & P \\
\cline { 2 - 7 } & Z & SN & SN & Z & SP & SP \\
\cline { 2 - 7 } & N & N & N & SN & Z & Z \\
\cline { 2 - 7 } & LN & LN & LN & N & N & SN \\
\hline
\end{tabular}

The respective fuzzy commands are summed together to deal with doublication. That is, all the cells with the same fuzzy command are combined as shown in equations 15 and 16. Linguistic values are set equal to 1 if they exceed the limit of 1 .

$$
\begin{gathered}
l_{\text {Out }}^{\text {Fuzzy }}=\left[\begin{array}{lllllll}
\sum L P_{l} & \sum P_{l} & \sum S P_{l} & \sum Z_{l} & \sum S P_{l} & \sum P_{l} & \sum L P_{l}
\end{array}\right] \\
f_{\text {Out }}^{F u z y}=\left[\begin{array}{lllllll}
\sum L P_{f} & \sum P_{f} & \sum S P_{f} & \sum Z_{f} & \sum S P_{f} & \sum P_{f} & \sum L P_{f}
\end{array}\right]
\end{gathered}
$$

The fuzzy commands are defuzzified back into a crisp output command using a membership function shown in Figure 4. The value in each cell is the height, $c^{i}$, of the trapezoid in each membership function. 


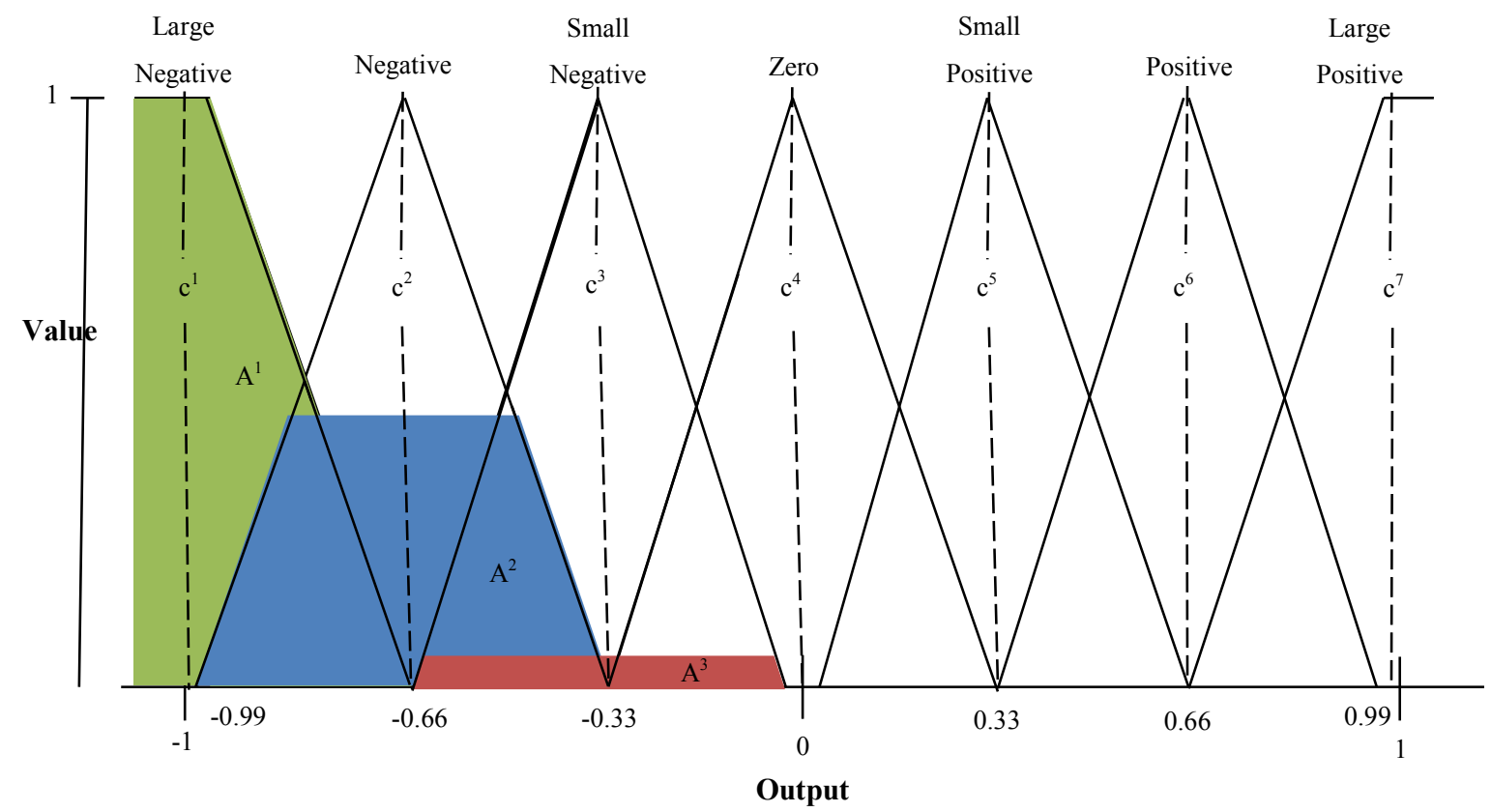

Figure 4: Membership Function with Seven Linguistic Values

The area below the output membership function, $A$, of each of the cells is calculated and then combined as shown in equation 17 and 18 in order to obtain the lateral and forward commands respectively.

$$
\begin{gathered}
\phi_{d}=K_{l, d} \frac{\sum_{j=1}^{n_{j}} c_{\text {lout }}^{j} A_{\text {lout }}^{j}}{\sum_{j=1}^{n_{j}} A_{\text {lout }}^{j}} \\
\theta_{d}=K_{f, d} \frac{\sum_{i=1}^{n_{i}} c_{\text {fout }}^{j} A_{\text {fout }}^{j}}{\sum_{i=1}^{n_{i}} A_{\text {fout }}^{j}}
\end{gathered}
$$

A 3D representation of the output command is shown in Figure 5. The gains $K_{f d}$ and $K_{l d}$ in equations 17 and 18 allow the commands to be scaled from a unitless interval $[-1,1]$ (shown in the figure) to the range of desired motion in degrees. The outer loop gains were refined until desirable performance was achieved. The refined gains are shown in Table 6. 


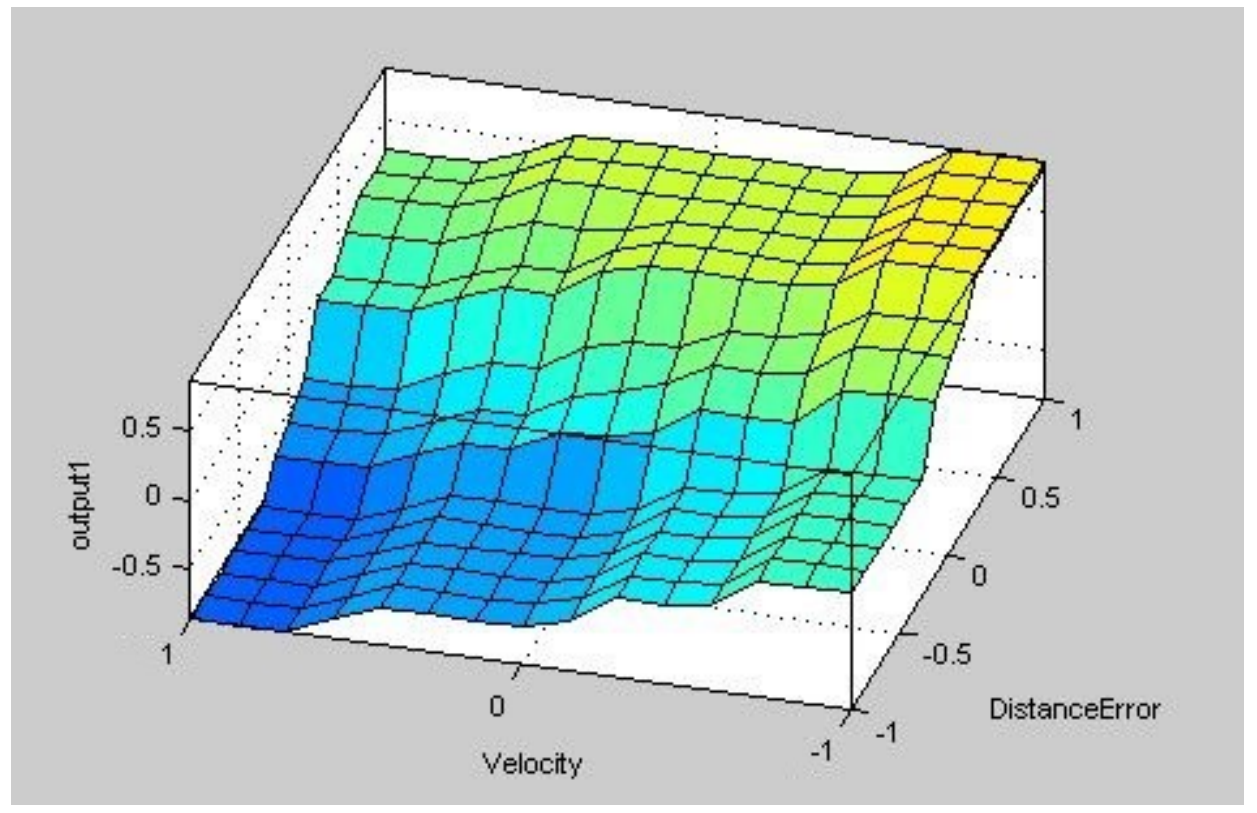

Figure 5: 3D Plot of the Fuzzy Logic Function.

Table 6: VTOL Fuzzy Logic Outer Loop Gains

\begin{tabular}{|c|c|}
\hline \multicolumn{2}{|c|}{ VTOL FL OLC Gains } \\
\hline$k$ for position & 1.7 \\
\hline$k$ for speed & 4.5 \\
\hline$K_{f, d}$ & -0.1 \\
\hline$K_{l, d}$ & 0.1 \\
\hline
\end{tabular}

\section{VTOL NLDI Outer Loop Control}

This method is inspired by the NLDI design implemented with the F-22 and Phastball aircraft but incorporates the quadrotors ability to hover. State information regarding positon of the follower aircraft can be recalculated into forward and lateral components using a rotation matrix as shown in equation 2 . For convenience the difference in yaw angle, $\psi$, is substituted using equation 19.

$$
\Delta \psi=\psi_{L}-\psi
$$

The rate of change of the in-plane geometry with respect to time is defined as

$$
\left[\begin{array}{l}
\dot{l} \\
\dot{f}
\end{array}\right]=\left[\begin{array}{cc}
-\sin \Delta \psi & \cos \Delta \psi \\
\cos \Delta \psi & \sin \Delta \psi
\end{array}\right]\left\{\begin{array}{l}
V_{x, L}-V_{x} \\
V_{y, L}-V_{y}
\end{array}\right\}+\mathrm{r}_{L}\left[\begin{array}{c}
f \\
-l
\end{array}\right]
$$

where the yaw rate is $r$, and $V$ is velocity. Next, equation 20 is derived into equation 21 in order to obtain the acceleration components needed to apply the geometry to the dynamics of the follower quadrotor. 


$$
\begin{aligned}
{\left[\begin{array}{c}
\ddot{l}_{d} \\
\ddot{f}_{d}
\end{array}\right]=} & {\left[\begin{array}{cc}
-\cos \Delta \psi & -\sin \Delta \psi \\
-\sin \Delta \psi & \cos \Delta \psi
\end{array}\right]\left\{\begin{array}{l}
V_{x, L}-V_{x} \\
V_{y, L}-V_{y}
\end{array}\right\}\left(r_{L}-r\right) } \\
& +\left[\begin{array}{cc}
-\sin \Delta \psi & \cos \Delta \psi \\
\cos \Delta \psi & \sin \Delta \psi
\end{array}\right]\left\{\begin{array}{l}
a_{x, L}-a_{x} \\
a_{y, L}-a_{y}
\end{array}\right\}+\dot{\mathrm{r}}_{L}\left[\begin{array}{c}
f \\
-l
\end{array}\right]+\mathrm{r}_{L}\left[\begin{array}{c}
\dot{f} \\
-\dot{l}
\end{array}\right]
\end{aligned}
$$

The follower's acceleration components noted as $a_{x}$ and $a_{y}$, relate to the vehicle dynamics in this way:

$$
\begin{aligned}
& a_{x}=\frac{-U}{m} \sin (\theta) \\
& a_{y}=\frac{U}{m} \sin (\phi)
\end{aligned}
$$

where $U$ is the total steady state thrust output, $m$ is the mass of the quadrotor, $\theta$ is the pitch angle, and $\phi$ is the roll angle. Using the small angle assumption we can linearize equation 22 and 23 into

$$
\begin{aligned}
& a_{x}=\frac{-U}{m} \theta \\
& a_{y}=\frac{U}{m} \phi
\end{aligned}
$$

respectively. Small angle assumption is a truncation of the McLaurin Series for sine, which is linearization by definition.

Finally, the desired command components are isolated to the left of equation 21 to produce the longitudinal and lateral attitude commands:

$$
\begin{array}{r}
{\left[\begin{array}{l}
\theta_{x, d} \\
\phi_{y, d}
\end{array}\right]=\frac{m}{U}\left\{\left[\begin{array}{cc}
\cos \Delta \psi & \sin \Delta \psi \\
-\sin \Delta \psi & \cos \Delta \psi
\end{array}\right]\left\{\begin{array}{l}
V_{x, L}-V_{x} \\
V_{y, L}-V_{y}
\end{array}\right\}\left(r_{L}-r\right)+\left[\begin{array}{cc}
\sin \Delta \psi & -\cos \Delta \psi \\
\cos \Delta \psi & \sin \Delta \psi
\end{array}\right]\left\{\begin{array}{l}
a_{x, L} \\
a_{y, L}
\end{array}\right\}\right\}} \\
-\frac{m}{U}\left\{\dot{\mathrm{r}}_{L}\left[\begin{array}{l}
f \\
l
\end{array}\right]+\mathrm{r}_{L}\left[\begin{array}{c}
\dot{f} \\
\dot{l}
\end{array}\right]+\left[\begin{array}{c}
-\ddot{l}_{d} \\
\ddot{f}_{d}
\end{array}\right]\right\}
\end{array}
$$

The $\ddot{l}_{d}$ and $\ddot{f}_{d}$ terms are then controlled with a set of compensator-type linear control laws as shown in equation 27.

$$
\left[\begin{array}{l}
\ddot{l}_{d} \\
\ddot{f}_{d}
\end{array}\right]=-K_{P}\left[\begin{array}{l}
l \\
f
\end{array}\right]-K_{I} \int\left[\begin{array}{l}
l \\
f
\end{array}\right]-K_{D}\left[\begin{array}{l}
\dot{l} \\
\dot{f}
\end{array}\right]
$$

The integral gain, $K_{I}$, was added to this controller after initial simulation tests showed poor error convergence. Since quadrotors can hover in place, integral control guarantees a zero steady state error any time the formation is stationary. 
Table 7: VTOL Nonlinear Dynamic Inversion Outer Loop Gains

\begin{tabular}{|c|c|c|c|}
\hline \multicolumn{4}{|c|}{ VTOL NLDI OLC Gains } \\
\hline Forward & $K_{P}=0.1$ & $K_{I}=0.001$ & $K_{D}=0.4$ \\
\hline Lateral & $K_{P}=0.1$ & $K_{I}=0.001$ & $K_{D}=0.4$ \\
\hline
\end{tabular}

\section{Phastball Control Design}

\section{Inner loop Design}

The control design is broken into a two loop structure for the follower aircraft ion the same way as described for the quadrotor. The outer loop deals with minimizing position error, and the inner loop performs disturbance correction and attitude tracking. The inner loop translates commands to control surface deflection and mitigates state perturbation not produced by the outer loop. The inner loop control laws are obtained by minimizing the cost function, $J$,

$$
J=\int_{0}^{\infty}\left(\bar{x}^{T} Q \bar{x}+\bar{u}^{T} R \bar{u}\right) d t
$$

where $u$ and $x$ are the optimized control action and the state of the aircraft respectively [52]. The state involves longitudinal components (angle of attack, $\alpha$; pitch rate, $q$; and pitch angle, $\theta$ ) and lateraldirectional components (side-slip, $\beta$; roll rate, $p$; roll angle, $\theta$; yaw rate, $r$; and yaw angle, $\psi$ ). $Q$ and $R$ are positive definite weighting matrices. Then optimized control action is to enable the aircraft to track the desired angles produced by the outer-loop: pitch, $\theta_{d}$, and roll, $\phi_{d}$, and yaw, $\psi_{d}$. The control action of the tracker is expressed as

$$
\left[\begin{array}{l}
u_{A} \\
u_{R}
\end{array}\right]=K_{r} \phi_{d}-K_{x} x
$$

and

$$
u_{E}=K_{r} \theta_{d}-K_{x} x
$$

for the lateral and longitudinal dimensions respectively [52]. $u_{A}, u_{R}$ and $u_{E}$ are the deflections of the ailerons, rudder, and elevator respectively. $K_{r}$ is the matrix of feed-forward gains associated with the desired deflection. $K_{x}$ is the matrix of feedback gains associated with all the states which are the lateral components, angle of attack $(\alpha)$; pitch rate $(q)$; and pitch angle $(\theta)$, and the latitudinal components, sideslip $(\beta)$; roll rate $(p)$; roll angle $(\phi)$; yaw rate $(r)$; and yaw angle $(\psi)$. Through simulation and iterative adjustment, the inner loop gains (equation 7) and then the outer-loop gains (equations 3-5) were refined until desirable performance was achieved. The refined gains are shown in Table 8. 
Table 8: Fixed Wing Inner Loop Gains

\begin{tabular}{|l|l|l|}
\hline \multirow{3}{*}{$\begin{array}{l}\text { Fixed } \\
\text { Wing }\end{array}$} & Longitudinal & Lateral \\
\cline { 2 - 3 } $\begin{array}{l}\text { ILC } \\
\text { Gains }\end{array}$ & $\mathrm{K}_{\mathrm{x}}=[0.0991,0.1308,0.6325]$ & $\mathrm{K}_{\mathrm{x}}=[-0.1665,0.045,0.0413,0.5385 ;$ \\
& & $-0.0827,0.0076,0.1708,0.1171]$ \\
\cline { 2 - 3 } & $\mathrm{K}_{\mathrm{r}}=[-0.6325]$ & $\mathrm{K}_{\mathrm{r}}=[-0.5413 ;-0.0147]$ \\
\hline
\end{tabular}

\section{Fixed-wing Outer Loop Design}

The formation flight controller considered the flight path typically lies in a 2D plane which simplifies flight control into two decoupled horizontal and vertical tracking problems. The position and velocity of the aircraft in formation were expressed with respect to a local tangent plane.

The outer loop control is designed using a nonlinear dynamic inversion (NLDI) approach. Detailed design for the outer loop controller was presented in [53] and the developed nonlinear control laws for the horizontal tracking problem are:

$$
\begin{aligned}
\phi_{d}= & \arctan \left\{\frac{1}{g \cos \gamma}\left[\ddot{l}_{d} \cos \left(x-x_{L}\right)+\ddot{f}_{d} \sin \left(x-x_{L}\right)\right]\right. \\
+ & \left.\frac{V}{g} \Omega_{L}+\frac{\Omega_{L}}{g \cos \gamma}\left[\dot{l} \sin \left(x-x_{L}\right)-\dot{f} \cos \left(x-x_{L}\right)\right]\right\} \\
\delta_{T} & =\frac{m}{K_{T} \cos \gamma}\left[\ddot{l}_{d} \sin \left(X-x_{L}\right)+\ddot{f}_{d} \cos \left(x-x_{L}\right)\right] \\
& +\frac{1}{K_{T}}\left[\frac{1}{2} \rho_{0} V^{2} S\left(C_{D 0}+C_{D \alpha} \alpha_{0}\right)+m \sin \gamma-T_{b}\right] \\
& -\frac{m}{K_{T} \cos \gamma} \Omega_{L}\left[i \cos \left(X-x_{L}\right)-\dot{f} \sin \left(x-x_{L}\right)\right]
\end{aligned}
$$

, where, $\phi_{d}$ and $\delta_{d}$ are the desired roll angle and thrust commands respectively; $m$ is mass (in $\mathrm{kg}$ ). $g$ is gravity; $\alpha$ and $\beta$ are the angle of attack and side slip angle respectively; $\gamma$ is the flight path angle, and $\Omega$ is the aircraft angular turn rate. $C_{D O}$ and $C_{D \alpha}$ are the aerodynamic coefficients for drag. $\chi$ is the aircraft azimuth angle. $K_{T}$ and $T_{b}$ are constants to be provided by the engine model. Leader parameters are labeled with '

The linearized horizontal formation error dynamics are then controlled with a set of compensator-type linear control laws: 


$$
\begin{aligned}
& \ddot{l}_{d}=-K_{l s} \dot{l}-K_{l} l \\
& \ddot{f}_{d}=-K_{f s} \dot{f}-K_{f} f
\end{aligned}
$$

A linear altitude tracker is used to control the vertical geometry by producing a desired pitch angle:

$$
\theta_{d}=-K_{v} v-K_{v s} \dot{v}
$$

, where, $\theta_{\mathrm{d}}$ is the desired pitch angle, $\mathrm{v}$ is the vertical distance, and $\mathrm{K}$ represents gains which are refined through simulation. The gains are shown in Table 9.

Table 9: Fixed Wing NonLinear Dynamic Inversion Outer Loop Gains

\begin{tabular}{|c|l|l|l|}
\hline \multirow{2}{*}{$\begin{array}{c}\text { Phastball } \\
\text { NLDI OLC } \\
\text { Gains }\end{array}$} & \multicolumn{1}{|c|}{ Forward } & \multicolumn{1}{|c|}{ Lateral } & Vertical \\
\cline { 2 - 4 } & $K_{f}=0.45$ & $K_{l}=0.6$ & $K_{v}=1.3$ \\
\cline { 2 - 4 } & $K_{f s}=1.2$ & $K_{l s}=1.7$ & $K_{v s}=0.8$ \\
\hline
\end{tabular}

\section{Controller Simulation and Validation}

\section{A. Controller Performance Validation}

Performance is defined as the controller's ability to track. In other words, the controller autonomously maneuvers the follower aircraft into the formation flight geometry and maintains its position relative to the leader aircraft. Tracking is characterized by four elements: overshoot percent, OS\%; reaction time, $T_{R}$; settling time, $T_{S}$; and steady state error, $e_{s s}$. They are defined as:

$$
\begin{gathered}
e_{S S}=e @ t_{\text {final }} \\
O S \%=a b s\left(\frac{e_{\text {max }}-e_{S S}}{e_{0}}\right) \\
T_{S}=t @ e_{S S} \pm 2 \% \\
T_{R}=0.6\left(t @ e_{\max }\right)
\end{gathered}
$$

These elements are also illustrated in Figure 6. 


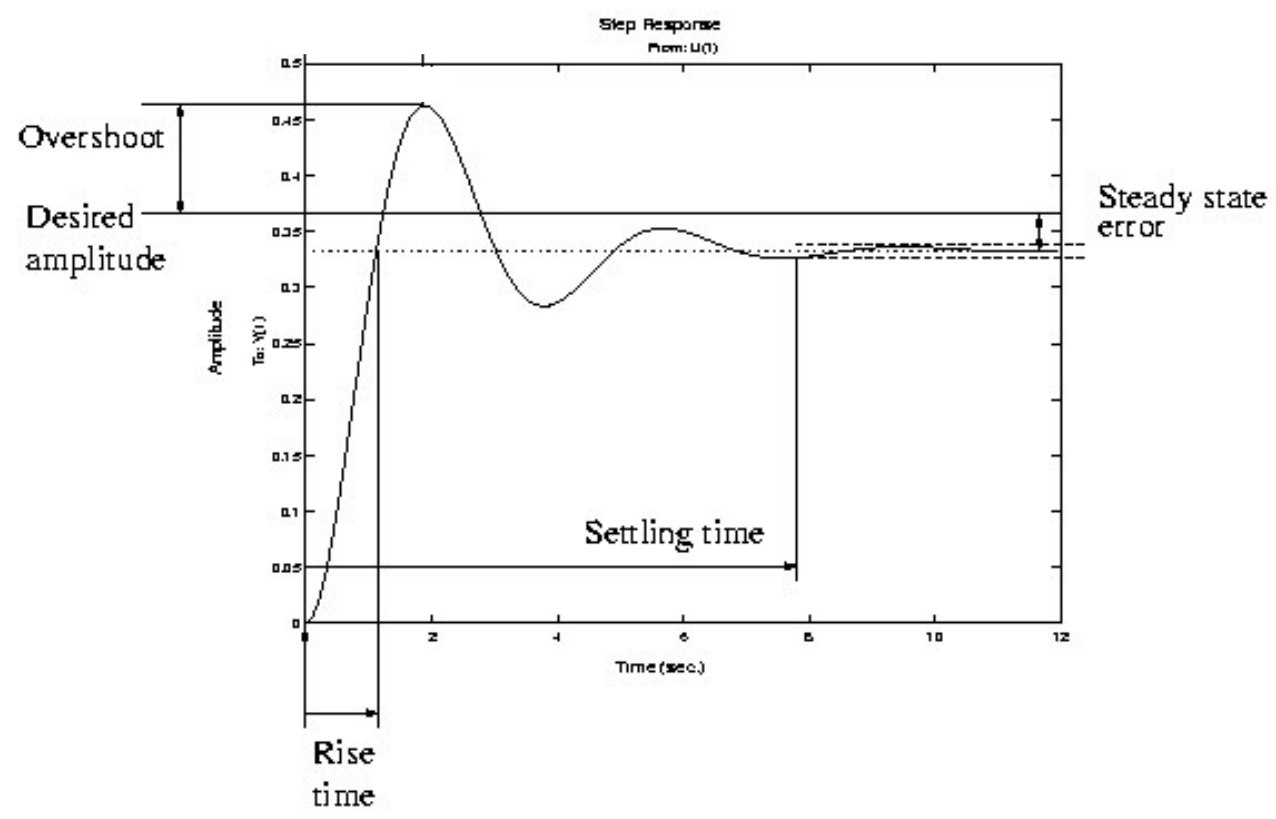

Figure 6: Elements of Tracking Performance

All three of the controllers are designed for a purpose for future testing and therefore have additional minimum requirements they have to achieve. Table 10 defines these goals for the VTOL controllers. The VTOL requirements are for the purpose of flying in an indoor facility area. The facilities will be discussed further in Chapter V. All requirements are weighted the same. Controller performance is given a score as a comprehensive comparison against ideal behavior. The score is formulated as shown in equation 40 .

Table 10: VTOL Controller Minimum Requirements

\begin{tabular}{|l|l|c|}
\multicolumn{3}{|c|}{ VTOL Controller Minimum Requirements } \\
\hline Index & \multicolumn{1}{|c|}{ Goal } & Weight \\
\hline NEO1. & OS $\%<50 \%$ & 1 \\
NEO2. & $\mathrm{T}_{\mathrm{S}}<10 \mathrm{~s}$ & 1 \\
NEO3. & $\mathrm{T}_{\mathrm{R}}<5 \mathrm{~s}$ & 1 \\
NEO4. & $\mathrm{e}_{\mathrm{ss}}<5 \mathrm{~cm}$ for stationary formation (step response) & 1 \\
NEO5. & $\mathrm{e}_{\mathrm{ss}}<25 \mathrm{~cm}$ for dynamic formation (ramp response) & 1 \\
\hline Score & \multicolumn{2}{|c|}{ see equation 40} \\
\hline
\end{tabular}

VTOL SCORE = average $\left(\frac{0.50-O S \%}{0.50}, \frac{10 s-T_{S}}{10 s}, \frac{5 s-T_{R}}{5}, \frac{5 \mathrm{~cm}-e_{s s \mid s t e p}}{5 \mathrm{~cm}}, \frac{25 \mathrm{~cm}-e_{s s \mid \mathrm{ramp}}}{25 \mathrm{~cm}}\right) \%$ 
Table 11 defines the goals for the fixed wing controller. The VTOL requirements are for the purpose of flying in an indoor facility area. All requirements are weighted with respect to importance. Controller performance is given a score as a comprehensive comparison against ideal behavior. The score is formulated as shown in equation 41. The lateral, forward, and vertical controllers are all scored individually since they are all mathematically different. The requirement weights are for the outdoor test area and also for the benefit of encountering the wing tip vortex from the leader aircraft. This is why PB3 and PB4 are weighted higher than PB1 and PB2.

Table 11: Fixed Wing Minimum Requirements

\begin{tabular}{|l|l|c|}
\hline \multicolumn{3}{|c|}{ Fixed Wing Controller Goals } \\
\hline Index & \multicolumn{1}{|c|}{ Goal } & Weight \\
\hline PB1. & OS $\%<30 \%$ & 0.8 \\
PB2. & $\mathrm{T}_{\mathrm{R}}<7 \mathrm{~s}$ & 0.2 \\
PB3. & $\mathrm{T}_{\mathrm{S}}<15 \mathrm{~s}$ & 1.5 \\
PB4. & $\mathrm{e}_{\mathrm{ss}}<100 \%$ wingspan $(\sim 2.4 \mathrm{~m})$ & 1.5 \\
\hline Score & see equation 41 & \\
\hline
\end{tabular}

$$
F W S C O R E=\text { avarage }\left(0.8 \frac{0.30-O S \%}{0.30}, 0.2 \frac{15 s-T_{R}}{15 s}, 1.5 \frac{15 s-T_{S}}{15 s}, 1.5 \frac{2.4 m-e_{S S}}{24 c m}\right) \%
$$

\section{B. Quadrotor Simulation and Validation}

\section{Quadrotor Dynamic Modeling}

To gain validation of the controllers' functionality, simulation allows for practical feedback study. A dynamic mathematic model of the test bed will simulate the quadrotor's inertial behavior when acted upon by the autopilot control. Rudimentary graphics allow for visual representation of a flying quadrotor.

The quadrotor's dynamics rely on the differential speed of the motors. Two pairs of motors are mounted on opposite ends of a cross shaped frame and spin in the same direction. Motor torque causes a moment on the frame of the quadrotor which is cancelled by the opposing moment from the opposing pair of motors assuming identical aerodynamics for the blades on each of the motors. The spinning blades produce lifting force. Conversely increasing or decreasing any pair of motors produces coupled rotational and translational behavior. For instance, in Figure 7.b increasing the speed of motor 1 while decreasing the speed of motor 3 produces pitch rotation coupled with longitudinal translation. 


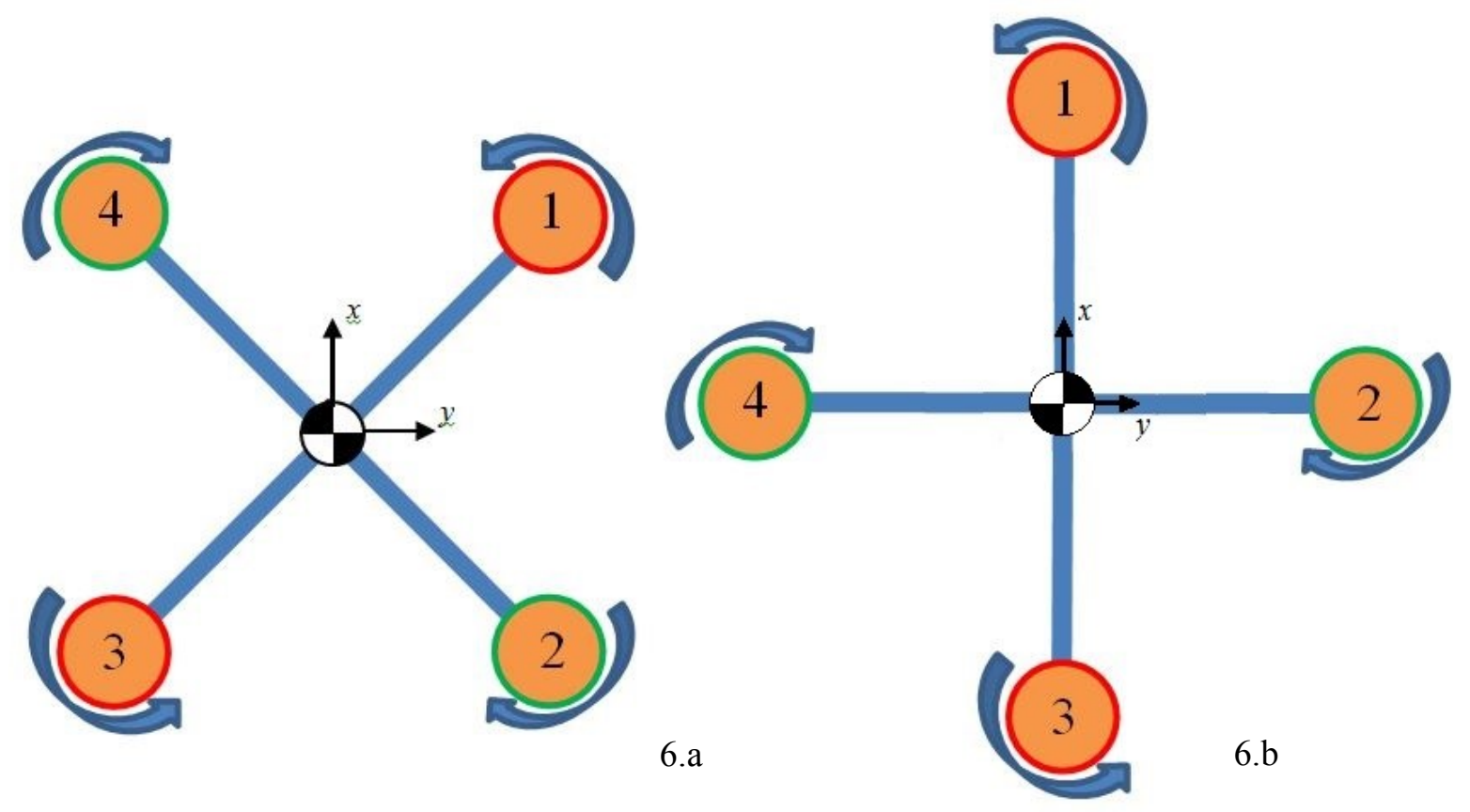

Figure 7: a. The ' $\mathrm{X}$ ' Configuration b. The Cross Configuration.

It is necessary to consider two frames of reference, the inertial Earth Fixed frame, $E$ (in the directions North East and Down), and the Body Fixed frame, $B$. The Body Fixed Frame is shown in Figure 7. Euler angles are used to convert parameters from $E$ to $B$ using the $\mathrm{R}$ matrix also known as the direction cosine matrix.

$$
\begin{aligned}
& R=\left[\begin{array}{ccc}
\cos \psi \cos \theta & \cos \psi \sin \theta \sin \phi-\sin \psi \cos \phi & \cos \psi \sin \theta \cos \phi+\sin \psi \sin \phi \\
\sin \psi \cos \theta & \sin \psi \sin \theta \sin \phi-\cos \psi \cos \phi & \sin \psi \sin \theta \cos \phi+\cos \psi \sin \phi \\
-\sin \theta & \cos \theta \sin \phi & \cos \theta \sin \phi
\end{array}\right] \\
& \xi=\left[\begin{array}{l}
X \\
Y \\
Z
\end{array}\right]_{E}=R\left[\begin{array}{l}
X \\
Y \\
Z
\end{array}\right]_{B}
\end{aligned}
$$

The XYZ represent any of the longitudinal, lateral, and downward directional components respectively. The rigid body dynamics of a quadrotor can then be defined by the Newton-Euler model and are used to create the applied force and rotor torque equation, Equation 43 [67][70].

$$
\left(\begin{array}{l}
F \\
\Gamma
\end{array}\right)=\left(\begin{array}{cc}
m I_{3} & 0 \\
0 & I
\end{array}\right)\left(\begin{array}{l}
\dot{V} \\
\dot{\Omega}
\end{array}\right)+\left(\begin{array}{c}
\Omega \times m V \\
\Omega \times I \Omega
\end{array}\right)
$$

$\xi$ represents the position vector, $m$ is the total quadrotor mass, $V$ is the velocity vector in the body frame, $\Omega$ is the rotational velocity vector, $I_{3}$ is the body inertia tensor in the $\mathrm{z}$ axis, $\mathrm{g}$ is gravitational acceleration, $F$ is the applied rotor force vector, and $\Gamma$ is the applied rotor torque vector [67]. 
The magnitude of the rotors' thrust and torque are functions of rotor speed.

$$
\begin{aligned}
& T_{i}=b \omega_{i}^{2} \\
& Q_{i}=k \omega_{i}^{2}
\end{aligned}
$$

$T$ and $Q$ are the thrust and torque, and $\omega$ is the rotor speed of the $i_{t h}$ rotor. $k$ and $b$ are aerodynamic parameters defined as:

$$
\begin{aligned}
& b=c_{t} \rho A r^{2} \\
& k=c_{q} \rho A r^{3}
\end{aligned}
$$

where $c_{t}$ and $c_{q}$ are thrust and torque coefficients respectively, $\rho$ is the air density, $A$ is the rotor disk area, and $r$ is the disk radius. The force vector is the sum of all rotor thrusts in the vertical direction of the body frame:

$$
F=\sum_{i=1,2,3,4} T_{i}\left(\begin{array}{c}
-\sin a_{1_{s} i} \\
\cos a_{1_{s} i} \sin b_{1_{s} i} \\
\cos b_{1_{s} i} \cos a_{1_{s} i}
\end{array}\right)
$$

where $a_{l s}$ and $b_{1 s}$ are the pitch and roll flapping angles defined by Raymond Prouty [71]. The torque vector is the sum of all rotor thrust couplings and gyroscopic moments. The thrust couplings are defined as:

$$
\Gamma_{T}=\left[\begin{array}{cccc}
0 & 0 & b d & -b d \\
b d & -b d & 0 & 0 \\
k & k & -k & -k
\end{array}\right]\left\{\begin{array}{c}
\omega_{1}^{2} \\
\omega_{2}^{2} \\
\omega_{3}^{2} \\
\omega_{4}^{2}
\end{array}\right\}
$$

where $d$ is the displacement between the rotor axis of rotation to the center of gravity of the quadrotor. The gyroscopic moments are defined as:

$$
\Gamma_{\text {gyro }}=\sum_{i=1,2,3,4} I_{R}\left(\omega_{i} \times e_{3}\right) \Omega
$$

where $I_{R}$ is the rotor inertia and $e_{3}$ is the inertial direction [70].

Motor dynamics are a function of drive torque, $\tau$ :

$$
I_{R} \dot{\omega}=\tau-Q
$$




\section{Quadrotor Simulink Model}

The nonlinear quadrotor model described in section A-1 was used by Paul Pounds [72] to create a simulator for Matblab/Simulink [73]. Figure 8 shows the basic simulator blocks. The outer loop is shown in orange, inner loop is colored blue, yaw control is in black, and altitude is in red. This simulator was used to test the ideal performance of the quadrotor controllers. The simulator's basic block functions are the input control distribution, output graphics, and aircraft dynamics S-function. The graphics display a quadrotor in a 3D space, shown in Figure 9.

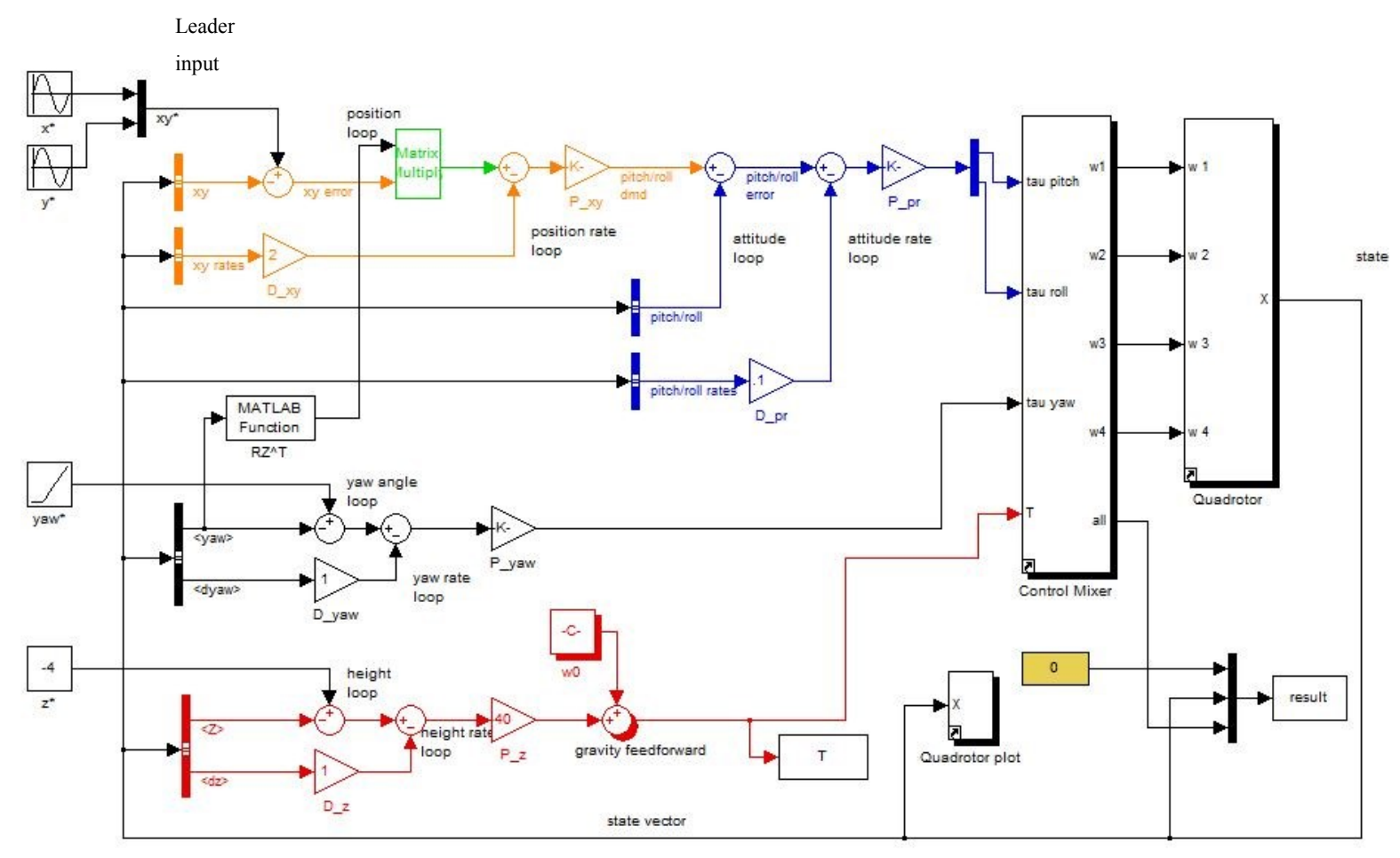

Figure 8: The Peter Corke Simulator [72]. 


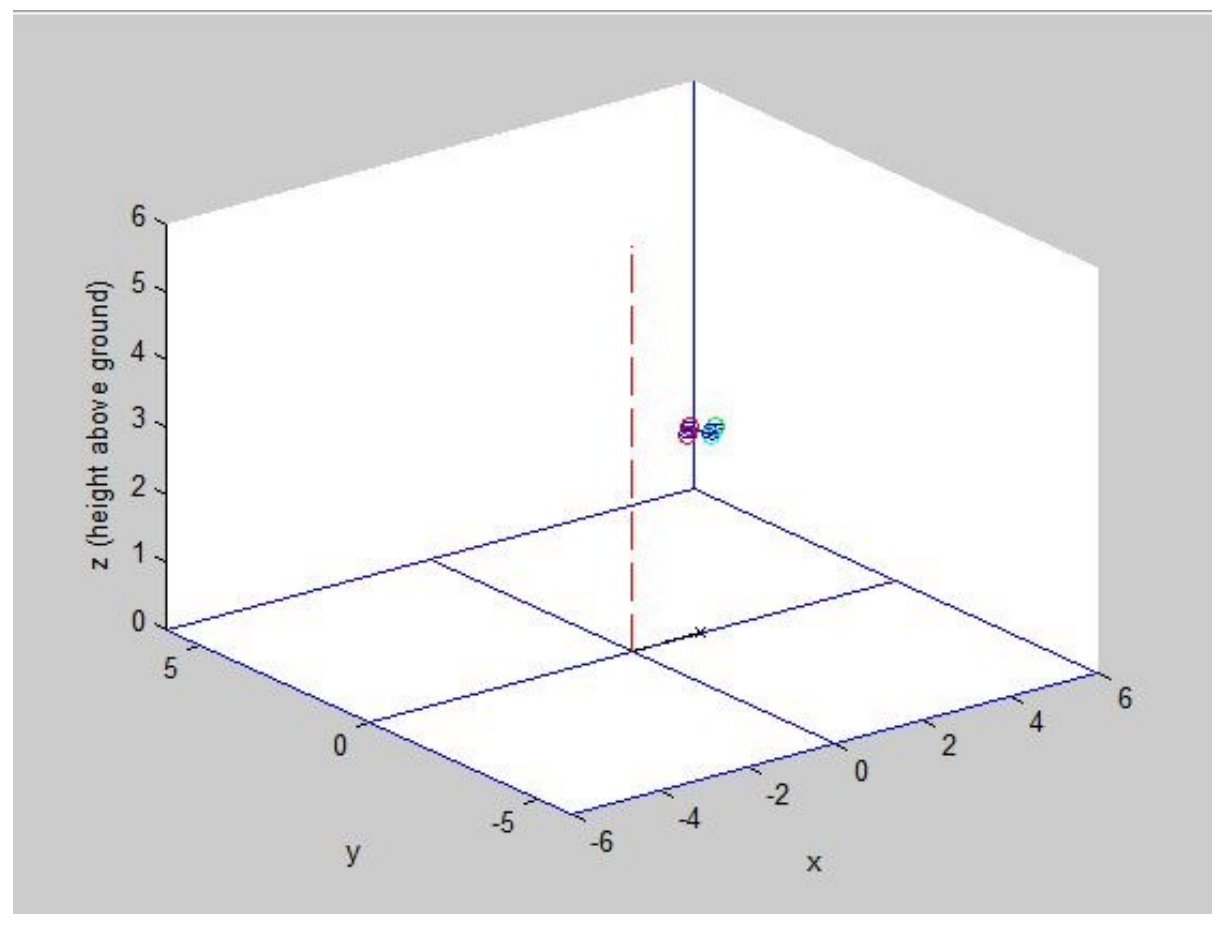

Figure 9: Graphics of the Simulator Showing the Quadrotor in a 3D Space

Each OLC is substituted in for the orange blocks of the original simulator in Figure 8. Simulated coordinates of the leader are generated and inputted as the reference to the controller. The error between the desired reference and the follower's $x$ and $y$ positions are recorded for analysis of controller behavior.

For the simulation the leader coordinates will be represented with position coordinates the quadrotor must follow. It starts at the coordinates $[0,-1.5]$ and steadily travels at a half meter per second for 45 seconds. The follower quadrotor starts at the coordinates $[0.5,-1.7]$. Fundamentally, the lateral controller is reacting to a step function and the longitudinal controller is reacting to a ramp function since pitch and roll control are decoupled yet identical. Each controller will try and match the current position of the leader. Position and error are saved for analysis of controller behavior.

\section{VTOL PID Simulation}

Simulink PID blocks were substituted in for the outer loop and a new subsystem was made for the inner loop of the Peter Corke simulator (the orange and blue portions of Figure 8 respectively). The position error is input into a rotation matrix to output the dimensions with respect to the quadrotor body axis. The position errors are then input into the PID block and the output signals are input into the inner loop. Figure 10 displays the before mentioned virtual leader input, the VTOL PID outer loop, and the inner loop. 


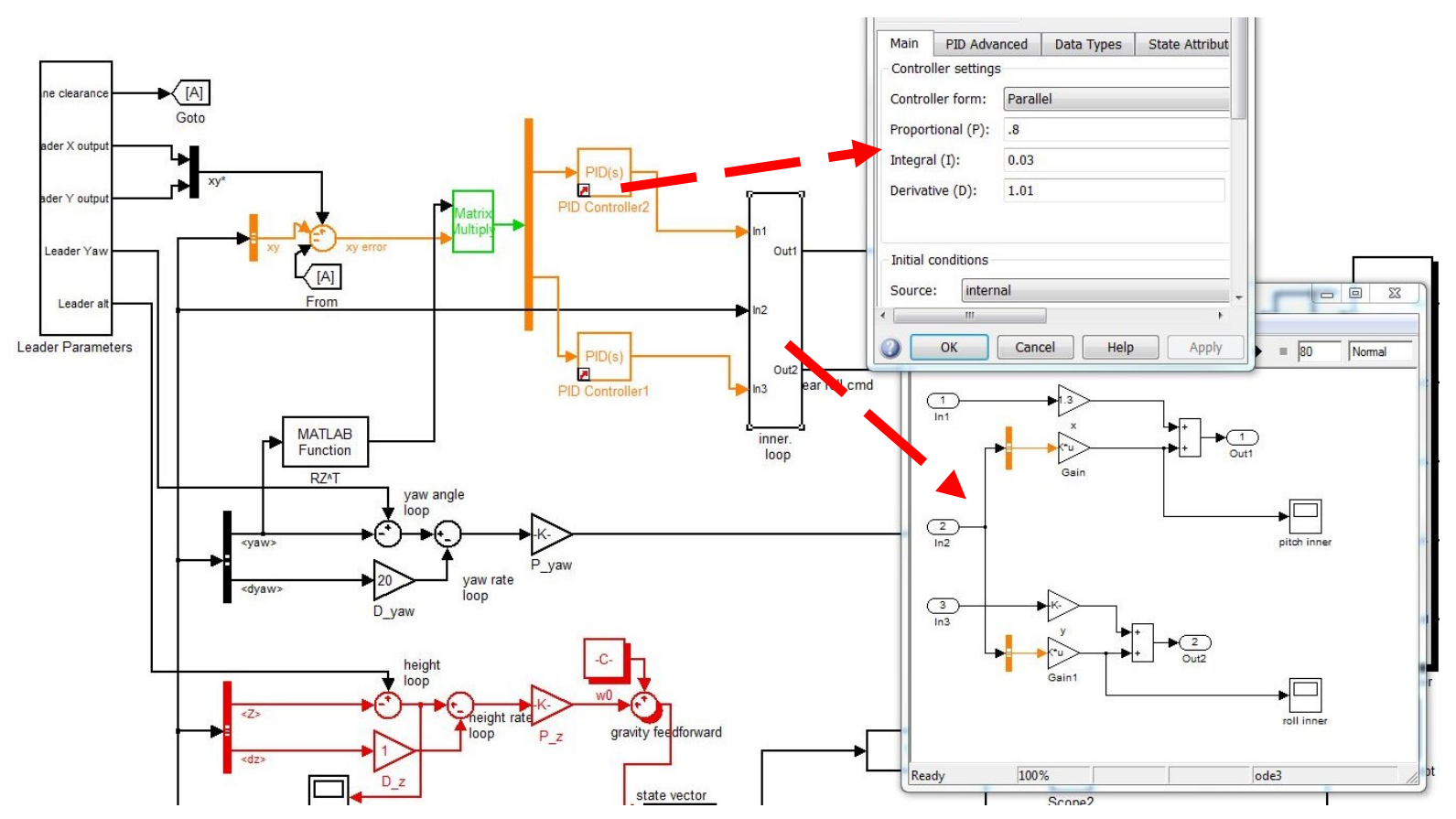

Figure 10: PID Controller Design

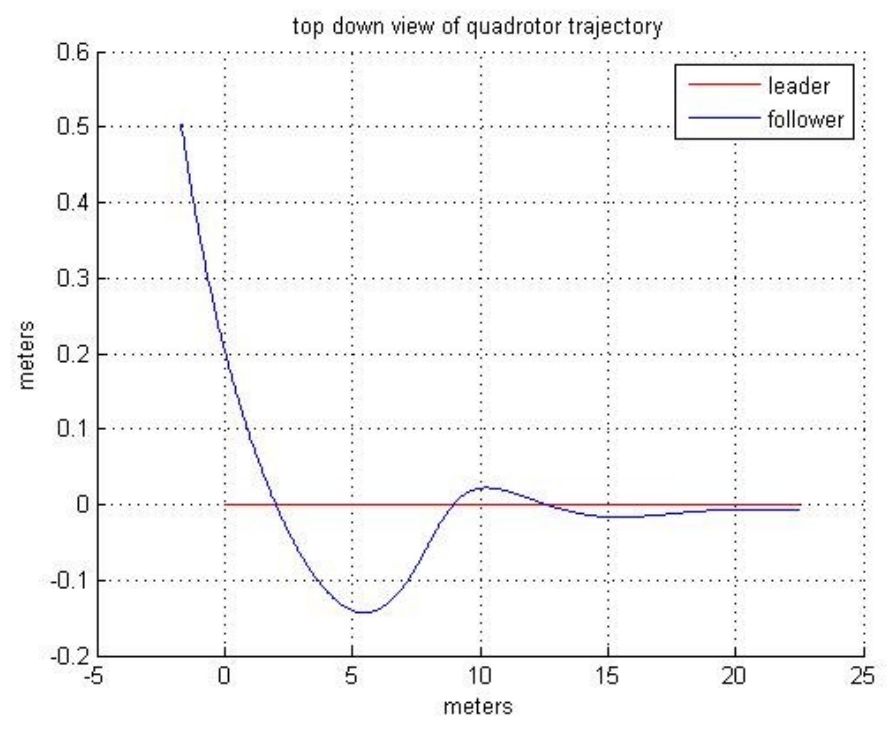

Figure 11: Trajectory of the Quadrotor Under PID Control 


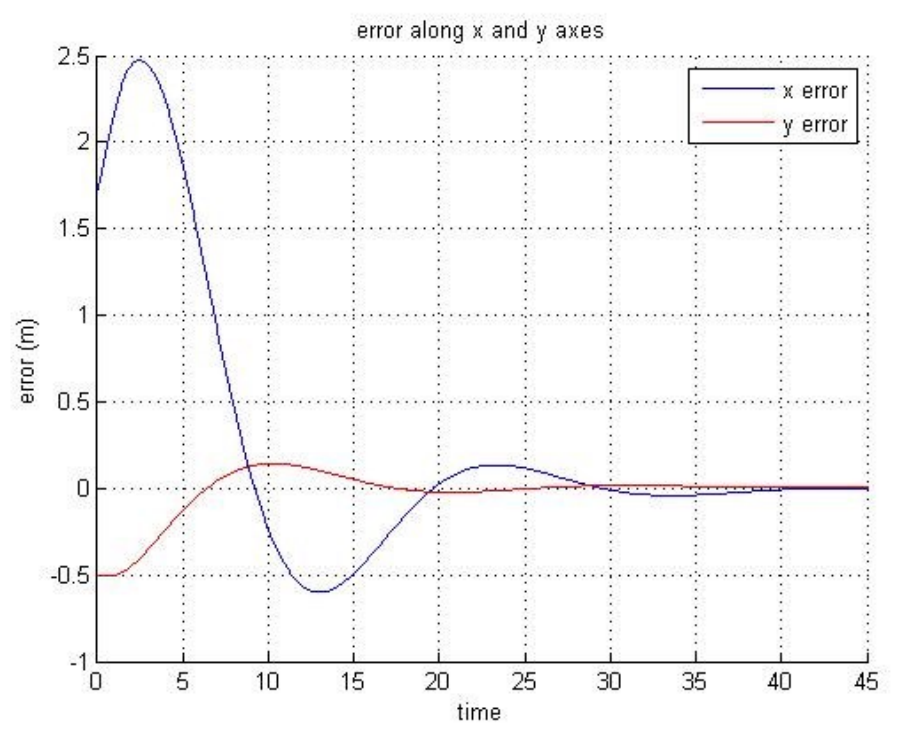

Figure 12: Position Error Using PID Controller

Figure 11 shows the trajectory of the follower as it intercepts the leader's path. Figure 12 shows the position error for the $\mathrm{x}$ and $\mathrm{y}$ coordinates. The behavior observed is acceptable for validation purposes. The overshoot is $24 \%$, settling time is 15 seconds, reaction time is 5 seconds, and the steady state error is $0.6 \mathrm{~cm}$. The error was analyzed using the validation parameters from section A of this chapter. Table 12 shows the calculated values and performance score of the simulated test.

Table 12: VTOL PID Controller Performance Analysis

\begin{tabular}{|l|l|c|}
\hline \multicolumn{3}{|c|}{ VTOL Controller Minimum Requirements } \\
\hline Index & \multicolumn{1}{|c|}{ Goal } & Actual \\
\hline NEO1. & OS $\%<50 \%$ & $24 \%$ \\
NEO2. & $\mathrm{T}_{\mathrm{S}}<10 \mathrm{~s}$ & $15 \mathrm{~s}$ \\
NEO3. & $\mathrm{T}_{\mathrm{R}}<5 \mathrm{~s}$ & $5 \mathrm{~s}$ \\
NEO4. & $\mathrm{e}_{\mathrm{ss}}<5 \mathrm{~cm}$ for stationary formation (step response) & $0 \mathrm{~cm}$ \\
NEO5. & $\mathrm{e}_{\mathrm{ss}}<25 \mathrm{~cm}$ for dynamic formation (ramp response) & $0.6 \mathrm{~cm}$ \\
\hline Score & & $39.2 \%$ \\
\hline
\end{tabular}

\section{VTOL Fuzzy Logic Simulation}

Using the 'fuzzy' command in Matlab, the fuzzy logic "Fuzzification", Interface Checks, and "Defuzzification" parameters were established and saved to '.fis' file formats. The fuzzy logic blocks were substituted into the outer loop as shown in Figure 13. The range for each of the membership 
functions of the Fuzzification and Defuzzification components is $[-1,1]$. The membership functions can be scaled using gains on the input and output signals of the fuzzy logic block. The rotation matrix is used to rotate the input position error and velocity signals into the in-plane body reference frame.

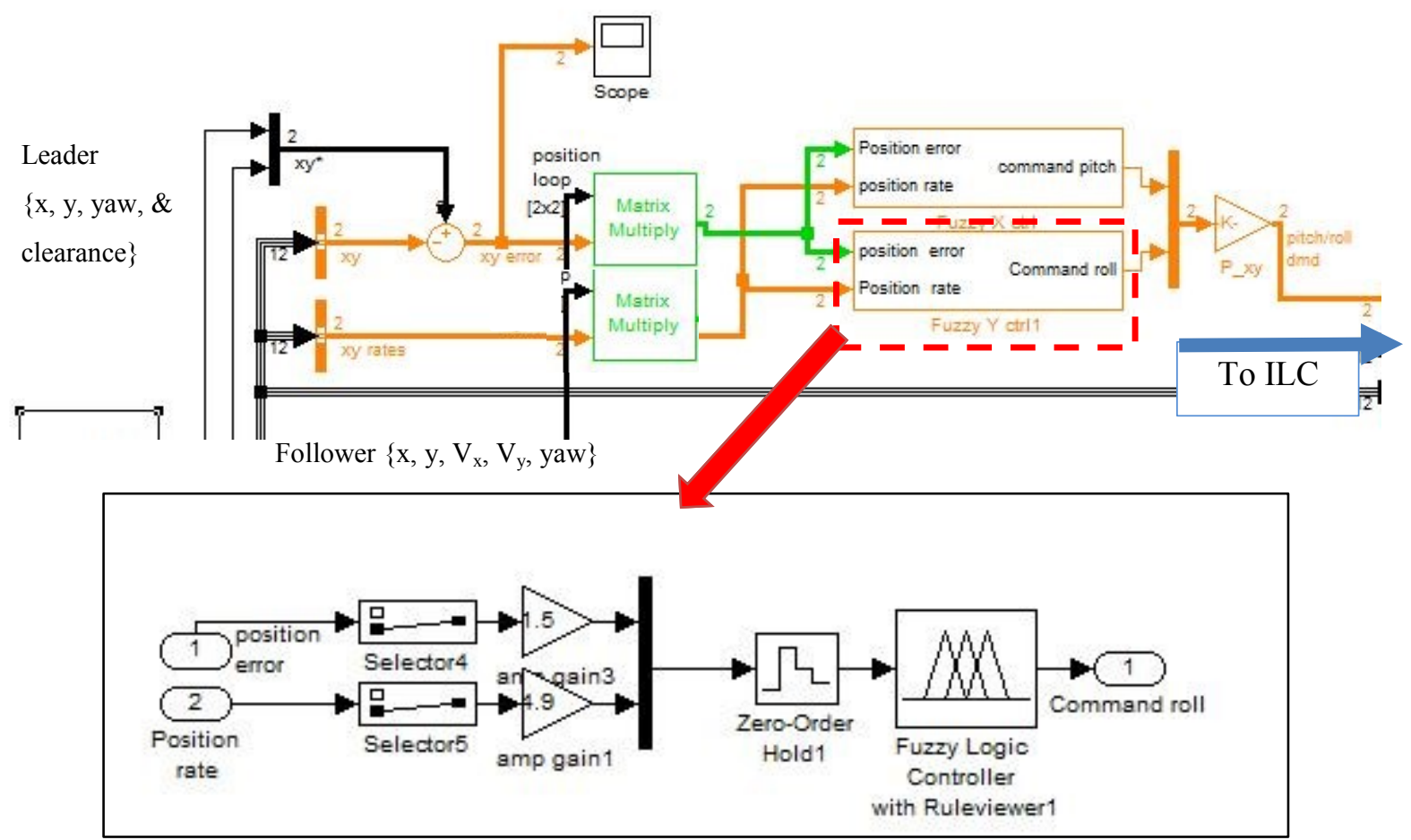

Figure 13: Fuzzy Logic OLC 


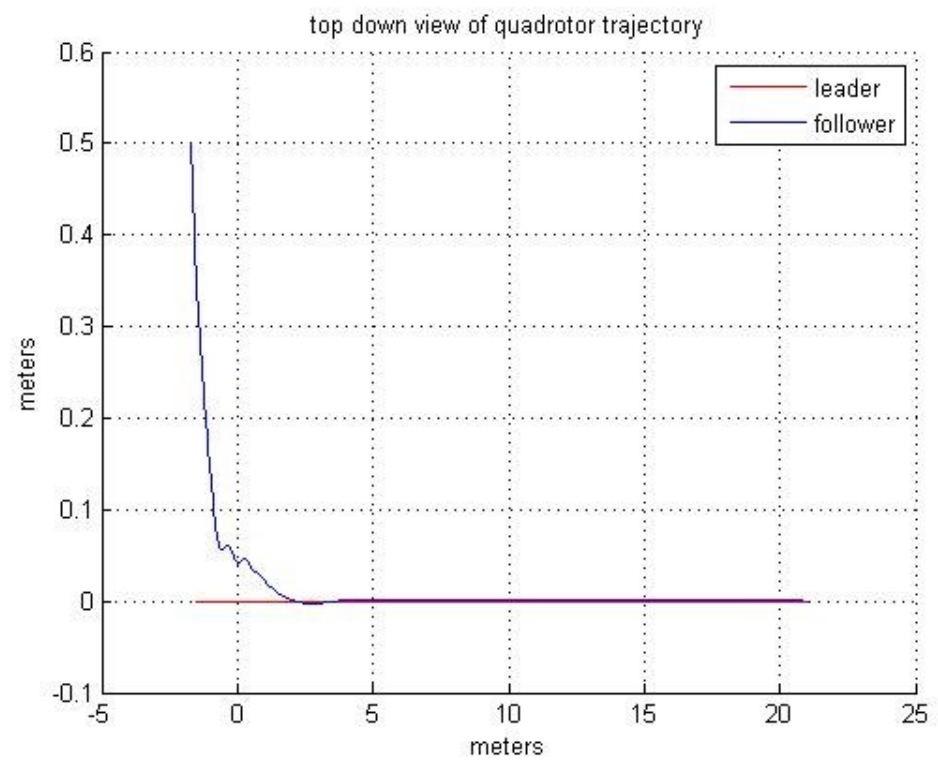

Figure 14: Trajectory of the Quadrotor Under Fuzzy Logic Control

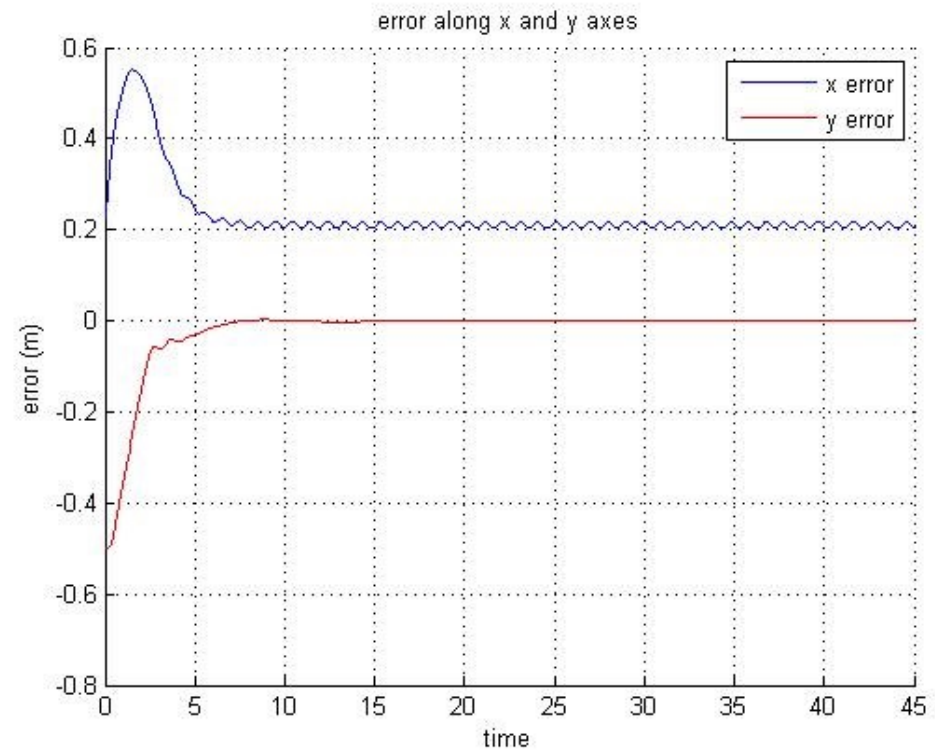

Figure 15: Position Error of the Fuzzy Logic Controller

Figure 14 shows the trajectory of the follower as it intercepts the leader's path. Figure 15 shows the position error for the $\mathrm{x}$ and $\mathrm{y}$ coordinates. The model quickly converges along the $y$ axis with a reaction time of 3 seconds and a zero steady state error. With respect to the $x$ axis, the follower is able to converge to a $22 \mathrm{~cm}$ steady state error although a very small but constant oscillation is present. Table 13 shows the calculated values and performance score of the simulated test. 
Table 13: VTOL Fuzzy Logic Controller Performance Analysis

\begin{tabular}{|l|l|c|}
\hline \multicolumn{3}{|c|}{ VTOL Controller Minimum Requirements } \\
\hline Index & \multicolumn{1}{|c|}{ Goal } & Actual \\
\hline NEO1. & $\mathrm{OS} \%<50 \%$ & $0 \%$ \\
NEO2. & $\mathrm{T}_{\mathrm{S}}<10 \mathrm{~s}$ & $4.5 \mathrm{~s}$ \\
NEO3. & $\mathrm{T}_{\mathrm{R}}<5 \mathrm{~s}$ & $1.5 \mathrm{~s}$ \\
NEO4. & $\mathrm{e}_{\mathrm{ss}}<5 \mathrm{~cm}$ for stationary formation (step response) & $0 \mathrm{~cm}$ \\
NEO5. & $\mathrm{e}_{\mathrm{ss}}<25 \mathrm{~cm}$ for dynamic formation (ramp response) & $22 \mathrm{~cm}$ \\
\hline Score & see equation 40 & $67.4 \%$ \\
\hline
\end{tabular}

\section{VTOL NLDI Simulation}

An S-function was written in Simulink in order to define the geometry and algorithms involved with the NLDI controller from section B-4. This S-function block is substituted in to be the outer loop control. Several signal modifiers are added to determine the rates required by the S-function. Figure 16 shows the NLDI OLC from the simulator.

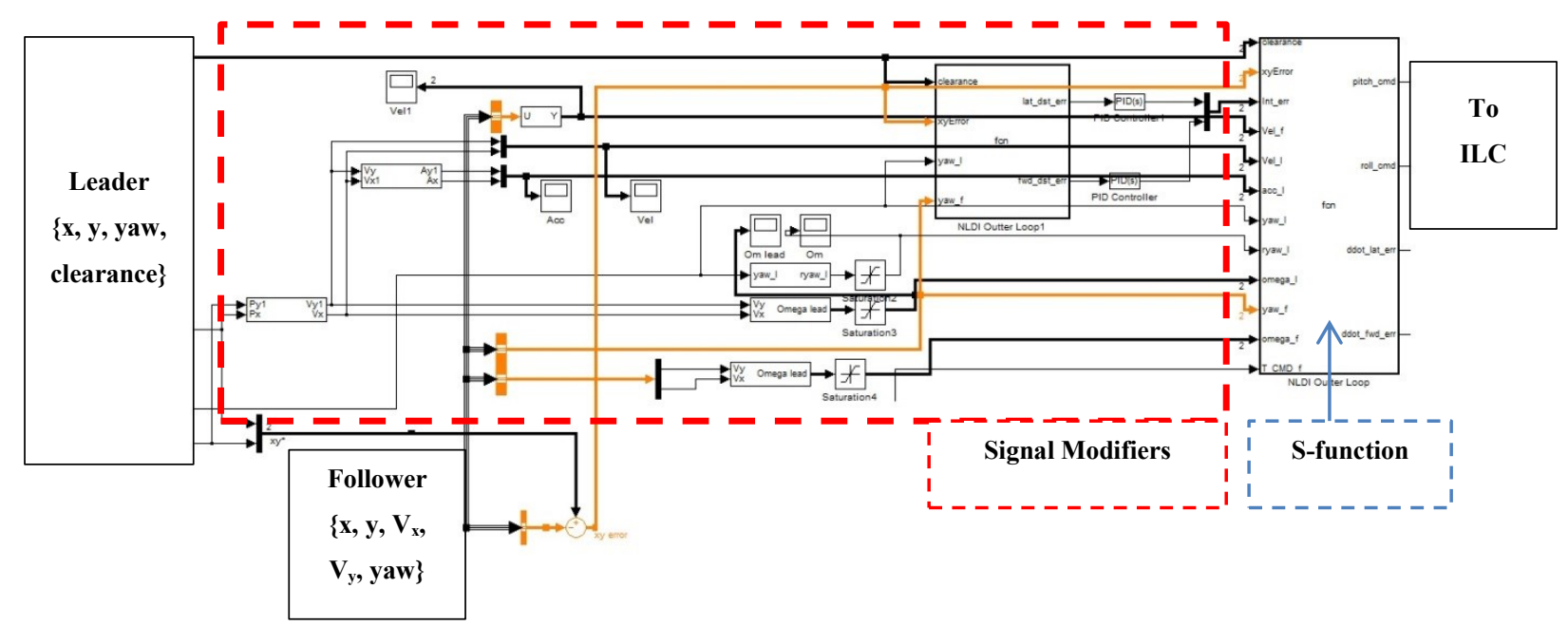

Figure 16: NLDI Simulink OLC 


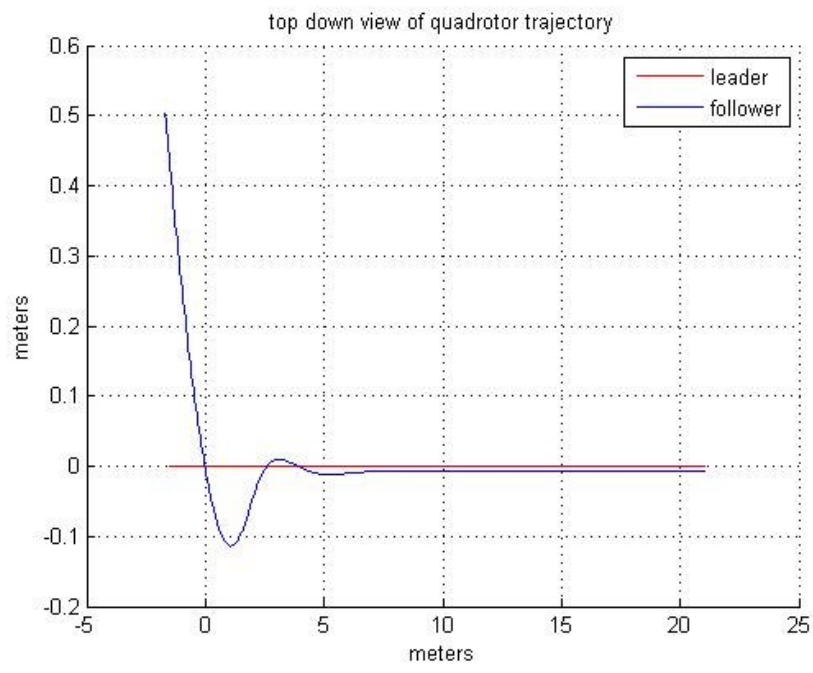

Figure 17: The Trajectory of the Quadrotor under VTOL NLDI Control

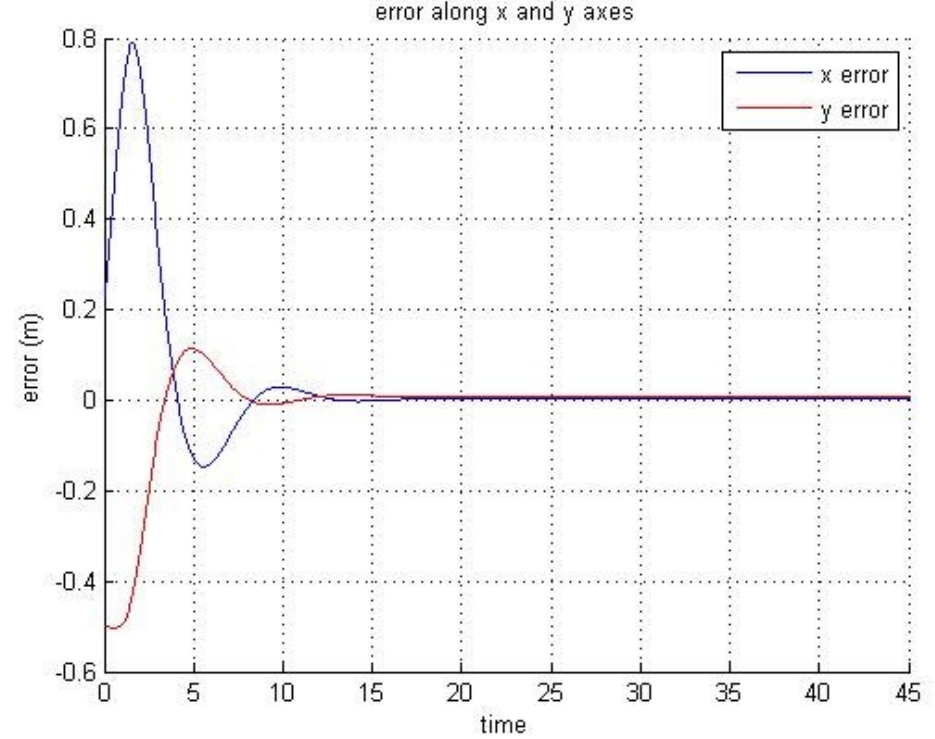

Figure 18: Position Error of the VTOL NLDI Controller

The trajectory is shown in Figure 17 and the position errors are shown in Figure 18. The overshoot is $24 \%$, settling time is 6 seconds, reaction time is 3 seconds, and the steady state error is $6 \mathrm{~mm}$. Table 14 shows the calculated values and performance score of the simulated test. 
Table 14: VTOL NLDI Controller Performance Analysis

\section{VTOL Controller Minimum Requirements}

\begin{tabular}{l|l|c}
\hline Index & \multicolumn{1}{|c|}{ Goal } & Actual \\
\hline NEO1. & OS $\%<50 \%$ & $11 \%$ \\
NEO2. & $\mathrm{T}_{\mathrm{S}}<10 \mathrm{~s}$ & $6 \mathrm{~s}$ \\
NEO3. & $\mathrm{T}_{\mathrm{R}}<5 \mathrm{~s}$ & $3 \mathrm{~s}$ \\
NEO4. & $\mathrm{e}_{\mathrm{ss}}<5 \mathrm{~cm}$ for stationary formation (step response) & $0 \mathrm{~cm}$ \\
NEO5. & $\mathrm{e}_{\mathrm{sS}}<25 \mathrm{~cm}$ for dynamic formation (ramp response) & $0.6 \mathrm{~cm}$ \\
\hline Score & see equation 40 & $75.4 \%$ \\
\hline
\end{tabular}

\section{Phastball Simulation and Validation}

\section{Phastball Simulink Model}

Previous research established a nonlinear model of the Phastball aircraft dynamics using parameter identification [74]. These parameters were used to develop a Matlab/Simulink simulation as shown in Figure 19. In this figure, leader data, indicated in blue, is fed to the control blocks of the two follower aircraft, indicated in red and green. The trajectories of each aircraft are then plotted on a 3D coordinate plane. The simulation's basic block functions are leader data inputs, control scheme, aircraft dynamics Sfunction, and the output graphics. Figure 20 shows the graphic of the leader and follower trajectories.

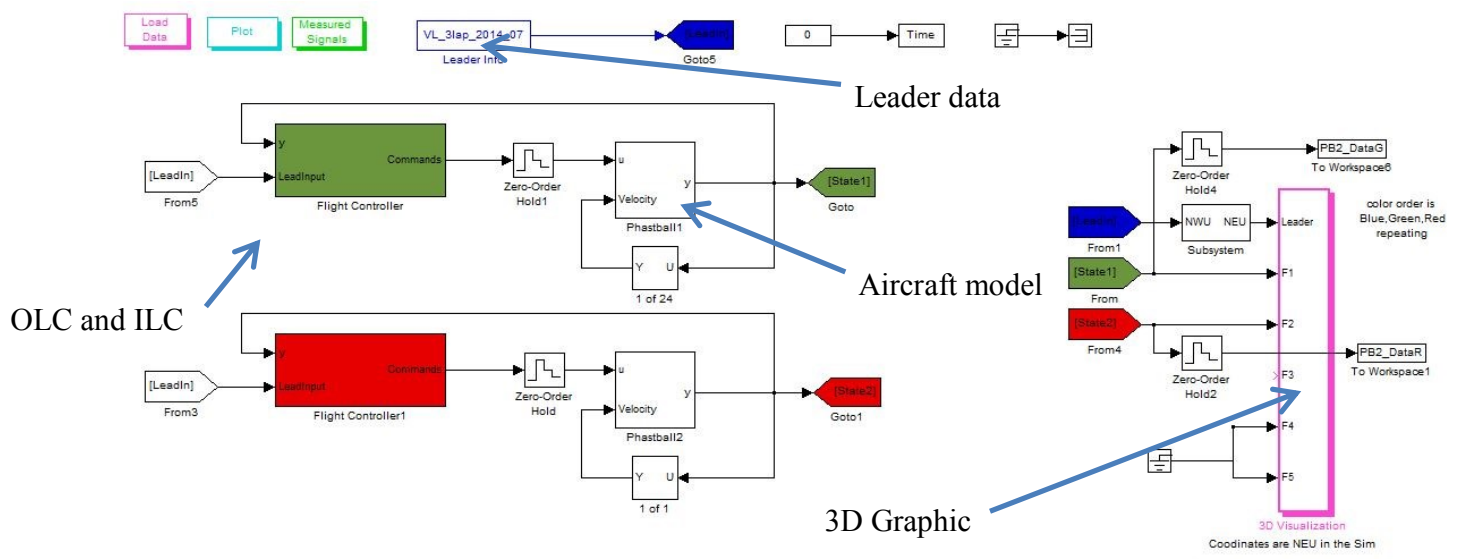

Figure 19: Phastball Simulator Block Diagram Showing Two Follower Models 


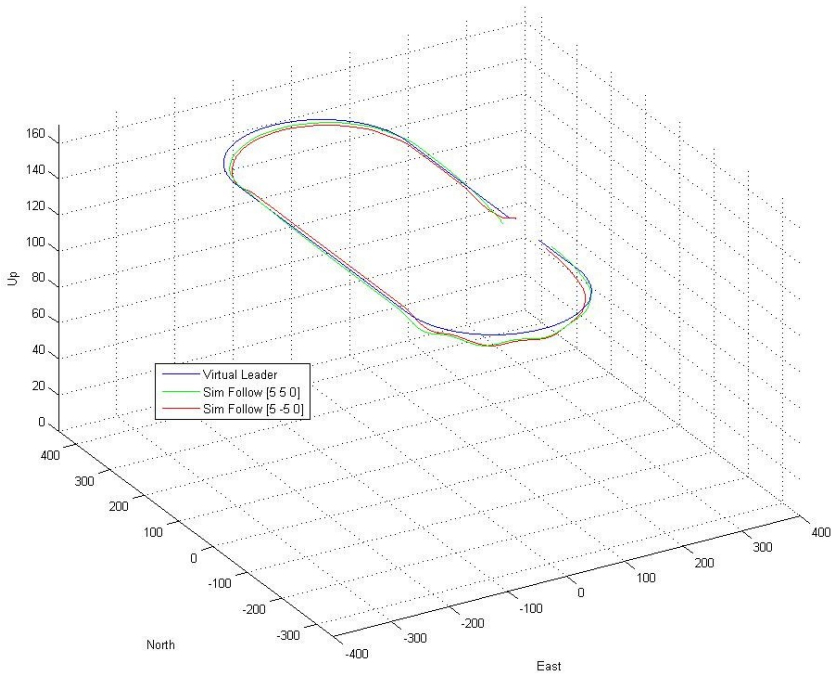

Figure 20: Isometric View of Flight Trajectories of the Virtual Leader and Two Followers

\section{Fixed-Wing NLDI Simulation}

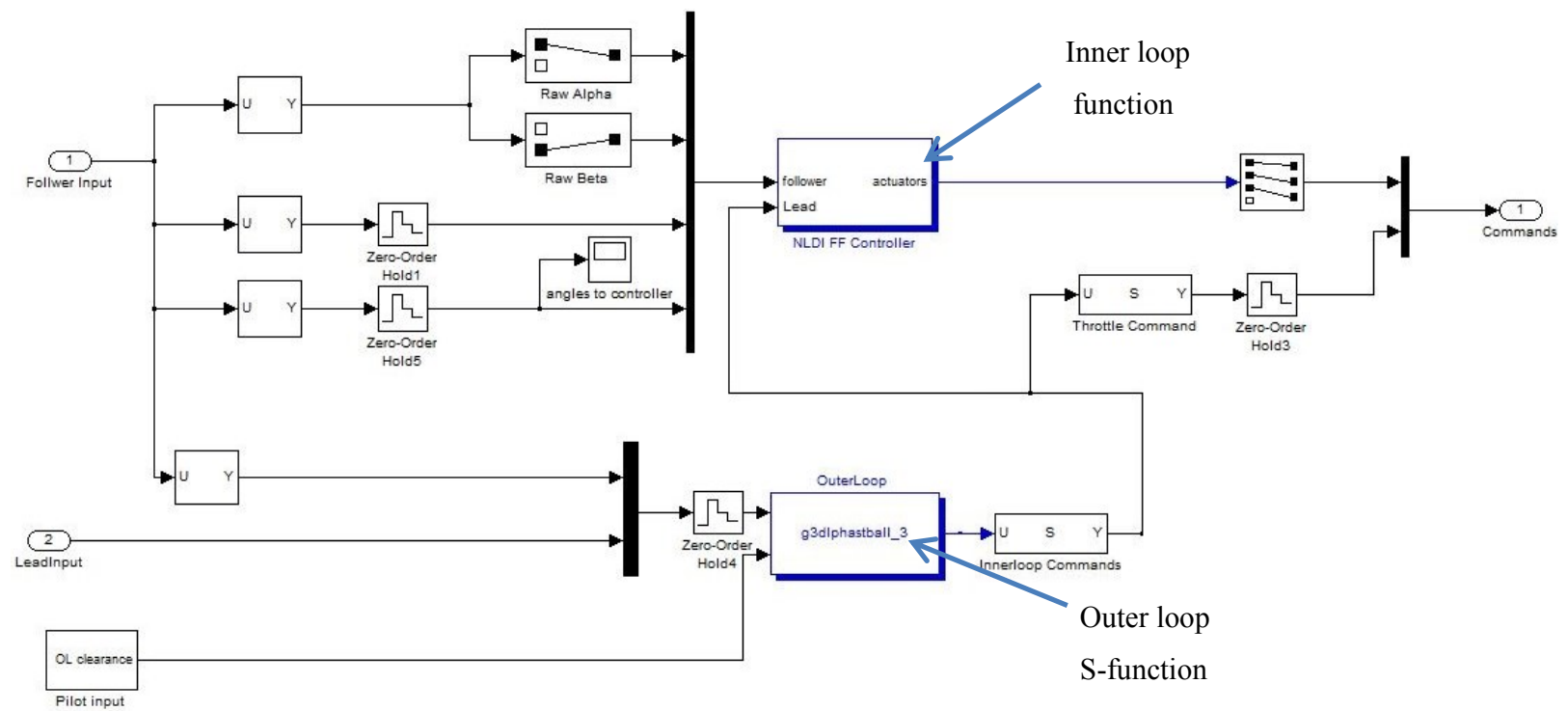

Figure 21: OLC and ILC control for Phastball

Above, Figure 21 shows the logic flow from state feedback and pilot input to OLC to ILC and then to command output. An S-function was written in Simulink in order to define the geometry and algorithms involved with the NLDI outer loop controller from section C-2. The roll and pitch commands are then input into the ILC functions from section C-1. Throttle command and ILC commands are outputted to the control surfaces and motor as explained in Chapter III. 
For the simulation the leader starts at the NWU coordinates $[0,130,136]$ and travels North at $30 \mathrm{~m} / \mathrm{s}$. The follower starts at the NWU coordinates $[-11,115,140]$. The clearance is set to $0.5 \mathrm{~m}$ behind the leader. The controller will try and match the current position of the leader plus 0.5 forward clearance. Position and error are saved for analysis of controller behavior.

Figure 22 shows the position of the Leader and the Red follower with respect to time. Figure 23 displays the error between these two values. The steady state was reached in 8 seconds. Reaction time is $1,2.5$, and 2 seconds for the vertical, lateral, and forward distances respectively. Settling time is 3.5, 6, and 4 seconds respectively. Steady state error is $-0.2 \mathrm{~m},-0.01 \mathrm{~m}$, and 0 . respectively. Tables $15-17$ show the calculated values and performance score of the simulated test.

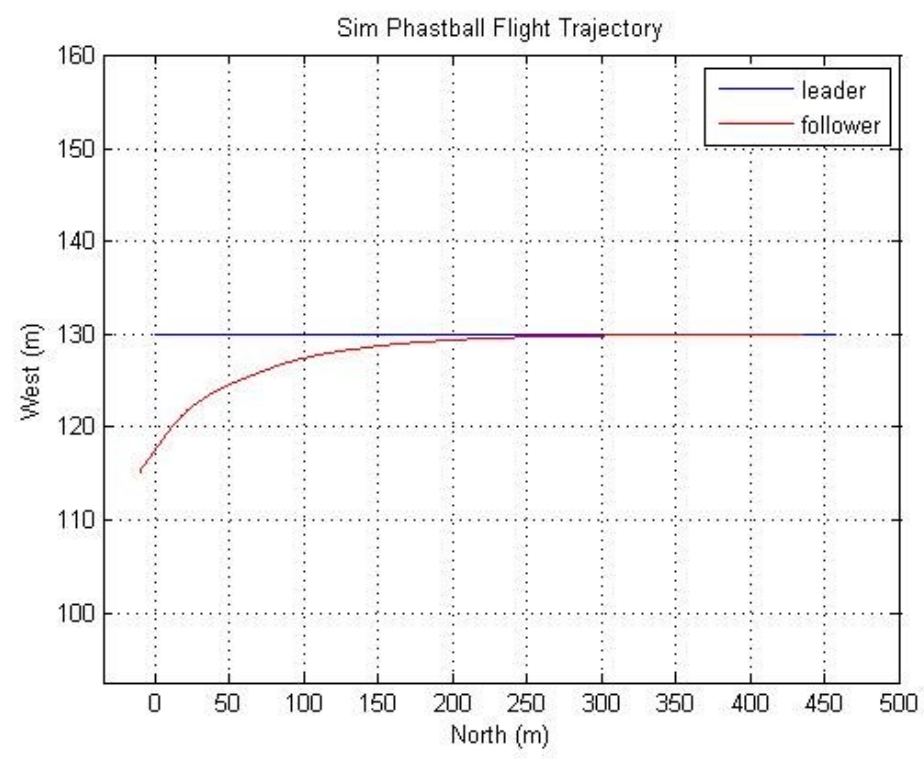

Figure 22: Phastball Leader and Follower Aircraft Trajectories 

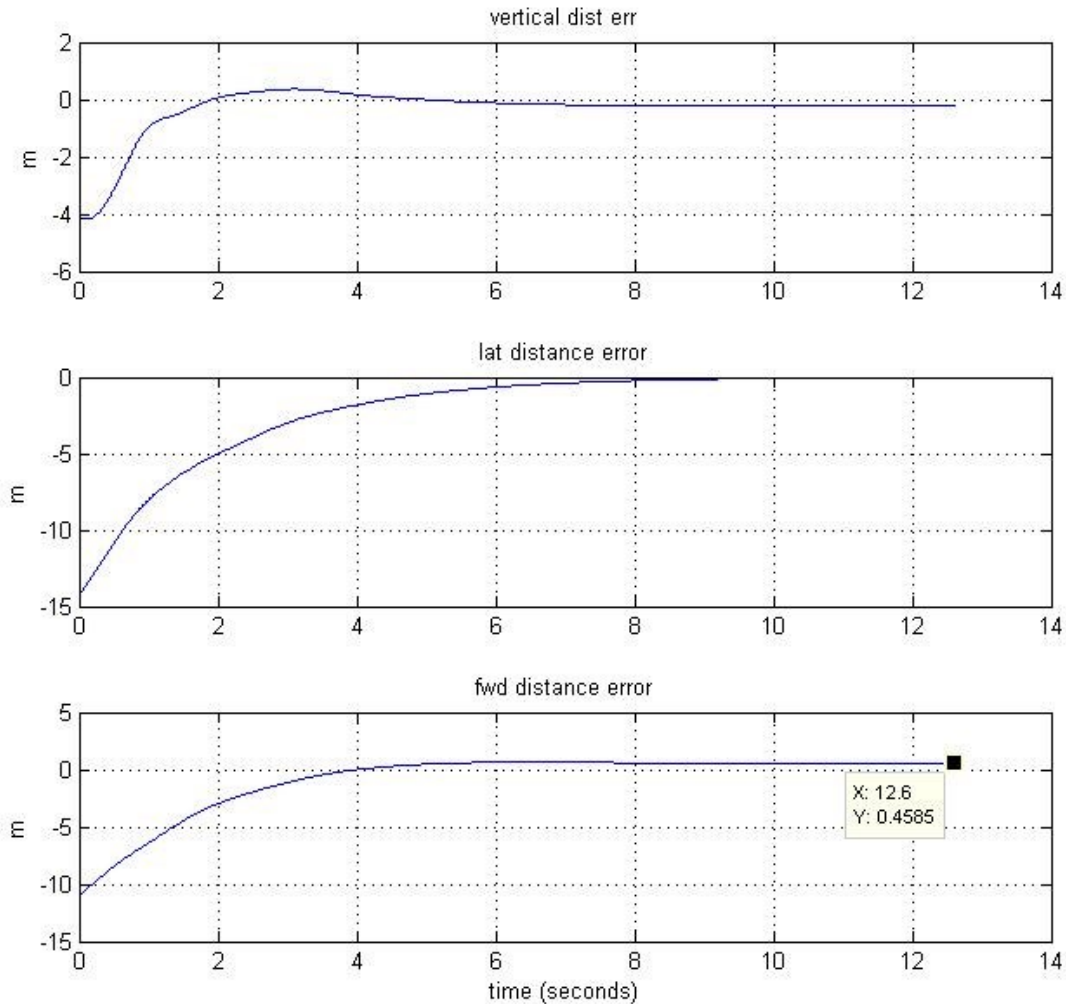

Figure 23: Error Distances in the Local Plane with Respect to the Leader Aircraft

Table 15: Fixed Wing NLDI Controller Performance of Vertical Error

\begin{tabular}{|l|l|c|}
\hline \multicolumn{3}{|c|}{ Fixed Wing Controller Goals } \\
\hline Index & \multicolumn{1}{|c|}{ Goal } & Actual \\
\hline PB1. & OS $\%<30 \%$ & $7.5 \%$ \\
PB2. & $\mathrm{T}_{\mathrm{R}}<7 \mathrm{~s}$ & $1 \mathrm{~s}$ \\
PB3. & $\mathrm{T}_{\mathrm{S}}<15 \mathrm{~s}$ & $3.5 \mathrm{~s}$ \\
PB4. & $\mathrm{e}_{\mathrm{ss}}<100 \%$ wingspan $(\sim 2.4 \mathrm{~m})$ & $-0.20 \mathrm{~m}$ \\
\hline Score & \multicolumn{2}{|c|}{ see equation 41} \\
\hline
\end{tabular}


Table 16: Fixed Wing NLDI Controller Performance of Lateral Error

\begin{tabular}{|l|l|c|}
\multicolumn{3}{|c|}{ Fixed Wing Controller Goals } \\
\hline Index & \multicolumn{1}{|c|}{ Goal } & Actual \\
\hline PB1. & OS $\%<30 \%$ & $0 \%$ \\
PB2. & $\mathrm{T}_{\mathrm{R}}<7 \mathrm{~s}$ & $2.5 \mathrm{~s}$ \\
PB3. & $\mathrm{T}_{\mathrm{S}}<15 \mathrm{~s}$ & $6 \mathrm{~s}$ \\
PB4. & $\mathrm{e}_{\mathrm{Ss}}<100 \%$ wingspan $(\sim 2.4 \mathrm{~m})$ & $0.01 \mathrm{~m}$ \\
\hline Score & see equation 41 & $83.1 \%$ \\
\hline
\end{tabular}

Table 17: Fixed Wing NLDI Controller Performance of Forward Error

\begin{tabular}{|c|c|c|}
\hline \multicolumn{3}{|c|}{ Fixed Wing Controller Goals } \\
\hline Index & Goal & Actual \\
\hline PB1. & $\mathrm{OS} \%<30 \%$ & $0 \%$ \\
\hline PB2. & $\mathrm{T}_{\mathrm{R}}<7 \mathrm{~s}$ & $2 s$ \\
\hline PB3. & $\mathrm{T}_{\mathrm{S}}<15 \mathrm{~s}$ & $4 s$ \\
\hline PB4. & $\mathrm{e}_{\mathrm{ss}}<100 \%$ wingspan $(\sim 2.4 \mathrm{~m})$ & $0.46 \mathrm{~m}$ \\
\hline Score & see equation 41 & $81.4 \%$ \\
\hline
\end{tabular}

\section{V.Description of the Test Beds and Facilities}

\section{A. The VTOL "NEO" Quad Rotor Test Bed}

The first test bed is the NEO $600 \mathrm{v} 2$, a COTS quadrotor. Table 18 displays the aircraft parameters. It has four brushless electric motors with a 30A ESC for each of them.

Table 18: Basic NEO Quadrotor Parameters

\begin{tabular}{|l|c|}
\hline Width & $60.9 \mathrm{~cm}$ \\
\hline Height & $45.7 \mathrm{~cm}$ \\
\hline Blade Length & $25.4 \mathrm{~cm}$ \\
\hline TO Weight & $1.59 \mathrm{~kg}$ \\
\hline Max Speed & $3 \mathrm{~m} / \mathrm{s}$ \\
\hline Flight Duration & $600 \mathrm{~seconds}$ \\
\hline Configuration & $\mathrm{X}$ \\
\hline
\end{tabular}


The Interactive Robotics Lab (IRL) currently has one operational NEO quadrotor. This test bed is agile enough that it can fly indoors and outdoors. Onboard, it contains a custom generation six avionics system. This Gen VI system, pictured in Figure 24, is capable of supporting both manual and autonomous flight. This avionics system features a flight computer and control signal distribution board, a laser rangefinder, ultrasonic sensors, netburner computer module, $\mathrm{R} / \mathrm{C}$ receiver, an avionics board containing an IMU module and GPS antenna connection, power sub-system, and real-time software. Through the described sensors, the state of the quadrotor can be determined. Using an EKF to process the GPS and IMU data the quadrotor's position can be determined outdoors within a 1.5 meter error. Indoors, a VICON tracking system can determine its position within one centimeter.

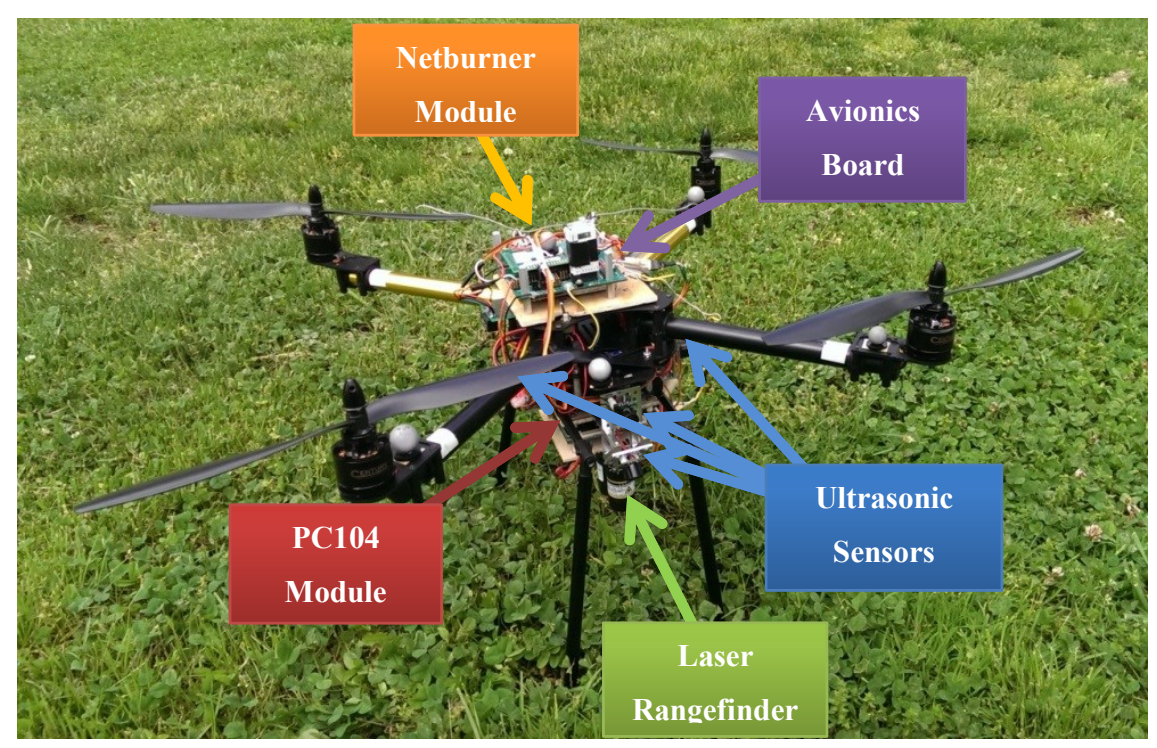

Figure 24: The NEO Quadrotor test bed displaying components of the Gen VI avionics

The Gen-VI flight computer collects and conditions the sensor data. The data can be used for autonomous flight control and pilot recording for pilot modeling. Control commands can come from its onboard computer, a transmitting PC via XBee wireless communication, or manual RC transmitted pilot commands.

\section{B. Quadrotor Flight Test facility}

Quadrotors are agile and so they can be flown indoors. The quadrotors are flown in the IRL flight test room with a VICON motion capture system mounted on the walls as shown in Figure 25. This system is made up of IR cameras that emit IR light from LED's which is reflected off of glittery markers and detected by the camera's CCD. The darkened walls absorb the IR light and reduce camera sensor noise. This system is able to detect six aircraft states, roll; pitch; yaw; $x$; $y$; and $z$, of multiple objects with-in the area of sight, which is a $3.6 \mathrm{~m} \times 3.6 \mathrm{~m} \times 1.8 \mathrm{~m}$ volume in the center of the room. 
The VICON system substitutes the position feedback that GPS typically provides outdoors. For formation flight, the state feedback from the leader and follower quadrotors is passed to a computer running a real-time Matlab/Simulink scheme which contains the outer loop control (OLC). This scheme transmits the active commands formulated from the state feedback via XBee transmitter. The quadrotor receives command signals, $\theta_{d}$ and $\phi_{d}$, from the XBee and also from the pilot's transmitter. The pilot has the ability to toggle which commands the quadrotor obeys. On-board the quadrotor, a netburner microprocessor applies the signal commands to the inner loop control (ILC) which controls the quadrotor's attitude to follow the input command signals as shown in Figure 26.

A white soccer net safely separates the operator from the flying aircraft. Other safety practices include the use of hard plastic helmets and tethers that clip on to the arms of the quadrotor.

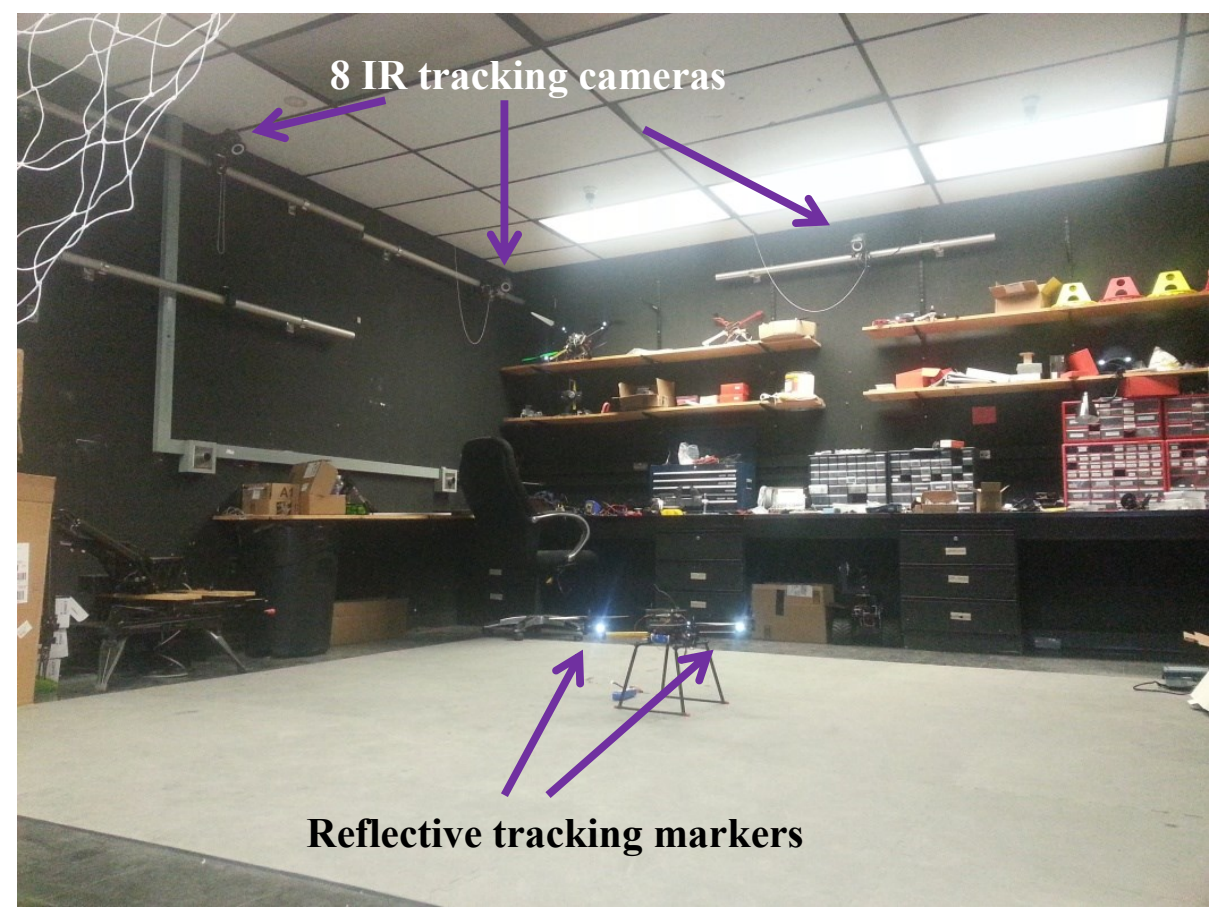

Figure 25: The Interactive Robotics Lab's flight test facility with motion tracking capability 


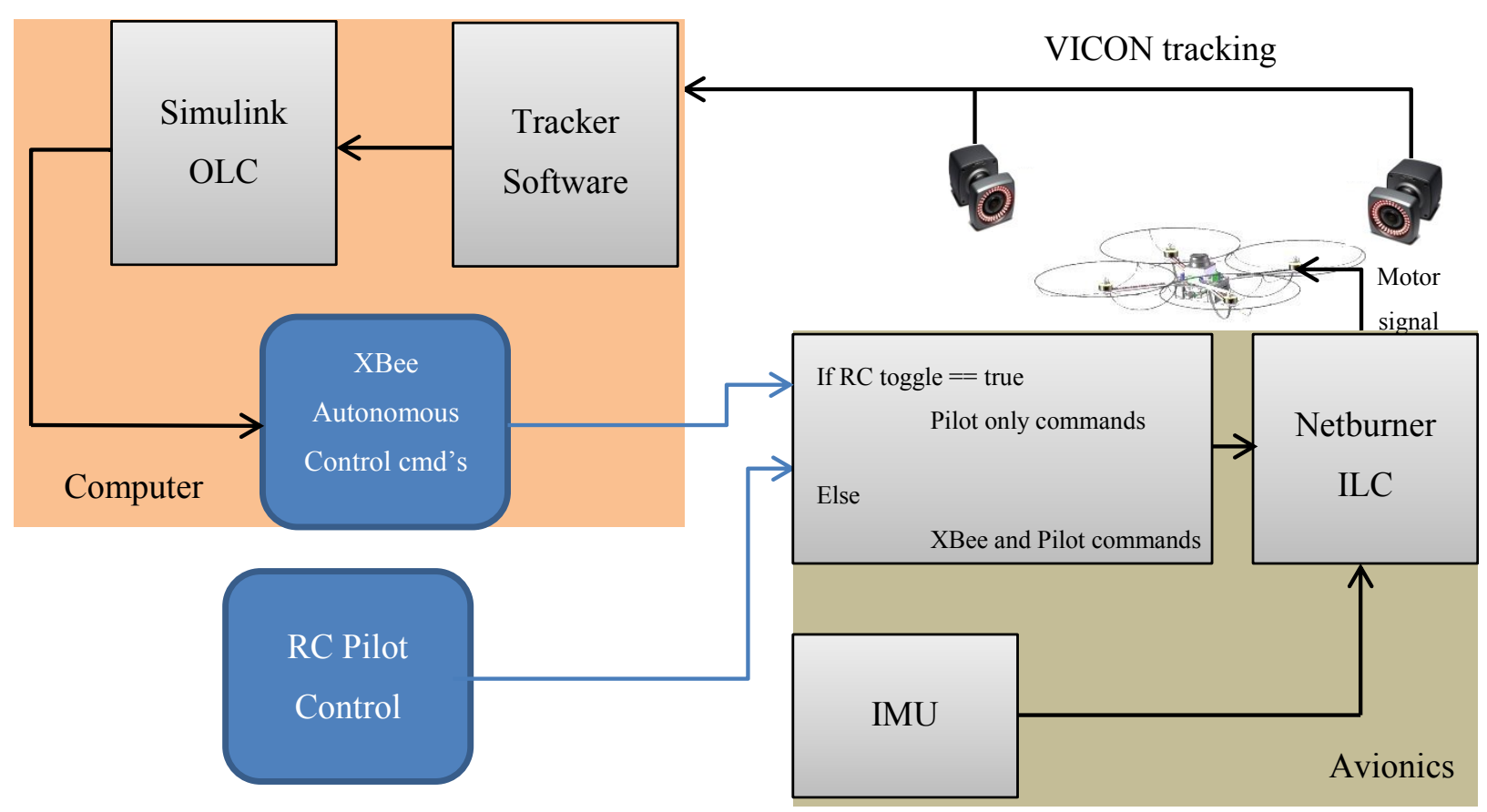

Figure 26: Schematic of Signal Communication

\section{The Fixed-wing "Phastball” Test Bed}

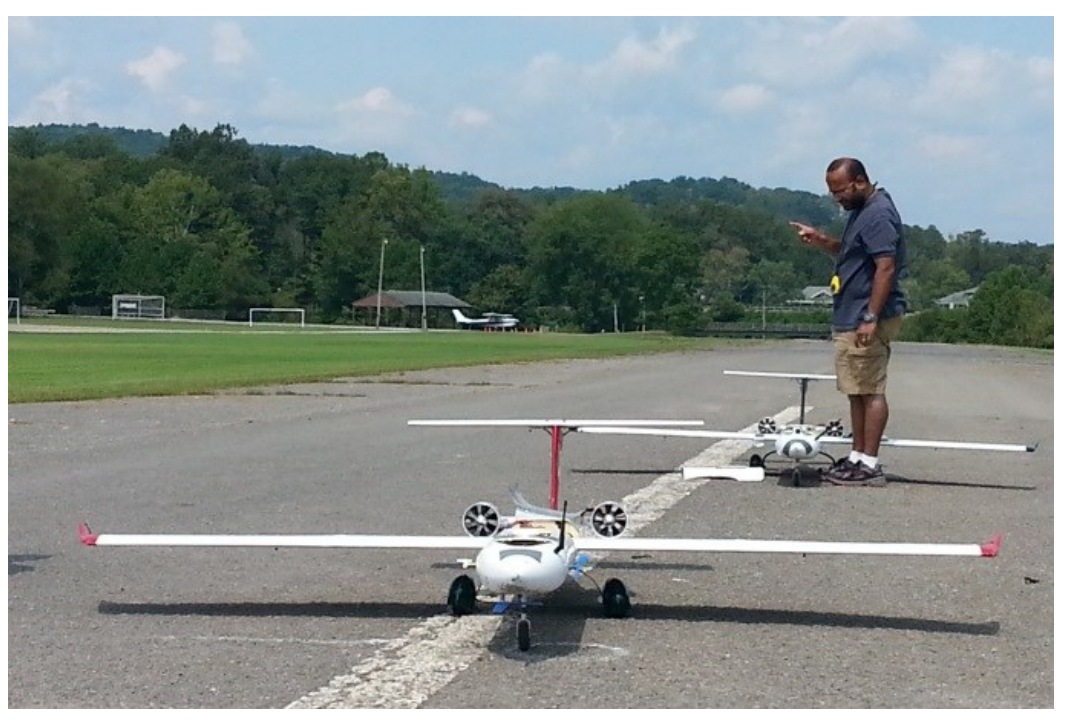

Figure 27: The 'Phastball' Fixed Wing Test Bed

The first test bed is a hand built fixed wing RC aircraft. This aircraft has a $2.4 \mathrm{~m}$ wingspan and can carry a MTOW of $11.4 \mathrm{~kg}$ (25 pounds). Table 19 displays the typical aircraft parameters. It has two brushless electric ducted fans mounted just behind the wings and before the $\mathrm{T}$ tail. 


\begin{tabular}{|l|l|}
\hline Wingspan & $2.4 \mathrm{~m}$ \\
\hline Length & $2.2 \mathrm{~m}$ \\
\hline Height & $0.55 \mathrm{~m}$ \\
\hline TO Weight & $10.5 \mathrm{~kg}$ \\
\hline Cruise Speed & $32 \mathrm{~m} / \mathrm{s}$ \\
\hline Max Flight Duration & $480 \mathrm{~seconds}$ \\
\hline
\end{tabular}

There are currently three flight worthy Phastballs in the fleet, Red, which has an earlier generation avionics suite and is capable of manual flight; Green, which has a current $5^{\text {th }}$ generation avionics system [75] and is capable of manual and autonomous flight; and Blue which is still undergoing testing for a new sixth generation avionics suite which will make it capable of manual and autonomous flight as well. The Green Phastball's Gen-V system features a flight computer, control signal distribution board, a nose sensor suite, R/C sub-system, IMU communication sub-system, power sub-system, and real-time software. The electrical boards, excluding the Netburner module, were all designed in house. An onboard GO-PRO ${ }^{\circledR}$ camera records flight video. Figure 28 displays Green Phastball's avionics and components.

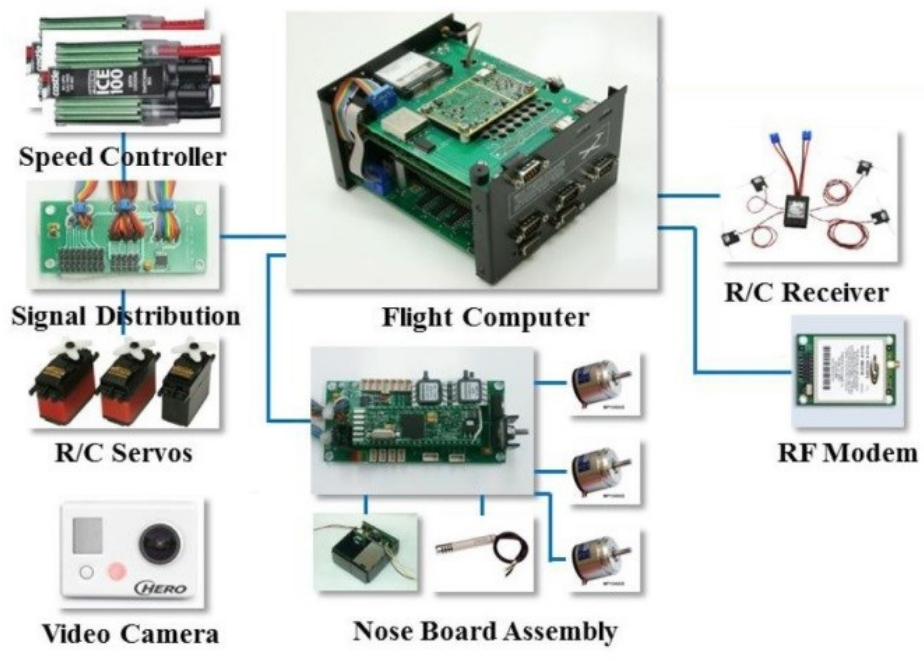

Figure 28: The Gen-V Avionics System [32]

The Gen-V flight computer collects and conditions the sensor data. With the received data it can transmit and use it for autonomous flight control and failure accommodation functions [75]. It integrates and distributes control command from five different sources: a ground research pilot, a ground R/C safety pilot, an on-board failure emulation system, an aircraft on-board flight control system, and an On-Board Excitation System (OBES). Hardware redundancies reinforce safety of the aircraft. 


\section{B. Phastball Flight Test Facility}

Due to their size, the Phastball's require a rather large flat area for experimental flight tests. Jackson Mill at Jane Lew, WV provides a large enough area and a 3/4 mile long landing strip for take-off and landing. A satellite image of the field is pictured below.

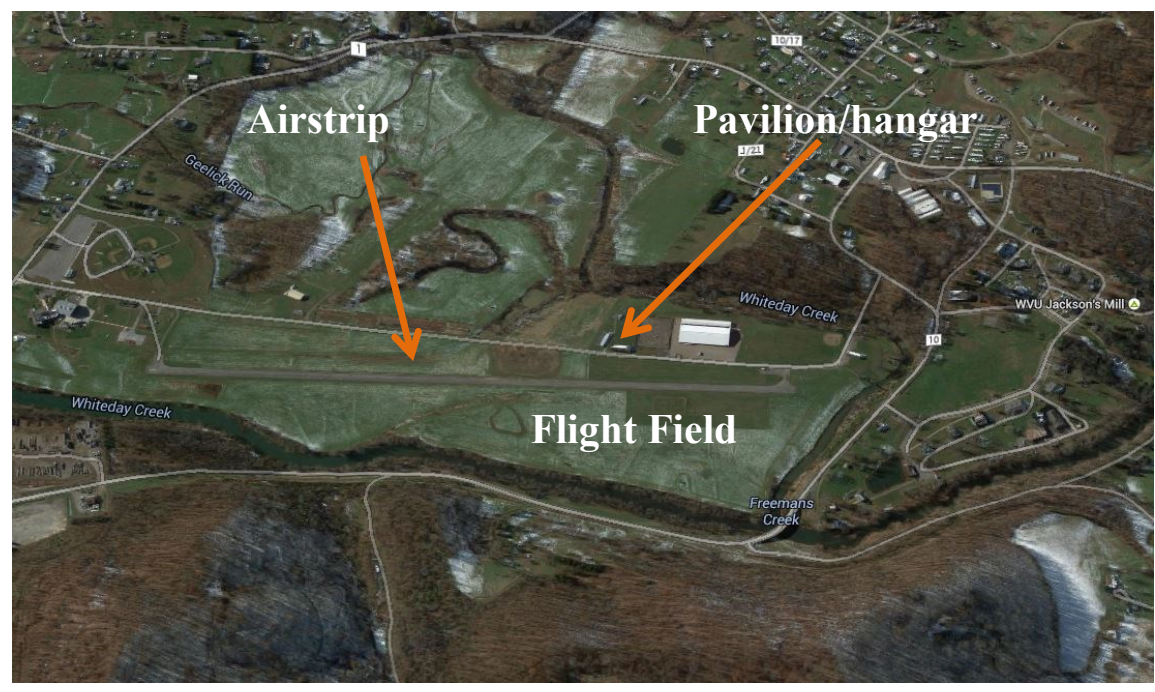

Figure 29: Jackson's Mill Airstrip From Google Maps ${ }^{\circledR}$

\section{Flight Results}

\section{A. Quadrotor Formation Flight Data Analysis}

The leader is remotely controlled by an RC pilot during takeoff. Once airborne, the pilot switches over to autonomous control and the quadrotor obeys the signal commands sent from the computer which computes the flight control scheme whether it's the PID, Fuzzy Logic, or NLDI controller. The program is designed to maintain predetermined formation geometry parameters.

Flight testing was not completed at the time of final report submission.

\section{B. Phastball Formation Flight Data Analysis}

Fixed wing autonomous formation flight testing was conducted two different ways, one-aircraft formation flight and two-aircraft formation flight. Flight testing requires one pilot for one-aircraft formation flights and two pilots for two-aircraft formation flight, one for each plane. A virtual leader is used for one-aircraft formation flight. A virtual leader is a set of data that substitutes as the received leader input for the designed controller. The virtual leader is an array of position and velocity values that simulate an aircraft's trajectory along an oval track. In actual flight testing, the virtual leader is used for 
preliminary testing especially when clearances are less than one meter. It is programmed into the onboard computer and activated when the pilot switches from manual to autonomous flight control.

For two-aircraft formation, each pilot takes-off manually in succession. Once airborne, the pilot of the follower rendezvous behind the leader aircraft at a safe distance and then activates the autonomous formation flight controller program. The follower aircraft then autonomously carries out the commands based on the control laws of the NLDI controller.

The follower aircraft receives leader aircraft data during the flight which is its 3-axis position and velocity information through a pair of $900 \mathrm{Mhz}$ Freewave RF modems. Initial flight testing used onboard data that simulated leader data to safely confirm desirable control performance. The signal is passed to the computer board which uses the flight software to determine the commands to send to the servo motors.

Figure 30 displays a top down look at the leader and follower Phastball trajectories for one lap traveling counter clockwise around the Jackson's Mill flight field. To date, three two-aircraft formation flights and 13 two-aircraft close formation flights (with a separation at around 5 wingspans) were performed with the Phastball aircraft. Figure 31 is a snapshot of the aircraft preforming close formation flight.

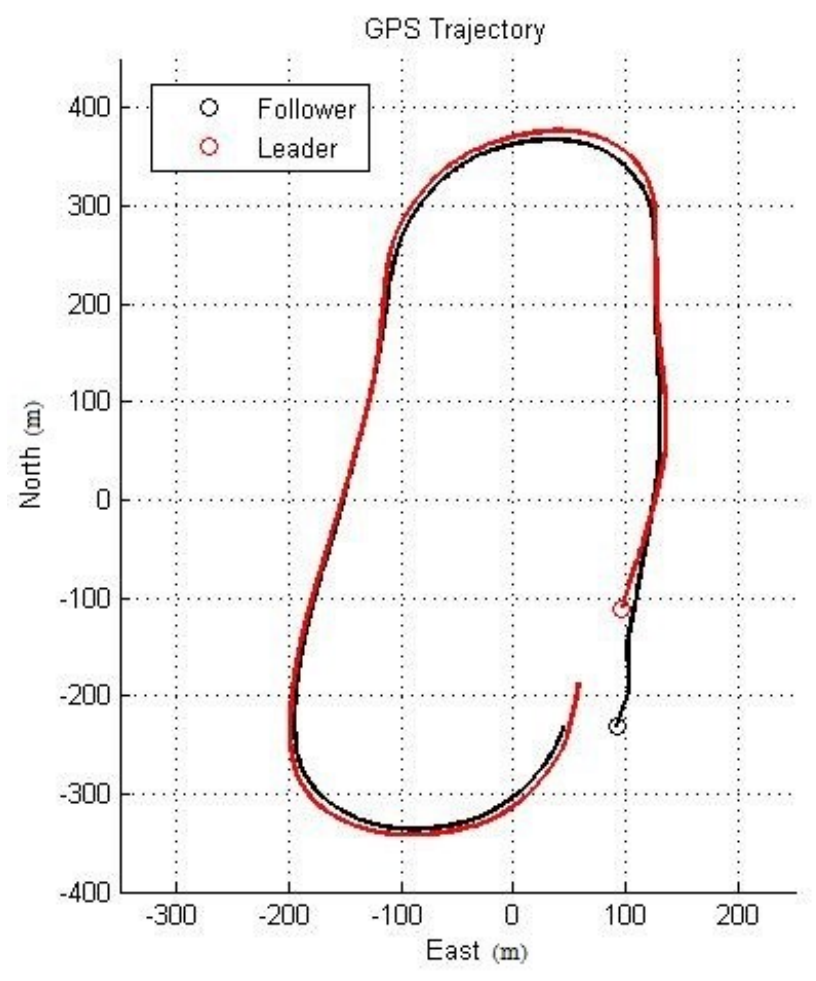

Figure 30: Oval Flight Path of a Single Lap in Formation. 


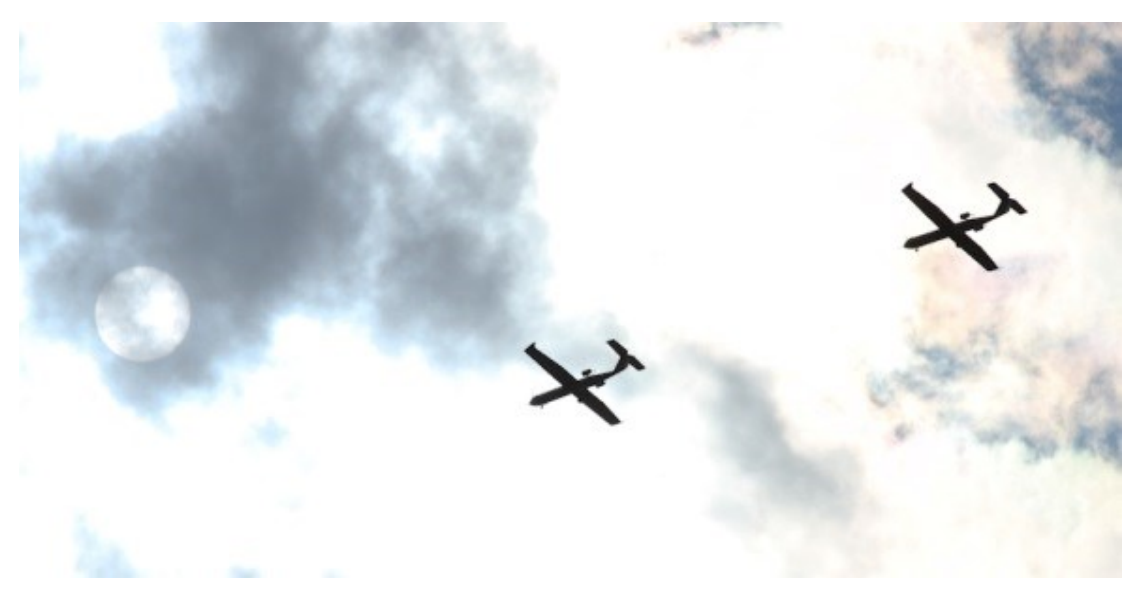

Figure 31: Aircraft Demonstrating Close Formation Flight

Fifteen flights were conducted for analysis. Flights 1, 2, and 3 are not considered close formation flights, for their forward clearance was $50 \mathrm{~m}, 40 \mathrm{~m}$, and $30 \mathrm{~m}$ respectively. Flights 4, 6, and 9 were conducted with variable formation geometry to evaluate transient behaviors. Figure 32 illustrates what the errors look like over the course of a single lap.
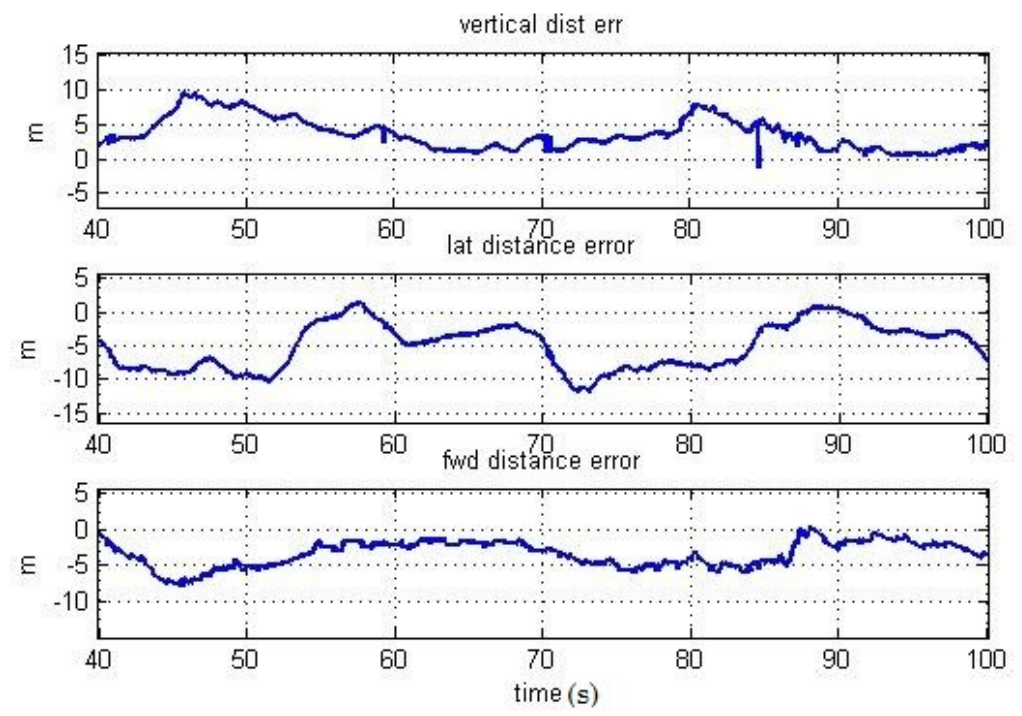

Figure 32: Formation Flight Errors of a Single Lap

Figure 33 shows the transient response for the forward distance error. The error is characterized for all the dimensions in Table 20. In Figure 33, the forward clearance decreased from $24 \mathrm{~m}$ to $12 \mathrm{~m}$ in 20 seconds after the pilot command, red line, added $22 \mathrm{~m}$ of offset. 


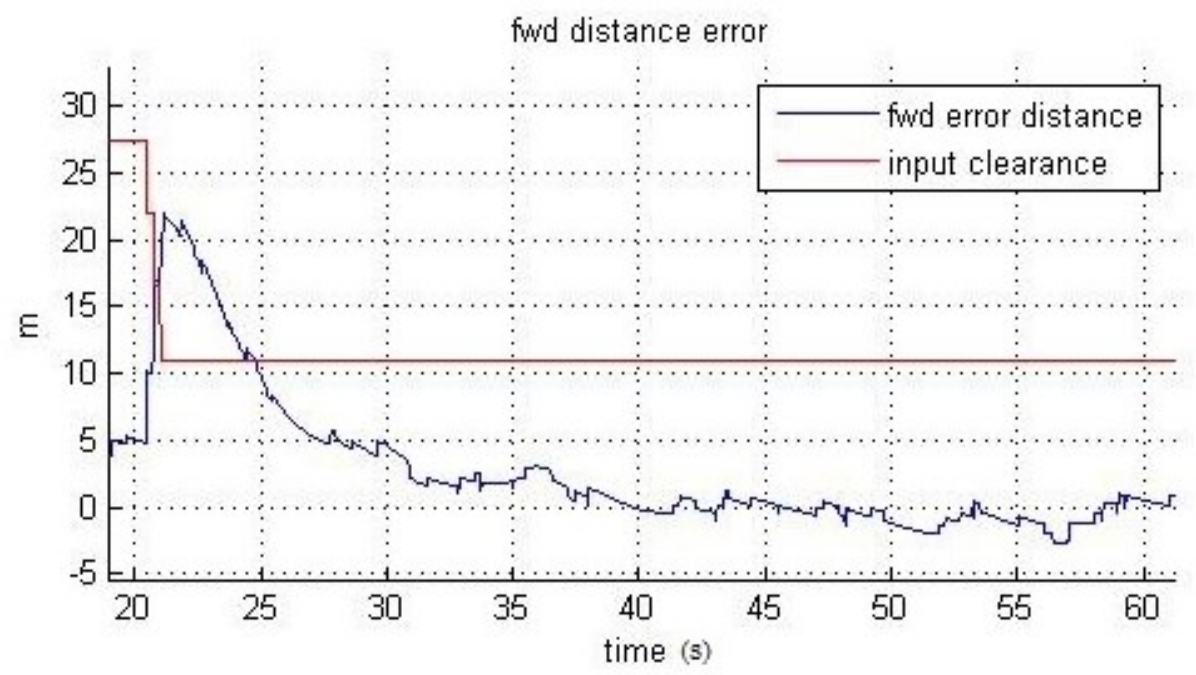

Figure 33: The Transient Response of the Forward Distance Error

The steady state error analyses are recorded for the straight-a-ways and the bank turns in Table 21 and Table 22 respectively. Straight-a-way performance is more accurate than bank turn performance. This is due to the assumptions made for the feedback linearization. When the aircraft makes a banked turn, this deviates from the assumed steady level flight conditions and the controller does not account for the change in flight condition.

The average forward error is -0.82 meters meaning the controller is maintaining a closer than desired formation geometry. The average vertical error distance of 1.34 meters means the follower is tracking lower than desired.

The average magnitude of mean distance error in the straight-a-ways of Table 21 is 1.33 meters with a standard deviation of 0.88 meters. However, this does not take into consideration the additional $1.5 \mathrm{~m}$ RMS error from the GPS.

In the bank turns, the average magnitude of mean distance error from Table 22 is 7.54 meters with a standard deviation of 1.68 meters. Table 23 displays the proximity (physical distance between GPS sensors) between the leader and follower to give a better depiction of the formation flight geometry. 
Table 20: Transient Behavior from the Initiation of Formation Flight

\begin{tabular}{|c|c|c|c|c|c|c|c|}
\hline \multicolumn{2}{|c|}{$\begin{array}{l}\text { Transient } \\
\text { Behavior }\end{array}$} & $\begin{array}{c}\text { Init. Err. } \\
\text { Distance (m) }\end{array}$ & $\mathrm{T}$ react $(\mathrm{s})$ & $\mathrm{T}$ peak $(\mathrm{s})$ & $\mathrm{T}$ rise $(\mathrm{s})$ & $\mathrm{T}$ settling (s) & OS\% \\
\hline \multirow{3}{*}{$\begin{array}{l}\text { Flight } \\
5\end{array}$} & Vrt & 10.00 & 6.00 & 7.96 & 5.06 & 7.44 & $2.48 \%$ \\
\hline & Lat & -6.54 & 5.38 & $\mathrm{n} / \mathrm{a}$ & 3.41 & 4.05 & $\mathrm{n} / \mathrm{a}$ \\
\hline & Fwd & 5.43 & 0.73 & 3.36 & 0.93 & 1.10 & $40.19 \%$ \\
\hline \multirow{3}{*}{$\begin{array}{l}\text { Flight } \\
7\end{array}$} & Vrt & 0.70 & 0.30 & $\mathrm{n} / \mathrm{a}$ & 1.44 & 1.67 & $\mathrm{n} / \mathrm{a}$ \\
\hline & Lat & -- & -- & -- & -- & -- & -- \\
\hline & Fwd & 12.22 & 6.17 & $\mathrm{n} / \mathrm{a}$ & 7.76 & 9.16 & $\mathrm{n} / \mathrm{a}$ \\
\hline \multirow{3}{*}{$\begin{array}{l}\text { Flight } \\
8\end{array}$} & Vrt & 10.05 & 2.10 & $\mathrm{n} / \mathrm{a}$ & 3.22 & 3.80 & $\mathrm{n} / \mathrm{a}$ \\
\hline & Lat & 5.15 & 7.02 & 11.12 & 18.20 & 18.43 & $236.23 \%$ \\
\hline & Fwd & 7.26 & 21.76 & $\mathrm{n} / \mathrm{a}$ & 27.37 & 32.30 & $\mathrm{n} / \mathrm{a}$ \\
\hline \multirow{3}{*}{$\begin{array}{l}\text { Flight } \\
10\end{array}$} & Vrt & 0.53 & 1.38 & 1.72 & 0.97 & 2.95 & $228.30 \%$ \\
\hline & Lat & 8.88 & 4.10 & $\mathrm{n} / \mathrm{a}$ & 5.67 & 6.69 & $\mathrm{n} / \mathrm{a}$ \\
\hline & Fwd & 20.54 & 32.44 & $\mathrm{n} / \mathrm{a}$ & 29.83 & 35.21 & $\mathrm{n} / \mathrm{a}$ \\
\hline \multirow{3}{*}{$\begin{array}{l}\text { Flight } \\
11\end{array}$} & Vrt & 3.99 & 3.50 & 5.28 & 5.10 & 6.79 & $29.02 \%$ \\
\hline & Lat & 14.53 & 3.60 & $\mathrm{n} / \mathrm{a}$ & 4.65 & 4.92 & $\mathrm{n} / \mathrm{a}$ \\
\hline & Fwd & 130.00 & 22.50 & 18.94 & 22.52 & 26.58 & $14.62 \%$ \\
\hline \multirow{3}{*}{$\begin{array}{l}\text { Flight } \\
12\end{array}$} & Vrt & -- & -- & -- & -- & -- & -- \\
\hline & Lat & 77.58 & 4.07 & 6.78 & 6.48 & 13.30 & $18.16 \%$ \\
\hline & Fwd & 16.72 & 13.54 & $\mathrm{n} / \mathrm{a}$ & 12.72 & 15.01 & $\mathrm{n} / \mathrm{a}$ \\
\hline \multirow{3}{*}{$\begin{array}{l}\text { Flight } \\
13\end{array}$} & Vrt & 10.10 & 2.32 & 4.20 & 4.03 & 11.40 & $37.54 \%$ \\
\hline & Lat & 23.18 & 8.50 & 11.10 & 9.16 & 10.81 & $0.00 \%$ \\
\hline & Fwd & 16.27 & 9.24 & $\mathrm{n} / \mathrm{a}$ & 11.90 & 12.30 & $\mathrm{n} / \mathrm{a}$ \\
\hline
\end{tabular}

*Some Flights omitted due to inconclusive results 
Table 21: Performance of the Phastball 2-Aircraft Formation Flight During the Straight Legs

\begin{tabular}{|c|c|c|c|c|c|c|c|}
\hline \multicolumn{2}{|c|}{ FF Straight legs } & Clearance & $\begin{array}{l}\text { Max Err. } \\
\text { Distance }\end{array}$ & $\begin{array}{c}\text { Mean Abs. Err. } \\
\text { Distance }\end{array}$ & $\begin{array}{l}\text { Mean Err. } \\
\text { Distance }\end{array}$ & Std. Dev. & $\begin{array}{l}\text { avg. \% wing } \\
\text { span }\end{array}$ \\
\hline \multirow{3}{*}{ Flight 1} & Forward $(\mathrm{m})$ & 50 & -6.112 & 2.623 & -2.356 & 1.896 & $98 \%$ \\
\hline & Lateral $(\mathrm{m})$ & 0 & -5.615 & 2.011 & -1.628 & 1.985 & $68 \%$ \\
\hline & Vertical (m) & 0 & 4.778 & 2.617 & 2.617 & 0.993 & $109 \%$ \\
\hline \multirow{3}{*}{ Flight 2} & Forward $(\mathrm{m})$ & 40 & -3.700 & 2.144 & -2.144 & 0.539 & $89 \%$ \\
\hline & Lateral $(\mathrm{m})$ & 0 & -8.447 & 2.803 & -2.640 & 1.890 & $110 \%$ \\
\hline & Vertical (m) & 0 & 5.973 & 2.730 & 2.730 & 1.333 & $114 \%$ \\
\hline \multirow{3}{*}{ Flight 3} & Forward $(\mathrm{m})$ & 30 & -2.281 & 0.798 & -0.744 & 0.552 & $31 \%$ \\
\hline & Lateral $(\mathrm{m})$ & 0 & -5.496 & 1.725 & -1.381 & 1.380 & $58 \%$ \\
\hline & Vertical $(m)$ & 0 & 6.322 & 2.357 & 2.357 & 1.041 & $98 \%$ \\
\hline \multirow{3}{*}{ Flight 5} & Forward $(\mathrm{m})$ & 12.00 & 1.087 & 0.394 & 0.345 & 0.331 & $14 \%$ \\
\hline & Lateral $(\mathrm{m})$ & 0.00 & 1.890 & 1.303 & -1.303 & 0.286 & $54 \%$ \\
\hline & Vertical $(m)$ & 0.00 & 3.017 & 2.295 & 2.295 & 0.356 & $96 \%$ \\
\hline \multirow{3}{*}{ Flight 7} & Forward $(\mathrm{m})$ & 12.00 & 1.899 & 0.649 & -0.499 & 0.596 & $21 \%$ \\
\hline & Lateral $(\mathrm{m})$ & 1.20 & 0.551 & 0.184 & -0.021 & 0.238 & $1 \%$ \\
\hline & Vertical $(\mathrm{m})$ & 2.40 & 2.229 & 1.640 & 1.640 & 0.212 & $68 \%$ \\
\hline \multirow{3}{*}{ Flight 8} & Forward $(\mathrm{m})$ & 12.00 & 1.529 & 0.536 & -0.143 & 0.596 & $6 \%$ \\
\hline & Lateral $(\mathrm{m})$ & 1.20 & 1.083 & 0.606 & -0.606 & 0.225 & $25 \%$ \\
\hline & Vertical $(m)$ & 2.40 & 2.027 & 1.302 & 1.302 & 0.327 & $54 \%$ \\
\hline \multirow{3}{*}{ Flight 10} & Forward $(\mathrm{m})$ & 12.00 & 3.563 & 1.763 & -1.521 & 1.239 & $63 \%$ \\
\hline & Lateral $(\mathrm{m})$ & 1.20 & 0.386 & 0.129 & -0.023 & 0.157 & $1 \%$ \\
\hline & Vertical $(\mathrm{m})$ & 2.40 & 2.350 & 1.696 & 1.696 & 0.368 & $71 \%$ \\
\hline \multirow{3}{*}{ Flight 11} & Forward $(\mathrm{m})$ & 12.00 & 2.463 & 1.168 & -0.904 & 1.020 & $38 \%$ \\
\hline & Lateral $(\mathrm{m})$ & 2.40 & 1.601 & 0.630 & -0.630 & 0.469 & $26 \%$ \\
\hline & Vertical $(m)$ & 2.40 & 1.145 & 0.434 & -0.340 & 0.397 & $14 \%$ \\
\hline \multirow{3}{*}{ Flight 12} & Forward $(\mathrm{m})$ & 12.00 & 2.637 & 1.510 & -1.510 & 0.787 & $63 \%$ \\
\hline & Lateral $(\mathrm{m})$ & 2.40 & 1.041 & 0.619 & -0.619 & 0.280 & $26 \%$ \\
\hline & Vertical $(m)$ & 2.40 & 1.815 & 1.293 & 1.293 & 0.317 & $54 \%$ \\
\hline \multirow{3}{*}{ Flight 13} & Forward $(\mathrm{m})$ & 12.00 & 2.686 & 1.542 & -1.526 & 0.749 & $64 \%$ \\
\hline & Lateral $(\mathrm{m})$ & 2.40 & 0.795 & 0.214 & -0.148 & 0.286 & $6 \%$ \\
\hline & Vertical (m) & 2.40 & 1.885 & 1.545 & 1.545 & 0.137 & $64 \%$ \\
\hline \multirow{3}{*}{ Flight 14} & Forward $(\mathrm{m})$ & 10.00 & 11.921 & 8.614 & -8.614 & 1.675 & $359 \%$ \\
\hline & Lateral $(\mathrm{m})$ & 0.00 & 1.726 & 0.675 & -0.570 & 0.415 & $24 \%$ \\
\hline & Vertical $(\mathrm{m})$ & 0.00 & 2.403 & 2.255 & 2.255 & 0.122 & $94 \%$ \\
\hline \multirow{3}{*}{ Flight 15} & Forward $(\mathrm{m})$ & 10.00 & 6.503 & 1.369 & 1.011 & 1.370 & $42 \%$ \\
\hline & Lateral $(\mathrm{m})$ & 0.00 & 1.083 & 0.556 & -0.556 & 0.169 & $23 \%$ \\
\hline & Vertical $(\mathrm{m})$ & 0.00 & 22.504 & 11.592 & 11.592 & 7.020 & $483 \%$ \\
\hline \multirow{3}{*}{ Flight 16} & Forward $(\mathrm{m})$ & 0.50 & - & - & - & - & $0 \%$ \\
\hline & Lateral (m) & 0.00 & 5.271 & 4.805 & -4.805 & 0.178 & $200 \%$ \\
\hline & Vertical $(\mathrm{m})$ & 0.00 & 1.882 & 1.664 & 1.664 & 0.165 & $69 \%$ \\
\hline \multirow{3}{*}{ Flight 17} & Forward $(\mathrm{m})$ & 0.50 & 1.926 & 0.838 & 0.303 & 0.937 & $13 \%$ \\
\hline & Lateral $(\mathrm{m})$ & 0.00 & 0.495 & 0.295 & -0.295 & 0.176 & $12 \%$ \\
\hline & Vertical $(\mathrm{m})$ & 0.00 & 2.593 & 1.745 & 1.745 & 0.358 & $73 \%$ \\
\hline \multirow{3}{*}{ Flight 18} & Forward $(\mathrm{m})$ & 0.50 & 1.155 & 0.647 & -0.399 & 0.649 & $17 \%$ \\
\hline & Lateral $(\mathrm{m})$ & 0.00 & 0.457 & 0.395 & -0.395 & 0.055 & $16 \%$ \\
\hline & Vertical (m) & 0.00 & 8.023 & 3.980 & 3.980 & 1.926 & $166 \%$ \\
\hline
\end{tabular}


Table 22: Performance of the Phastball 2-Aircraft Formation Flight During Turns

\begin{tabular}{|c|c|c|c|c|c|c|c|}
\hline \multicolumn{2}{|c|}{ FF Turns } & Clearance & $\begin{array}{l}\text { Max Err. } \\
\text { Distance }\end{array}$ & $\begin{array}{l}\text { Mean Abs. Err. } \\
\text { Distance }\end{array}$ & $\begin{array}{l}\text { Mean Err. } \\
\text { Distance }\end{array}$ & Std. Dev. & $\begin{array}{l}\text { avg. \% wing } \\
\text { span }\end{array}$ \\
\hline \multirow{3}{*}{ Flight 1} & Forward $(\mathrm{m})$ & 50.00 & -12.475 & 5.650 & -7.177 & 5.220 & $299 \%$ \\
\hline & Lateral $(\mathrm{m})$ & 0.00 & -22.371 & 8.048 & -12.949 & 5.437 & $540 \%$ \\
\hline & Vertical $(\mathrm{m})$ & 0.00 & 9.051 & 4.209 & 5.481 & 2.247 & $228 \%$ \\
\hline \multirow{3}{*}{ Flight 2} & Forward $(\mathrm{m})$ & 40.00 & -5.968 & 3.300 & -4.788 & 0.641 & $200 \%$ \\
\hline & Lateral $(\mathrm{m})$ & 0.00 & -11.773 & 5.251 & -8.406 & 1.606 & $350 \%$ \\
\hline & Vertical $(m)$ & 0.00 & 7.942 & 3.327 & 4.091 & 1.805 & $170 \%$ \\
\hline \multirow{3}{*}{ Flight 3} & Forward $(\mathrm{m})$ & 30.00 & -5.010 & 1.713 & -2.940 & 0.649 & $123 \%$ \\
\hline & Lateral $(\mathrm{m})$ & 0.00 & -7.350 & 3.211 & -5.198 & 1.865 & $217 \%$ \\
\hline & Vertical $(m)$ & 0.00 & 12.051 & 4.107 & 6.452 & 2.673 & $269 \%$ \\
\hline \multirow{3}{*}{ Flight 5} & Forward $(\mathrm{m})$ & 12.00 & 1.986 & 0.762 & 0.729 & 0.445 & $30 \%$ \\
\hline & Lateral $(\mathrm{m})$ & 0.00 & 3.438 & 2.394 & 2.394 & 0.524 & $100 \%$ \\
\hline & Vertical $(m)$ & 0.00 & 9.485 & 3.960 & 3.960 & 1.052 & $165 \%$ \\
\hline \multirow{3}{*}{ Flight 5} & Forward $(\mathrm{m})$ & 12.00 & 2.951 & 1.863 & 1.863 & 0.445 & $78 \%$ \\
\hline & Lateral (m) & 1.20 & 4.177 & 3.180 & 3.180 & 0.469 & $132 \%$ \\
\hline & Vertical $(m)$ & 2.40 & 6.812 & 4.265 & 4.265 & 1.380 & $178 \%$ \\
\hline \multirow{3}{*}{ Flight 6} & Forward $(\mathrm{m})$ & 12.00 & 6.059 & 3.431 & 3.431 & 1.307 & $143 \%$ \\
\hline & Lateral $(\mathrm{m})$ & 1.20 & 4.402 & 3.836 & 3.836 & 0.221 & $160 \%$ \\
\hline & Vertical $(m)$ & 2.40 & 8.423 & 5.994 & 5.994 & 1.015 & $250 \%$ \\
\hline \multirow{3}{*}{ Flight 7} & Forward $(\mathrm{m})$ & 12.00 & 3.338 & 0.949 & 0.818 & 0.885 & $34 \%$ \\
\hline & Lateral $(\mathrm{m})$ & 1.20 & 4.512 & 3.561 & 3.561 & 0.479 & $148 \%$ \\
\hline & Vertical $(m)$ & 2.40 & 11.391 & 8.718 & 8.718 & 1.585 & $363 \%$ \\
\hline \multirow{3}{*}{ Flight 8} & Forward $(\mathrm{m})$ & 12.00 & 3.401 & 0.972 & 0.955 & 0.904 & $40 \%$ \\
\hline & Lateral $(\mathrm{m})$ & 2.40 & 6.449 & 4.878 & 4.878 & 0.660 & $203 \%$ \\
\hline & Vertical $(m)$ & 2.40 & 5.019 & 3.811 & 3.811 & 0.960 & $159 \%$ \\
\hline \multirow{3}{*}{ Flight 9} & Forward $(\mathrm{m})$ & 12.00 & 2.030 & 0.777 & 0.567 & 0.753 & $24 \%$ \\
\hline & Lateral $(\mathrm{m})$ & 2.40 & 4.778 & 4.264 & 4.264 & 0.412 & $178 \%$ \\
\hline & Vertical $(m)$ & 2.40 & 13.094 & 10.773 & 10.773 & 2.187 & $449 \%$ \\
\hline \multirow{3}{*}{ Flight 10} & Forward $(\mathrm{m})$ & 12.00 & 2.492 & 1.082 & 0.747 & 1.152 & $31 \%$ \\
\hline & Lateral $(\mathrm{m})$ & 2.40 & 5.584 & 4.719 & 4.719 & 0.557 & $197 \%$ \\
\hline & Vertical $(m)$ & 2.40 & 7.298 & 5.454 & 5.454 & 1.032 & $227 \%$ \\
\hline \multirow{3}{*}{ Flight 14} & Forward $(\mathrm{m})$ & 10.00 & 15.201 & 10.664 & 6.915 & 8.929 & $288 \%$ \\
\hline & Lateral $(\mathrm{m})$ & 0.00 & 5.959 & 1.793 & 1.763 & 1.671 & $73 \%$ \\
\hline & Vertical $(m)$ & 0.00 & 12.387 & 8.683 & 8.683 & 2.083 & $362 \%$ \\
\hline \multirow{3}{*}{ Flight 15} & Forward $(\mathrm{m})$ & 10.00 & 4.338 & 1.987 & 1.712 & 1.117 & $71 \%$ \\
\hline & Lateral $(\mathrm{m})$ & 0.00 & 9.140 & 8.532 & -8.53 & 0.257 & $356 \%$ \\
\hline & Vertical $(m)$ & 0.00 & 21.934 & 11.643 & 11.64 & 5.365 & $485 \%$ \\
\hline \multirow{3}{*}{ Flight 16} & Forward $(\mathrm{m})$ & 0.50 & 3.351 & 2.233 & -2.228 & 0.844 & $93 \%$ \\
\hline & Lateral $(\mathrm{m})$ & 0.00 & 13.565 & 12.651 & -12.651 & 0.486 & $527 \%$ \\
\hline & Vertical $(m)$ & 0.00 & 18.932 & 9.911 & 9.911 & 4.611 & $413 \%$ \\
\hline \multirow{3}{*}{ Flight 17} & Forward $(\mathrm{m})$ & 0.50 & 5.078 & 4.261 & 4.261 & 0.365 & $178 \%$ \\
\hline & Lateral $(\mathrm{m})$ & 0.00 & 10.043 & 9.312 & -9.312 & 0.555 & $388 \%$ \\
\hline & Vertical $(m)$ & 0.00 & 17.359 & 16.145 & 16.145 & 0.996 & $673 \%$ \\
\hline \multirow{3}{*}{ Flight 18} & Forward $(\mathrm{m})$ & 0.50 & 4.431 & 2.596 & 2.596 & 1.506 & $108 \%$ \\
\hline & Lateral $(\mathrm{m})$ & 0.00 & 14.210 & 12.616 & -12.616 & 1.034 & $526 \%$ \\
\hline & Vertical (m) & 0.00 & 16.457 & 9.272 & 9.272 & 4.150 & $386 \%$ \\
\hline
\end{tabular}


Table 23: Proximity Between Leader and Follower During Formation Flight

\begin{tabular}{|c|c|c|c|c|c|c|c|}
\hline \multicolumn{8}{|c|}{ Aircraft Proximity During FF } \\
\hline & & \multicolumn{3}{|c|}{ Straight legs } & \multicolumn{3}{|c|}{ Turns } \\
\hline & $\begin{array}{c}\text { Clearance } \\
(\mathrm{m})\end{array}$ & $\operatorname{Max}(\mathrm{m})$ & $\operatorname{Min}(m)$ & $\begin{array}{c}\text { Average } \\
\text { (m) }\end{array}$ & $\operatorname{Max}(\mathrm{m})$ & $\operatorname{Min}(m)$ & $\begin{array}{c}\text { Average } \\
\text { (m) }\end{array}$ \\
\hline Flight 1 & 50 & 51.791 & 44.245 & 48.018 & 54.963 & 40.485 & 47.724 \\
\hline Flight 2 & 40 & 38.896 & 36.958 & 37.927 & 38.473 & 34.936 & 36.705 \\
\hline Flight 3 & 30 & 31.104 & 27.799 & 29.451 & 30.979 & 27.002 & 28.990 \\
\hline Flight 5 & 12.24 & 16.407 & 14.434 & 15.421 & 22.520 & 14.481 & 18.500 \\
\hline Flight 7 & 12.30 & 15.275 & 13.558 & 14.417 & 20.815 & 15.535 & 18.175 \\
\hline Flight 8 & 12.30 & 15.057 & 12.875 & 13.966 & 23.567 & 13.423 & 18.495 \\
\hline Flight 10 & 12.30 & 16.582 & 13.332 & 14.957 & 24.995 & 18.625 & 21.810 \\
\hline Flight 11 & 12.47 & 15.624 & 12.480 & 14.052 & 21.322 & 16.642 & 18.982 \\
\hline Flight 12 & 12.47 & 15.837 & 13.260 & 14.549 & 26.556 & 19.696 & 23.126 \\
\hline Flight 13 & 12.47 & 15.847 & 13.740 & 14.793 & 21.992 & 17.651 & 19.821 \\
\hline flight 14 & 10.00 & 22.283 & 15.696 & 1.228 & 30.495 & 19.578 & 2.049 \\
\hline flight 15 & 10.00 & 33.450 & 11.28 & 2.345 & 34.155 & 11.782 & 2.416 \\
\hline flight 16 & 0.50 & 6.097 & 6.253 & 11.194 & 24.031 & 14.536 & 47.062 \\
\hline flight 17 & 0.50 & 3.768 & 1.635 & 6.536 & 21.189 & 6.279 & 41.377 \\
\hline flight 18 & 0.50 & 8.619 & 1.367 & 16.238 & 22.691 & 1.413 & 44.381 \\
\hline
\end{tabular}

When the follower is maintaining a large clearance, the error is relatively large in both the straight legs and the turns. As the clearance is decreased to about $10 \mathrm{~m}$, the error decreases to about half of what it was. In close proximity, there is significant side slip caused by banking that the controller does not account for but is still able to maintain sufficient control of the aircraft. The side slip causes the follower to droop to the side of the formation in the direction of the turn.

Error in the bank turns is not favorable. In practicality however, aircraft in formation are nearly always cruising in a straight path so this is not a concern. When transitioning from a turn to a straight-away, the reaction time is relatively small and the formation quickly returns to a favorable state.

Finally, the vertical, lateral, and forward controller's performance is scored in Table 24. Since transient data is required to score each controller, only straight leg data from transient flights $7,8,10,11$, 12 , and 13 are scored. These selected flights have the same clearances. The vertical clearance of $2.4 \mathrm{~m}$ was added as an offset since the vertical controller had a consistent positive steady state error. That way the follower would more closely follow directly behind the leader in order to improve the performance score for the vertical controller. Therefore this $2.4 \mathrm{~m}$ offset will be subtracted out from the resulting vertical error. Scoring showed relatively good ratings and reinforces the possibility of encountering wing tip vortices. 
Table 24: Phastball Performance Scoring

\begin{tabular}{|c|c|c|c|c|c|c|c|}
\hline \multicolumn{8}{|c|}{ Score for Controller Performance } \\
\hline & & $\begin{array}{l}\text { Clearance } \\
\text {-offset (m) }\end{array}$ & OS $\%$ & $\mathrm{~T}$ react $(\mathrm{s})$ & $\begin{array}{l}\text { T settling } \\
\text { (s) }\end{array}$ & $\begin{array}{l}\text { Mean } \\
\text { Err. }\end{array}$ & SCORE \\
\hline Ideal & & & $30.00 \%$ & 7 & 15 & 2.4 & $0.0 \%$ \\
\hline \multirow{3}{*}{$\begin{array}{c}\text { Flight } \\
7\end{array}$} & Vertical (m) & 0 & $0.00 \%$ & 0.3 & 1.67 & $0.76^{*}$ & $83.7 \%$ \\
\hline & Lateral (m) & 1.2 & -- & -- & -- & -0.021 & -- \\
\hline & Forward $(\mathrm{m})$ & 12 & $0.00 \%$ & 6.17 & 9.16 & -0.499 & $64.9 \%$ \\
\hline \multirow{3}{*}{$\begin{array}{c}\text { Flight } \\
8\end{array}$} & Vertical (m) & 0 & $0.00 \%$ & 2.1 & 3.8 & $1.098^{*}$ & $71.8 \%$ \\
\hline & Lateral (m) & 1.2 & $236.23 \%$ & 7.02 & 18.43 & -0.606 & $-118.0 \%$ \\
\hline & Forward $(\mathrm{m})$ & 12 & $0.00 \%$ & 21.76 & 32.3 & -0.143 & $1.5 \%$ \\
\hline \multirow{3}{*}{$\begin{array}{l}\text { Flight } \\
10\end{array}$} & Vertical $(\mathrm{m})$ & 0 & $228.30 \%$ & 1.38 & 2.95 & $0.704 *$ & $-71.6 \%$ \\
\hline & Lateral (m) & 1.2 & $0.00 \%$ & 4.1 & 6.69 & -0.023 & $80.0 \%$ \\
\hline & Forward (m) & 12 & $0.00 \%$ & 32.44 & 35.21 & -1.521 & $-35.0 \%$ \\
\hline \multirow{3}{*}{$\begin{array}{c}\text { Flight } \\
11\end{array}$} & Vertical (m) & 0 & $29.02 \%$ & 3.5 & 6.79 & $2.74 *$ & $18.4 \%$ \\
\hline & Lateral (m) & 2.4 & $0.00 \%$ & 3.6 & 4.92 & -0.63 & $75.3 \%$ \\
\hline & Forward (m) & 12 & $14.62 \%$ & 22.5 & 26.58 & -0.904 & $-6.4 \%$ \\
\hline \multirow{3}{*}{$\begin{array}{c}\text { Flight } \\
12\end{array}$} & Vertical (m) & 0 & -- & -- & -- & $1.107 *$ & - \\
\hline & Lateral (m) & 2.4 & $18.16 \%$ & 4.07 & 13.3 & -0.619 & $42.1 \%$ \\
\hline & Forward (m) & 12 & $0.00 \%$ & 13.54 & 15.01 & -1.51 & $29.2 \%$ \\
\hline \multirow{3}{*}{$\begin{array}{c}\text { Flight } \\
13\end{array}$} & Vertical (m) & 0 & $37.54 \%$ & 2.32 & 11.4 & $0.855^{*}$ & $31.5 \%$ \\
\hline & Lateral (m) & 2.4 & $0.00 \%$ & 8.5 & 10.81 & -0.148 & $64.6 \%$ \\
\hline & Forward (m) & 12 & $0.00 \%$ & 9.24 & 12.3 & -1.526 & $38.8 \%$ \\
\hline
\end{tabular}

\section{Conclusion}

\section{A. Summary}

This research set out to design a PID, Fuzzy Logic, and NLDI controllers for the NEO quadrotor test bed and an NLDI controller for the Phastball fixed wing test bed. These controllers are used to implement formation flight tracking capabilities, which appeal to traffic mitigation and energy savings. Through simulation and flight testing the designs were validated and the performance of the position tracking was analyzed.

For the quadrotor, autonomous close formation flight was simulated for the PID, Fuzzy Logic, and NLDI controllers. In simulation, the FL control smoothly converged better than the PID or NLDI controllers with no overshoot, but the steady state observed along the $\mathrm{x}$ axis was larger than the other two. The NLDI controller out-performed the PID and FL controllers in simulation by converging to formation 
in less time than the PID controller and with less error than the FL controller. Scoring analysis rated the PID controller at 39.2\%, the Fuzzy Logic controller at 67.4\%, and NLDI controller at $75.4 \%$.

For the Phastball, autonomous close formation flight control with the NLDI design was achieved. Favorable performance was observed in flight testing at cruise conditions. When the formation deviated from cruise conditions, the follower aircraft drooped from the formation by a couple meters in the direction of the turn. The autonomous controller maintained safe operations of the aircraft and reestablished favorable formation tolerances quickly once cruising was resumed. Scoring analysis rated the vertical controller at $41.1 \%$ on average, the lateral controller at $52.4 \%$ on average, and the forward controller at $22.4 \%$ on average. Though many outliers reduce the scores, close formation flight was achieved and the conditions for encountering wing tip vortices are good.

\section{B. Quadrotor Future Research Approach}

Future work for the NEO quadrotor aircraft will exhume indoor autonomous formation flight testing with the three controllers. Outdoor testing will also be tested with the addition of an onboard GPS antenna. The outdoor conditions will provide a more robust sense of tracking performance and the controller's ability to overcome wind gusts. Outdoor testing will also take advantage of the ultrasound and laser rangefinder sensors to implement obstacle avoidance.

In order to make the linear feedback controller even more robust, adaptive control could be applied to the NDLI controller using a neural network or other means. This adaptation will potentially allow for more aggressive flight conditions and maneuvers.

\section{Phastball Future Research Approach}

It is noteworthy to point out that a controller called Extended NLDI has already been developed and tested in simulation. This Extended NLDI controller incorporates the aircraft models dynamic coefficients into the inner and outer loops. Simulation results with the WVU YF-22 research aircraft model show that the Extended NLDI controller has superior position tracking through a series of different flight paths and flight maneuvers [76]. Since this new design has not been tested aboard a real aircraft, the Phastball would be a good candidate for extended NLDI formation flight test experiments.

New Differential GPS (DGPS) is in development for the lead, Red Phastball, and also a faster, lighter next generation avionics system is in development for the follower, Blue Phastball. DGPS will provide more precise location detection mitigating the known 1.5 RMS error down to approximately a few centimeters. 
The NLDI controller can benefit from online adaptive control to account for unmodeled aircraft dynamics since the state of each test bed is fully known. A Neural Network is suggested based on the precedence from the literature review [54][59][60][65][66]. This adaptation will potentially maintain close flight formation during for more aggressive flight conditions and maneuvers. 


\section{References}

[1] Bernhard, W. “The Homing or Carrier Pigeon.” London: George Routlege and Sons 1871. pp. 29.

[2] Blakelock, J. “Automatic Control of Aircraft and Missiles 2nd Ed.” John Wiley and Sons, Inc. 1991. pp. $1-6$.

[3] McRuer, D. \& Graham, D. "Flight control century: triumphs of the systems approach." Journal of Guidance, Control, and Dynamics. Vol 27 sec 2. pp. 161-173.

[4] Parch, R.W. \& Van Zant, T. "Human Factors in Simple and Complex Systems, 2nd ed." Boca Raton: CRC Press, 2008.

[5] European Commission. "Towards a European Strategy for the Development of Civil Applications of Remotely Piloted Aircraft Systems (RPAS)," Commission Staff Working Document, SWD, 2012, 259 final, Brussels, September 9, 2012, pp. 4.

[6] ICAO. "ICAO RPAS Symposium." [online.] RPAS 2015. International Civil Aviation Organization. Available: http://www.icao.int/Meetings/RPAS/Documents/ICAO\%20RPAS\%20Symposium\%20201 5\%20presentation.pdf [March 2015].

[7] CAA. "RPAS, UAV, UAS, Drones and Model Aircraft." [online.] Civil Aviation Authority of New Zealand. Available: http://www.caa.govt.nz/rpas/ [March 2015].

[8] RITA. "Airline Activity" [Online] Research and Innovative Tech. Admin. Bureau of Transportation Statistics. 2014. Available: http://www.transtats.bts.gov/ [Sept 15, 2014]

[9] Supply Chain Digest. "Supply Chain News: Amazon.com Co-Locating Mini-Fulfillment Centers Inside Key Customer DCs" [Online] SCDigest On Target Magazine. Oct 24, 2013. Available: http://www.scdigest.com/ontarget/13-10-24-1.php?cid=7512 [Oct 10, 2014].

[10] Rose, C. “Amazon's Jeff Bezos Looks to the Future.” [Online] CBS News. News. Dec 01, 2013. Available: http://www.cbsnews.com/news/amazons-jeff-bezos-looks-to-the-future [Oct 12, 2014]

[11] Madrigal, A. "Inside Google's Secret Drone Delivery Program." [Online] The Atlantic. Technology. August 28, 2014. Available: http://www.theatlantic.com/technology/archive/2014/08/inside-googlessecret-drone-delivery-program/379306/?single_page=true [Aug 29, 2014]

[12] “Tacocopter” [Online] Tacocopter Inc. Available: http://tacocopter.com [August 12, 2013]

[13] QuiQui. “QuiQui” [Online] QuiQui. 2014. Available: http://quiqui.me/ [Auguts 12 2013]

[14] Hern, A. "DHL Launches First Commercial Drone 'Parcelcopter' Delivery Service." [Online] The Guardian. Technology. Sept 29 2014. Available: http:/www.theguardian.com/technology/2014/sep /25/german-dhl-launches-first-commercial-drone-delivery-service [Sept 29, 2014] 
[15] Murphy, D.W. \& Cycon, J. "Applications for Mini VTOL UAV for Law Enforcement." Enabling Technologies for Law Enforcement and Security. International Society for Optics and Photonics. Jan 1999. pp. 35-43.

[16] FAA. "Overview of Small UAS Notice of Proposed Rulemaking," [online] Federal Aviation Administration. 2015.

Available: http://www.faa.gov/regulations_policies/rulemaking/media/021515_sUAS_Summary.pdf [Feb 26, 2015]

[17] BEA. "Interim Report on the Accident on $1^{\text {st }}$ June 2009 to the Airbus A330-203." [online] Bureau d'Enquetes et d'Analyses pour la securite de l'aviation civile. F-GZCP $-1^{\text {st }}$ June 2009. Available: http://www.bea.aero/docspa/2009/f-cp090601e1.en/pdf/f-cp090601e1.en.pdf [Oct 10, 2014].

[18] Dawson, H. “A Review of the Legal Status of Drones (Unmanned Aircraft)." [Online] ASB Law LLP. July 15, 2014. Available: http://www.asb-law.com/_data/assets/pdf_file/0010/11242/drones_law_asb law_15july2014.pdf [Oct 10, 2014].

[19] DARPA. “The DARPA Urban Challenge." [Online] DARPA. 2007. Available: http://archive.darpa.mil/grandchallenge/ [Oct 10, 2014].

[20] Urmson, C.; Anhalt, J.; Bagnell, D.; \& Baker, C. "Tartan Racing: A Multi-Modal Approach to the DARPA Urban Challenge." [Online] DARPA. April 13, 2007. Available: http://archive.darpa.mil/grandchallenge/TechPapers/Tartan_Racing.pdf [Oct 10, 2014]

[21] Huntsberger, T.; Aghazarian, H.; Howard, A.; \& Trotz, D. C. "Stereo vision-based navigation for autonomous surface vessels." Journal of Field Robotics, 2011. Vol. 28 pp. 3-18. doi: $10.1002 /$ rob.20380

[22] NASA. "POSTMAN: Point of Sail Tacking for Maritime Autonomous Navigation." [Online] Tech Briefs Aug 1, 2012. Available: Aug 1st http://www.techbriefs.com/component/content/article/14238 [Oct 10, 2014].

[23] Koay, T. B. "STARFISH - A Small Team of Autonomous Robotic Fish.” Indian Journal of Geo-Marine Sciences Vol 40, April 2011, pp. 157-167.

[24] Tham, K.Y. "Study of Command and Control (C\&C) Structures on Integrating UAS into Manned Environmonets" [Online] Thesis. Navy Postgraduate School. Monteray, CA. 2012. Available: http//:hdl.handle.net/10945/17468 [Nov 2, 2014]

[25] Ewers, D. "AARD - Autonomous Airborne Refueling Demonstration," Presented at the East Coast SETP Symposium. Arlington, VA, April. 2007. 
[26] Yang, A.; Naeem, W.; Irwin, G.W.; \& Kang Li. "A decentralised control strategy for formation flight of unmanned aerial vehicles," Control (CONTROL), 2012 UKACC International Conference. Cardiff, United Kingdom, 3-5 Sept. 2012. pp.345,350.

[27] Fabrizio, G.; Pollini, L.; \& Innocenti, M. "Formation flight control - A behavioral approach." AIAA Guidance, Navigation, and Control Conference and Exhibit. Montreal, CA, Aug. 2001.

[28] Weimerskirch, H.; Martin, J.; Clerquin, Y.; \& Alexandere, P. "Energy Savings in Flight Formation." Nature. Vol. 413, pp. 697-698.

[29] Cutts, C., \& J. Speakman. "Energy Savings in Formation Flight of Pink-Footed Geese." Journal of Experimental Biology 189.1, 1994, pp. 251-261.

[30] Ray, R.; Cobleigh, B.; Vachon, M. \& StJohn, C. "Flight test techniques used to evaluate performance benefits during formation flight." Flight Mechanics Conf., Monterey, CA. 2002.

[31] Pahle, J., Berger, D., Venti, M. W., Faber, J. J., Duggan, C., \& Cardinal, K. "A Preliminary Flight Investigation of Formation Flight for Drag Reduction on the C-17 Aircraft." Presented at the Aerospace Control and Guidance Systems Committee; Salt Lake City, UT. 7 Mar. 2012.

[32] Albon, C. "AMC pitching new flight formation to reduce fuel consumption." [Online] Inside the Pentagon's Inside the Air Force. Vol. 24. sec. 33, 2013. Available: http://search.proquest.com/docview/1424342847?accountid=2837. [Oct 12, 2014]

[33] Brodecki, M.; Subbarao, K. \& Chu, Q. "Formation Flight Control System for In-Flight Sweet Spot Estimation." 51st AIAA Aerospace Sciences Meeting. Grapevine, TX, Jan 2013.

[34] Giulietti, F.; Pollini, L. \& Innocenti, M. “Autonomous formation flight.” IEEE Control Systems Magazine. Dec 2000. Vol. 20, No. 6. pp. 34-44.

[35] Dogan, A.; Sato, S.; \& Blake W. "Flight Control and Simulation for Aerial Refueling." Proc. AIAA Guidance, Navigation, and Control Conference, San Francisco. Aug 15-18, 2005.

[36] Waishek, J.; Dogan, A.; \& Blake, W. "Derivation of the Dynamics Equations of Receiver Aircraft in Aerial Refueling.” Journal of Guidence, Control, and Dynamics. 2009. Vol. 32. No. 2. pp. 586-598.

[37] Li, Y.; Li, B.; Sun, Z.; \& Song, Y.D. "Robust Autopilot for Close Formation Flight of Multi-UAVs, System Theory." Proc. from the Thirty-Eigth Southeastern Symposium. March 2006. pp. 258-262.

[38] Qi, Q. \& Tang, W. "Robust Formation Flight Control System Design For Multi-UAVs.” In Control Conference. $201231^{\text {st }}$ Chinese. pp. 4617-4621.

[39] Chao, Z.; Zhou, S.L.; Ming, L.; \& Zhang, W.G. "UAV Formation Flight Based on Nonlinear Model Predictive Control.” Mathematical Problems in Engineering. 2012. doi:10.1155/2012/261367 
[40] Camacho, E.F. \& Bordons, C. "Modeling Predictive Control.” Springer Science \& Business Media. May 2007. pp. 1-10.

[41] Dargan, J.; Patcher, M.; \& D’Azzo, J.J. “Automatic Formation Flight Control.” Proc. AIAA Guidance, Navigation, and Control Conf., Hilton Head, SC, Aug. 1992, pp. 838-857.

[42] Buzogany, L.E.; Patcher, M.; \& D’Azzo, J.J. “Automatic Control of Aircraft in Formation Flight.” Proc. AIAA Guidance, Navigation, and Control Conf.. Monterey, CA, Aug. 1993, pp. 1349-1370.

[43] Veth, M.; Patcher, M.; \& D’Azzo, J.J. “Energy Preserving Formation Flight Control.” AIAA Aerospace Sciences Meeting and Exhibit, Reno, NV. Jan. 9-12, 1995.

[44] Reyna, V.P.; Patcher, M. \& D’Azzo, J.J. “Formation Flight. Control Automation.” Proc. AIAA Guidance, Navigation, and Control Conf.. pp. 1379-1404.

[45] Singh, S.N.; Chandler, P.; Schumacher, C.; \& Banda, S. “Adaptive Feedback Linearizing Nonlinear Close Formation Control of UAVs.” Proc. American Control Conference. 2000. Vol. 2. pp. 854-858.

[46] Venkataramanan, S. \& Dogan, A. "Nonlinear Control for Reconfiguration of UAV Formation," Proc. AIAA Guidence, Navigation, and Control Conference. Austin, TX. Aug. 2003.

[47] Boskovic, J.D. \& Mehra, R.K. “An Adaptive Reconfigurable Formation Flight Control Design.” Proc. American Control Conference. June 2003. Vol 1. pp. 284-289.

[48] Duan, H.; Luo, Q.; Shi, Y.; \& Ma, G. "Hybrid Particle Swarm Optimization and Genetic Algorithm for Multi-UAV Formation Reconfiguration,” IEEE Computational Intelligence Magazine, vol.8, no.3, pp.16,27, Aug. 2013.

[49] Haissig, C.M. "Millitary Formation Flight as a Model for Increased Capacity in Civilian Airspace.” Digital Avionics Systems Conference. 2004. The $23^{\text {rd }}$. Vol. 1.

[50] How, J.P.; King, E. \& Kuwata, Y. "Flight Demonstration of Cooperative Control for UAV teams." Proc. AIAA 3rd Unmanned unlimited technical Conference, Workshop and Exhibit. Sept. 2004. AIAA2004-6490.

[51] Bayraktar, S. \& Pappas, G.J. "Experimental Cooperative Control of Fixed-Wing Unmanned Aerial Vehicles.” Decision and Control, 2004. 43 ${ }^{\text {rd }}$ IEEE Conference. Vol. 4. pp. 4292-4298.

[52] Gu, Y., Campa, G., Seanor, B., Gururajan, S., \& Napolitano, M. R. “Autonomous formation flight-design and experiments.” Aerial Vehicles. 2009. pp. 233-256.

[53] Rice, C., Gu, Y., Chao, H. "Control Performance Analysis for Autonomous Close Formation Flight Experiments.” Unmanned Aircraft Systems (ICUAS), 2014,International Conference. pp. 1175-1180 IEEE, 2014. 
[54] Calise, A.J. \& Rysdyk, R.T. "Nonlinear adaptive flight control using neural networks." IEEE Control Systems Magazine. Dec. 1998. Vol. 18. No. 6. pp. 14-25.

[55] Bugajski, D.J.; Enns, D.F.; \& Elgersma, M.R. “A Dynamic Inversion Based Control Law with Application to the High Angle of Attack Research Vehicle," Proc. AIAA Guidence, Navigation, and Control Conference. pp. 20-22, 1990.

[56] Snell, S.A.; Enns, D.F.; \& Garrard, W.L. "Nonlinear Inversion flight Control for a Supermaneuverable Aircraft.” AIAA Journal of Guidance, Control, and Dynamics. Vol. 15(4). pp. 976-984. 1992.

[57] Buffington, J.M.; Sparks, A.G.; \& Banda, S.S. "Full Conventional Envelope Longitudinal Axis Flight Control with Thrust Vectoring.” Proc. American Control Conference. pp. 415-419. 1993

[58] Aerospace Students. "Nonlinear Dynamic Inversion." [Online] Aerospace Students Available: http://aerostudents.com/files/advancedFlightControl/nonlinearDynamicInversion.pdf [Oct 10, 2014].

[59] Ngo, A.D.; Reigelsperger, W.C.; Banda, S.S; Bessolo, J.A. "Tailless Aircraft Control Law Design Using Dynamic Inversion \& $\mu$-synthesis” proc. of IEEE International Conference. Control Appications. 1996. pp. 107-112.

[60] Brinker, J.S. \& Wise, K.A. "Flight testing of reconfigurable control law on the X-36 tailless aircraft." Journal of Guidance, Control, and Dynamics 2001 Vol 24. pp. 903-909.

[61] Buffington, J.M.; Sparks, A.G.; \& Banda, S.S. "Full conventional envelope longitudinal axis flight control with thrust vectoring." American Control Conference, 1993.

[62] Wise, K. A.; Lavretsky, E.; \& Hovakimyan, N. “Adaptive control of flight: theory, applications, and open problems.” American Control Conference. June 2006 (pp. 6-pp).

[63] Abaspour, A.; Sadeghi, M.; \& Hosain, S. "Using fuzzy logic in dynamic inversion flight controller with considering uncertainties." Fuzzy Systems (IFSC), 2013 13th Iranian Conference on. IEEE, 2013. pp. $1-6$.

[64] Raimundez, C.; \& Blas, A.B. "Adaptive tracking in mobile robots with input-output linearization." Industrial Electronics Society, IECON 2013-39th Annual Conference of the IEEE. 2013. pp. 3299-3304.

[65] Schumacher, C.; \& Johnson, J. D. "PI control of a tailless fighter aircraft with dynamic inversion and neural networks.” American Control Conference, 1999. Proceedings of the 1999. Vol. 6, pp. 41734177.

[66] Rysdyk, R., \& Calise, A. J. "Robust nonlinear adaptive flight control for consistent handling qualities.” Control Systems Technology, IEEE Transactions. 2005. Vol. 13(6). pp. 896-910. 
[67] Khalil, H. K. "Nonlinear Systems." Vol. 8 of Second Prentice-Hall International Editions. New York: Macmillan Publishing Company. 1992. pp. 589-597.

[68] Rysdyk, R.; and Calise, A.J. "Adaptive model inversion flight control for tilt-rotor aircraft." Journal of Guidance, Control, and Dynamics. 1999. Vol. 22, pp. 402-407.

[69] Perhinschi, M.; Smith, B.; \& Betoney, P. "Fuzzy Logic-Based Detection Scheme for Pilot Fatigue." Aircraft Engineering and Aerospace Technology. Jan 2010. Vol. 82(1). pp. 39 - 47. DOI: $10.1108 / 00022661011028100$

[70] Hamel, T.; Mahony, R.; Lozano, R.; \& Ostrowski, J. "Dynamic Modeling and Configuration Stabilization for an X4-Flyer." $15^{\text {th }}$ Triennial World Congress of the International Federation of Automatic Control. Barcelona, Spain, 2002.

[71] Prouty, R. “Helicopter Performance, Stability, and Control.” Krieger Publishing Co. 2002.

[72] Pounds, P. "Design, Construction and Control of a Large Quadrotor Micro Air Vehicle." Thesis. Austrailian National University. 2007. Available: http://www.eng.yale.edu/pep5/P_Pounds_Thesis_ 2008.pdf [Nov 25, 2014].

[73] Corke, P. "Robotics Toolbox for Matlab." [Online] PeterCorke.com Available: http//:www.petercorke.com/robotics_toolbox.html [Feb 27, 2013]

[74] McGrail, A. "OnBoard Parameter Identification for a Small UAV." Thesis. West Virginia University. Morgantown, WV. 2012.

[75] Gu, Y.; Gross, J.; Barchesky, F.; Chao, H.Y.; \& Napolitano, M.R. “Avionic Design for a Sub-Scale Fault Tolerant Flight Control Test-Bed," InTech Recent Advances in Aircraft Technology. 2012. Chapter 21. pp. 499-522. ISBN: 978-953-51-0150-5

[76] Wilburn, B.K.; Perhinschi, M.G. "Unmanned Aerial Vehicle Trajectory Tracking Algorithm Comparison.” International Journal of Intelligent Unmanned Systems, 2013, Vol 1 pp. 276-302. 